\title{
Modifying behaviours and notions of masculinity: Effect of a programme led by locally elected representatives
}

Shireen J. Jejeebhoy

A.J. Francis Zavier

Population Council

K.G. Santhya

Population Council

Rajib Acharya

Population Council

Neelanjana Pandey

Population Council

See next page for additional authors

Follow this and additional works at: https://knowledgecommons.popcouncil.org/departments_sbsr-pgy

Part of the Demography, Population, and Ecology Commons, Domestic and Intimate Partner Violence Commons, Family, Life Course, and Society Commons, and the International Public Health Commons How does access to this work benefit you? Let us know!

\section{Recommended Citation}

Jejeebhoy, Shireen J., A.J. Francis Zavier, K.G. Santhya, Rajib Acharya, Neelanjana Pandey, Santosh Kumar Singh, Komal Saxena, Aparajita Gogoi, Madhu Joshi, and Sandeep Ojha. 2017. "Modifying behaviours and notions of masculinity: Effect of a programme led by locally elected representatives." New Delhi:

Population Council. 


\section{Authors}

Shireen J. Jejeebhoy, A.J. Francis Zavier, K.G. Santhya, Rajib Acharya, Neelanjana Pandey, Santosh Kumar Singh, Komal Saxena, Aparajita Gogoi, Madhu Joshi, and Sandeep Ojha 


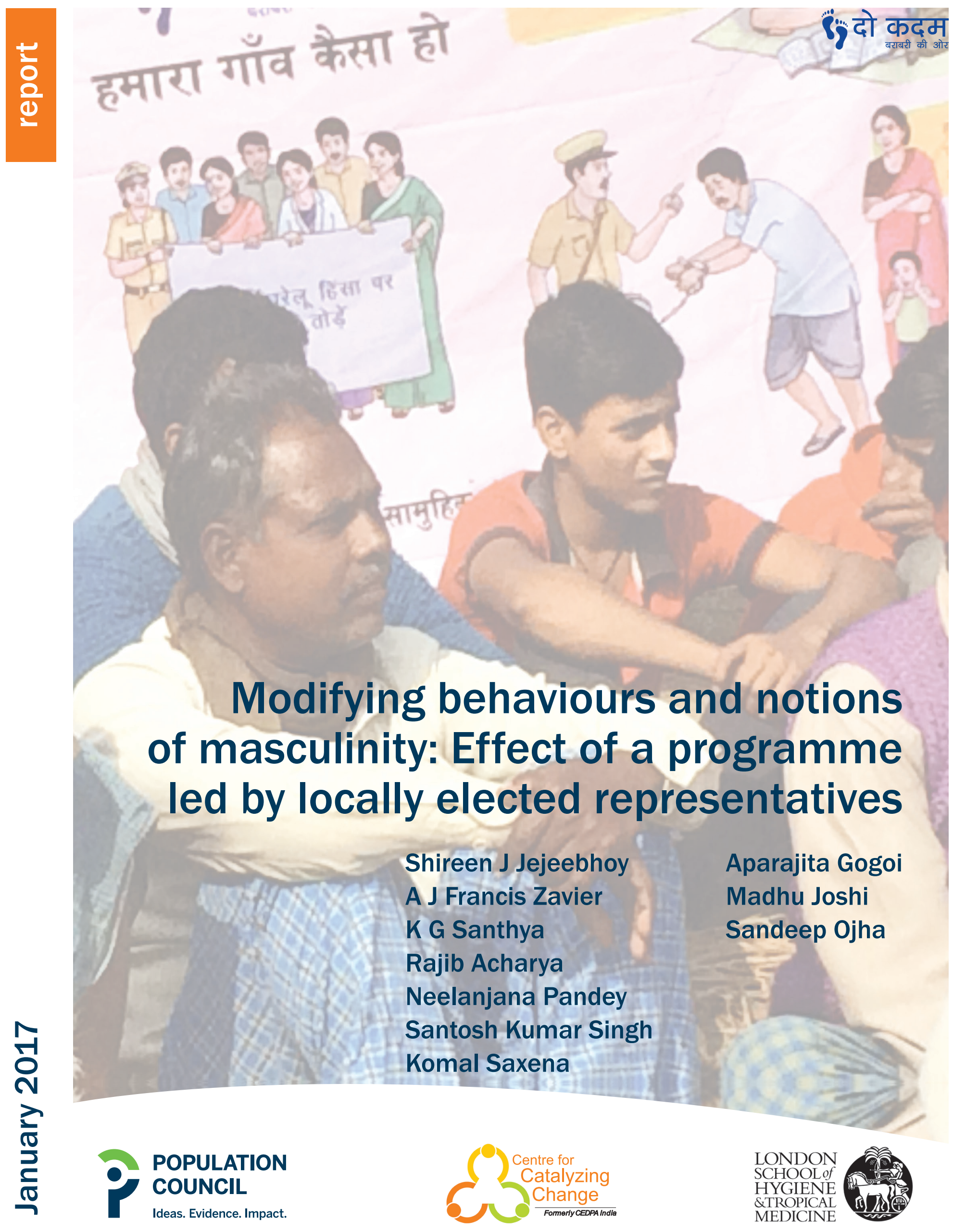




\section{P. porvuntow}

Ideas. Evidence. Impact.

The Population Council confronts critical health and development issues-from stopping the spread of HIV to improving reproductive health and ensuring that young people lead full and productive lives. Through biomedical, social science, and public health research in 50 countries, we work with our partners to deliver solutions that lead to more effective policies, programs, and technologies that improve lives around the world. Established in 1952 and headquartered in New York, the Council is a nongovernmental, nonprofit organization governed by an international board of trustees.

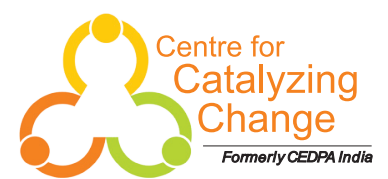

The Centre for Development and Population Activities, India is now the Centre for Catalyzing Change (C3). Over two decades of sustained work to empower and mobilize young people, men and women commemorates the journey of the organisation, that began as one of the first organizations working with life skills education for adolescents through it comprehensive programs. We are a non-governmental organization with the mission to empower women in all sectors of development and to that end we work with young people, including in and out of school adolescent boys and girls in rural and urban India. Our technical expertise extends to incubating, implementing and scaling up programs focused on its thematic areas of youth education, gender and maternal health/reproductive rights, specialising in at- scale programme implementation, monitoring and evaluation. Till date, we have reached more than one million girls and boys in India and equipped them with practical life skills, improved confidence in personal decision-making and increased self-esteem. In the past couple of years we have been using digital technology to build young people's capacities on health, life skills and gender equity issues.

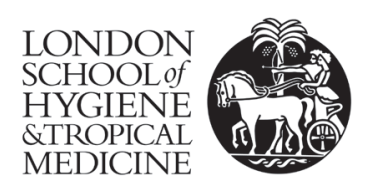

Our mission is to improve health and health equity in the UK and worldwide; working in partnership to achieve excellence in public and global health research, education and translation of knowledge into policy and practice.

Suggested Citation: Jejeebhoy, S. J., A. J. Francis Zavier, K. G. Santhya et al. 2017. Modifying behaviours and notions of masculinity: Effect of a programme led by locally elected representatives. New Delhi: Population Council.

For additional copies of the report please contact:

\section{Population Council}

Zone 5A, Ground Floor

India Habitat Centre, Lodi Road

New Delhi, India 110003

Phone: +91-11-2464 2901

Email: info.india@popcouncil.org

Website: www.popcouncil.org

The study has been funded by UK aid from the UK Government; however the views expressed do not necessarily reflect the UK Government's official policies. 


\section{Modifying behaviours and notions of masculinity: Effect of a programme led by locally elected representatives}

Shireen J Jejeebhoy

A J Francis Zavier

K G Santhya

Rajib Acharya

Neelanjana Pandey

Santosh Kumar Singh

Komal Saxena
Aparajita Gogoi

Madhu Joshi

Sandeep Ojha 


\section{Table of Content}

List of Tables

List of Figures $\quad$ vii

Acknowledgements

Executive summary

Chapter 1 Introduction 1

Chapter 2 Profile 10

Chapter 3 Do Kadam Barabari Ki Ore: The intervention 26

Chapter 4 Awareness and experiences of the Do Kadam project among men and women 31

Chapter 5 Perspectives and experiences of PRI representatives 39

Chapter 6 Effect of the intervention programme among community members 48

Chapter 7 Summary and recommendations 61

$\begin{array}{ll}\text { Appendix-1 } & 66\end{array}$

$\begin{array}{ll}\text { References } & 67\end{array}$

$\begin{array}{ll}\text { Authors } & 69\end{array}$

$\begin{array}{ll}\text { List of Investigators } & 70\end{array}$ 


\section{List of Tables}

Table 1.1: $\quad$ Profile of the study district and state 3

Table 1.2: $\quad$ Response rates at baseline and endline and reasons for non-response for men and women $\quad 9$

$\begin{array}{lr}\text { Table 2.1: } & \text { Selected household characteristics of men and women, baseline survey } \\ \end{array}$

Table 2.2: Selected socio-demographic characteristics of men and women, baseline survey 11

Table 2.3: Awareness of the Domestic Violence Act and related services, men and women, baseline survey 12

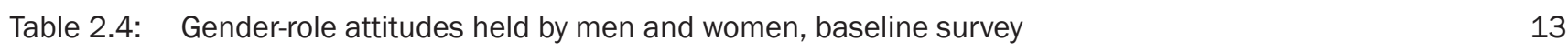

Table 2.5: Attitudes towards physical violence within marriage held by men and women, baseline survey 14

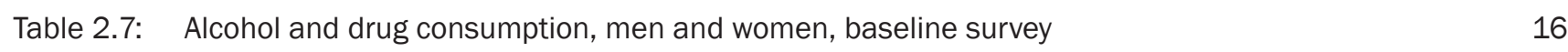

$\begin{array}{ll}\text { Table 2.8: } & \text { Men's controlling behaviours over their wife, men and women, baseline survey } \\ \end{array}$

Table 2.9: Reports of men and women on violence perpetrated by husband and other family members on women, baseline survey

\begin{tabular}{ll} 
Table 2.10: & Cycle of violence, men and women, baseline survey \\
\hline
\end{tabular}

Table 2.11: Help-seeking experiences by women who experienced physical violence recently, baseline survey 21

Table 2.12: Percentage of women reporting ever having thoughts of leaving the marriage and of committing suicide, baseline survey

Table 2.13: Panchayati Raj Institutions related engagement and participation in PRI activities, men and women, baseline survey

Table 3.1: Extent of participation in the intervention programme as per monthly monitoring reports 29

Table 4.1: Awareness of the Do Kadam intervention, men and women in intervention villages, endline survey 31

Table 4.2: Participation in the Do Kadam intervention, men and women in intervention villages, endline survey 32

Table 4.3: Reasons for not attending village-level sensitisation sessions held by the Do Kadam intervention, endline survey

Table 4.4: Topics addressed in intervention-related village-level learning sessions and street plays, endline survey

Table 4.5: Perceptions of men and women about changes experienced in the six months preceding the interview in comparison and intervention villages, endline survey 
Table 6.1: Effect of exposure to the intervention programme on awareness of the Domestic Violence Act and/or services for women in distress: Difference in differences estimators

Table 6.2: Effect of exposure to the intervention programme on gender role attitudes and attitudes about the acceptability of physical violence in marriage: Difference in differences estimators

Table 6.3: Effect of exposure to the intervention programme on men's controlling behaviours and marital violence, as reported by men and women: Difference in differences estimators

Table 6.4: Effect of exposure to the intervention programme on men's/husbands' alcohol consumption, as reported by men and women: Difference in differences estimators 


\section{List of Figures}

Figure 1: PRI members' participation in Do Kadam Barabari Ki Ore programme, intervention villages, project monitoring data

Figure 2: $\quad$ Awareness of the Do Kadam Barabari Ki Ore programme, married men and women in intervention villages, endline survey

Figure 3: $\quad$ Participation in the Do Kadam Barabari Ki Ore intervention, married men and women in intervention villages, endline survey

Figure 4: Community members' perceptions about engagement of PRI members on issues related to VAWG and alcohol abuse

Figure 5: Effect of exposure to the Do Kadam programme on awareness of the Domestic Violence Act and services for women in distress

Figure 6: Effect of exposure to the Do Kadam programme on husband's alcohol consumption as reported by women

xviii

Figure 4.1: Interaction with PRI representatives in previous six months, as reported by men and women from intervention areas, baseline and endline surveys

Figure 4.2: Percentage of men and women from intervention areas reporting that their PRI representatives held meetings in which domestic violence and gender equality were discussed in the previous six months, baseline and endline surveys

Figure 4.3: Percentage of men and women from intervention areas reporting that their PRI representatives had intervened in cases of domestic violence or alcohol abuse in previous six months, baseline and endline surveys

Figure 4.4: Community members' participation in PRI organised events in fulfilment of their generic responsibilities or the Do Kadam programme in the previous six months, as reported by men and women in intervention area, baseline and endline surveys

Figure 6.1: Percentages of men and women in comparison and intervention villages reporting in-depth knowledge of the Domestic Violence Act, baseline and endline surveys

Figure 6.2: Percentages of men and women in comparison and intervention villages reporting knowledge of services for women who experience violence (helpline and short stay home), baseline and endline surveys

Figure 6.3: Mean score on the index of gender egalitarian attitudes obtained by men and women in comparison and intervention villages, baseline and endline surveys

Figure 6.4: Mean score on the index of acceptability of physical violence within marriage obtained by men and women in comparison and intervention villages, baseline and endline surveys

Figure 6.5: Mean score on the index of men's controlling behaviours over their wife, as reported by men and women in comparison and intervention villages, baseline and endline surveys 
Figure 6.6: Percentages reporting the perpetration (men) and experience (women) of physical violence within marriage in the six months preceding each interview, as reported by men and women in comparison and intervention villages, baseline and endline surveys

Figure 6.7: Percentages reporting the perpetration (men) and experience (women) of emotional violence within marriage in the six months preceding each interview, as reported by men and women in comparison and intervention villages, baseline and endline surveys

Figure 6.8: Percentages reporting the perpetration (men) and experience (women) of sexual violence within marriage in the six months preceding each interview, as reported by men and women in comparison and intervention villages, baseline and endline surveys

Figure 6.9: Percentages reporting men's (men)/husbands' (women) alcohol consumption at least once a week or more frequently, as reported by men and women in comparison and intervention villages, baseline and endline surveys

Figure 6.10: Percentages of women reporting that they had witnessed their husband drunk at least once a week in comparison and intervention villages, baseline and endline surveys 


\section{Acknowledgements}

We are grateful to the UK Department for International Development (DFID) for supporting our programme of research, Do Kadam Barabari Ki Ore (Two Steps Towards Equality), to assess what works to address violence against women in Bihar state, India. Under this programme of research and evaluation, a total of five projects were implemented in partnership with the Centre for Catalyzing Change and the London School of Hygiene and Tropical Medicine. One of the five projects, findings of which are presented in this report, sought to train locally elected representatives to act as change agents to promote egalitarian gender norms among men and women in their communities.

This study has benefitted immeasurably from the inputs of many. In particular, we are grateful to, Mamta Kohli, Nupur Barua, Nel Druce, Peter Evans and Arundhati Choudhury, DFID India, for their support and to Mamta Kohli and Nupur Barua for their guidance and insights throughout the course of this project. We are extremely grateful, moreover, to Mr. Amitabh Verma, former Principal Secretary, Panchayati Raj Department, Government of Bihar for his encouragement and support that had made it possible to conduct the study in the state of Bihar.

Lori Heise from the London School of Hygiene and Tropical Medicine and Kelly Hallman from the Population Council, New York provided valuable inputs into the intervention design and the study protocol, and critically reviewed and made comments and suggestions on the earlier draft of this report; we are most grateful to them for their insights.

We are also grateful to the staff of Abhiyan who partnered with the Centre for Catalyzing Change in implementing intervention activities.

Sapna Desai supported with the analysis of the survey data and her contribution is much appreciated.

At the Population Council, several colleagues have supported us in both the technical and administrative aspects of this study. We are grateful to MA Jose for overseeing the administration of the fieldwork and to Komal Saxena, an author of this report, who was also responsible for editorial matters and for preparing the manuscript for publication. We would also like to acknowledge support from Christine Tse for her inputs in editing the manuscript.

At the Centre for Catalyzing Change, we acknowledge the contributions of the Do Kadam team members in the Patna office, including Shefali Chauhan, Kumar Alok and Prakash Ranjan.

We would also like to acknowledge the dedication of our research assistants who conducted the survey and the indepth interviews with men and women in the community and the PRI representatives.

Finally, we would like to record our deep appreciation of the members of the Gram Panchayat and Gram Kachehri who participated in the Do Kadam programme and to the men and women in the community who took part in the research. We hope that our recommendations based on the insights and experiences that they shared with us will help shape programmes intended to address the issue of violence against women and girls in Bihar.

Shireen J Jejeebhoy

A J Francis Zavier

K G Santhya

Rajib Acharya

Neelanjana Pandey

Santosh Kumar Singh

Komal Saxena
Aparajita Gogoi

Madhu Joshi

Sandeep Ojha 


\section{Executive summary}

Violence against women and girls remains widespread in India, and patriarchal norms and attitudes continue to underpin gender roles. Community mobilisation has increasingly been recognised as an important strategy to change unequal gender norms and reduce violence against women and girls. In India, locally elected representatives of Panchayati Raj Institutions (PRIs, local self-governance bodies) are among the most promising potential agents of change, as the responsibility for implementing schemes for social justice, protection of women from violence falls directly within their mandate. The potential for building the capacity of these elected representatives and instilling in them a sense of accountability for preventing violence has rarely been tested. In order to fill this gap, the Population Council, together with the Centre for Catalyzing Change (C3) and the London School of Hygiene and Tropical Medicine, and with support from UKaid, implemented the Do Kadam Barabari Ki Ore (Two Steps Towards Equality) programme.

The project, situated in Patna district, aimed to orient and engage locally elected leaders-namely, members of Gram Panchayats and Gram Kachehris-in changing community norms relating to the acceptability of violence against women, and preventing violence against women as well as one factor closely associated with the perpetration of such violence, namely alcohol abuse. Specifically, it assessed: (1) the feasibility of sensitising and training PRI members to act as change agents to transform gender norms among men and women in their communities; (2) the effect of the intervention on generating egalitarian gender role attitudes among PRI members and a reduction in VAWG perpetrated/experienced by them; and (3) the effect of the intervention on changing gender role attitudes, including attitudes about marital violence among men and women at the community-level, and reduction in VAWG and alcohol misuse at the community-level.

\section{The intervention}

The intervention was implemented over a seven-month period in nine villages from two panchayats of Masaurhi Block in Patna district. It comprised a number of components. It began with developing a 14-session curriculum for sensitising PRI members and building their capacity to address violence against women and girls and alcohol abuse ${ }^{1}$ in their communities. Male and female PRI members received training through an initial three-day training workshop followed by fortnightly training sessions based on the curriculum for the entire seven months of the intervention. Aside from these sessions, exposure visits were held for PRI members in order to provide them first-hand information on services and programmes available to support women in distress and those in need of help to address alcohol problems, and efforts were made to build the confidence of the PRI members to enable them to impart what they learned in these visits to the community at large, and support them to refer individual cases.

Following their exposure to each training session, PRI representatives, with support from C3 and its local partner, Abhiyan, held community-level sensitisation sessions in their wards to build awareness among community members on issues addressed during the training sessions that they had attended. Aside from these sessions, PRI representatives were supported to hold community-wide campaigns and such events as street theatre, film shows, and local rallies on ending gender discrimination, violence against women and girls, and domestic violence related to alcohol abuse. Finally, although the intervention aimed to take steps to revitalise the Social Justice Committee, we experienced challenges and delays in doing so. As an alternative, C3 India supported PRI representatives in establishing a parallel but more informal mechanism, the Mahila Nyay Samiti (Women's Justice Committee) to take on this function.

The programme was conducted with inputs from the Department of Panchayati Raj Institutions in the Government of Bihar.

\section{Evaluation design}

A mixed-method evaluation design was used, comprising both quantitative and qualitative methods. We used a quasi-experimental design to evaluate the effects of the project among married men and women in the community.

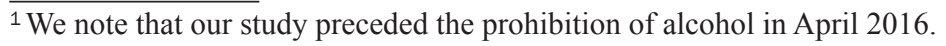


Before we launched the intervention, we interviewed a total of 763 married men in the ages 18-54 and 767 married women in the ages 18-49 who were selected both from villages in which the intervention was implemented (intervention villages) and from villages in which the intervention was not implemented (comparison villages). After the intervention was completed, we interviewed a fresh group of 757 married men and 766 married women from the same villages. Additionally, we held in-depth interviews with selected men and women who had participated in the survey from intervention villages at two points in time-before launching the intervention (baseline) and after the intervention was over (endline); 10 men and women each were interviewed at baseline, of whom 16 were reinterviewed after completing the intervention. We also conducted in-depth interviews with 18 PRI members from villages in which the intervention activities were implemented before launching the intervention and at its conclusion to assess their perceptions about the acceptability and effects of the project on their own attitudes and practices as well as on those of their community members.

\section{The context}

The baseline assessment underscores deeply entrenched unequal gender role attitudes, including about the acceptability of marital violence; women and men expressed gender egalitarian attitudes in three out of seven statements posed to them. They also underscore widespread gender disparities and power differences in marital life, including men's controlling behaviour over their wife, and physical, emotional, and sexual violence perpetrated by men against their wife. The perpetration and experience, respectively, of emotional abuse in the six months preceding the interview was reported by three in four men and women (72\%-74\%); 21 percent of men, and 25 percent of women, respectively, reported physical violence, and 35 percent and 42 percent, respectively, reported sexual violence during the same period. Men's alcohol abuse was noted by large proportions of women, and often associated by them with their violent behaviour. Two in five women reported that their husband was drunk at least once a week. Women who experienced violence rarely shared their experience with or sought help from a family member, neighbour, or friend, and rarely obtained help from them. Just one-quarter, one-fifth, and one-seventh of women who reported a recent violence experience obtained help from their husband's family, their own parents, and neighbours, respectively. Likewise, women who experienced violence very rarely approached formal sources of help, such as the police, the helpline, or the short stay home (23\%). Knowledge about the DV Act and the fact that a man could be jailed for violations, and awareness of helpline and short stay home services available to women who experience violence was limited, and more men than women reported awareness of the Act and of the services. For example, three in five men (61\%) of men, and just one-quarter of women (26\%) had heard about a law that protects women from domestic violence. Finally, contact with PRI representatives was reported by most men and fewer than half of all women; while about one in ten men reported that a PRI representative had intervened in cases of violence or alcohol abuse, hardly any women were familiar with meetings held by PRI representatives on social issues, or interventions made by PRI representatives to stop marital violence or alcohol abuse. In-depth interview findings support those of the survey: they underscore the extent to which inegalitarian gender norms, men's alcohol abuse, marital violence, and the fear of violence among women shape the lives of men and women in the community.

\section{The acceptability and feasibility of the intervention}

The acceptability and feasibility of the intervention were assessed from the perspectives of PRI members and community men and women.

\section{PRI members' perspectives}

The two intervention panchayats included 52 gram panchayat and gram kachehri members, of whom more than half were women. All of these 52 elected representatives attended at least one training session; 79 percent attended more than half of all sessions, 23 percent attended almost all of the 14 fortnightly training sessions, and 79 percent participated in at least one exposure visit. Most PRI representatives reported that this was the very first training programme they had ever attended. As can be seen from the following reports, PRI members responded favourably to the programmes.

Yes, I participated and it was a three-day training programme. We were told about equality between boys and girls, that we should stop alcohol, that there shouldn't be any violence against women, everyone should live in harmony. Yes, I learned new things, like women should make a group and help in stopping 
alcohol, everyone should live in harmony. [Female, aged 50, completed Class 2, panchayat representative for 8 years, endline, ID05]

We were taken to the women's police station, the women's helpline, etc. I knew about them before but had never been to any such facility. So I visited these facilities for the first time because of this programme. I was very happy. [Male, aged 43, completed Class 15, panchayat member for 3 years, endline, ID14]

Figure 1: PRI members' participation in Do Kadam Barabari Ki Ore programme, intervention villages, project monitoring data

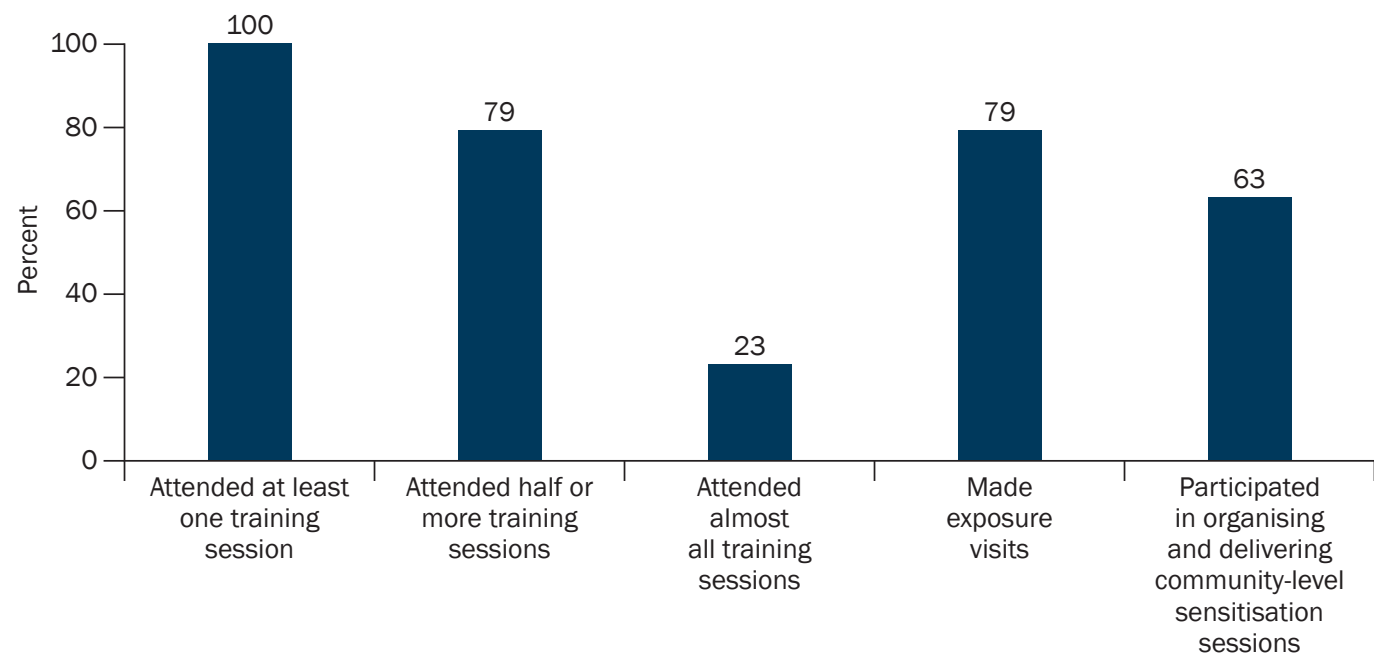

Over three-fifths (63\%) of PRI members participated in organising and delivering community-level sessions. These sessions attracted an audience of, on average, 32 community members. Over the course of the intervention, two meetings of the Mahila Nyay Samiti were held in each gram panchayat, in which committee members discussed individual cases and referred them, as appropriate, to other services, such as the Helpline and the Mahila Thana. ${ }^{2}$ A few PRI members suggested that while earlier meetings used to address village development matters, over the previous months, gender equality, marital violence, and alcohol abuse were also discussed. The following responses describe the sessions and meetings.

There is a meeting every month. About what development is taking place in the village, where there is a need for a canal, where a handpump is needed. Since the Do Kadam programme has begun, we also discuss violence against women and how one should behave in marriage. Sometimes 100, 90 people attend, sometimes 50. [Male, age 43, completed Class 12, panchayat member for 8 years, endline, ID12]

Yes, we organised the session, we discussed education, how to be free from alcohol, domestic violence. Both men and women participated, sometimes 20-25, not necessarily the same people. [Male, aged 38, completed Class 12, panchayat representative for 3 years, endline, ID16]

They have meetings and explain to women and they get written investigations done for women who experience violence. [Male, aged 48, completed Class 10, panchayat representative for 3 years, endline, ID13]

There is a committee, but I have no knowledge about it. [Female, aged 30, completed Class 10, Panchayat representative for nine years, endline, ID03]

\section{Community members' perspectives}

At the time of the endline, over two-thirds of men and three-fifths of women residing in intervention villages reported awareness of the Do Kadam programme. More community members were aware of the street plays than were aware

\footnotetext{
${ }^{2}$ We note that although the intervention aimed to take steps to revitalise the Social Justice Committee, we experienced challenges in doing so; as an alternative, C3 India supported PRI representatives in establishing a parallel but more informal mechanism, the Mahila Nyay Samiti (Women's Justice Committee) to take on this function towards the end of the intervention period.
} 
Figure 2: Awareness of the Do Kadam Barabari Ki Ore programme, married men and women in intervention villages, endline survey

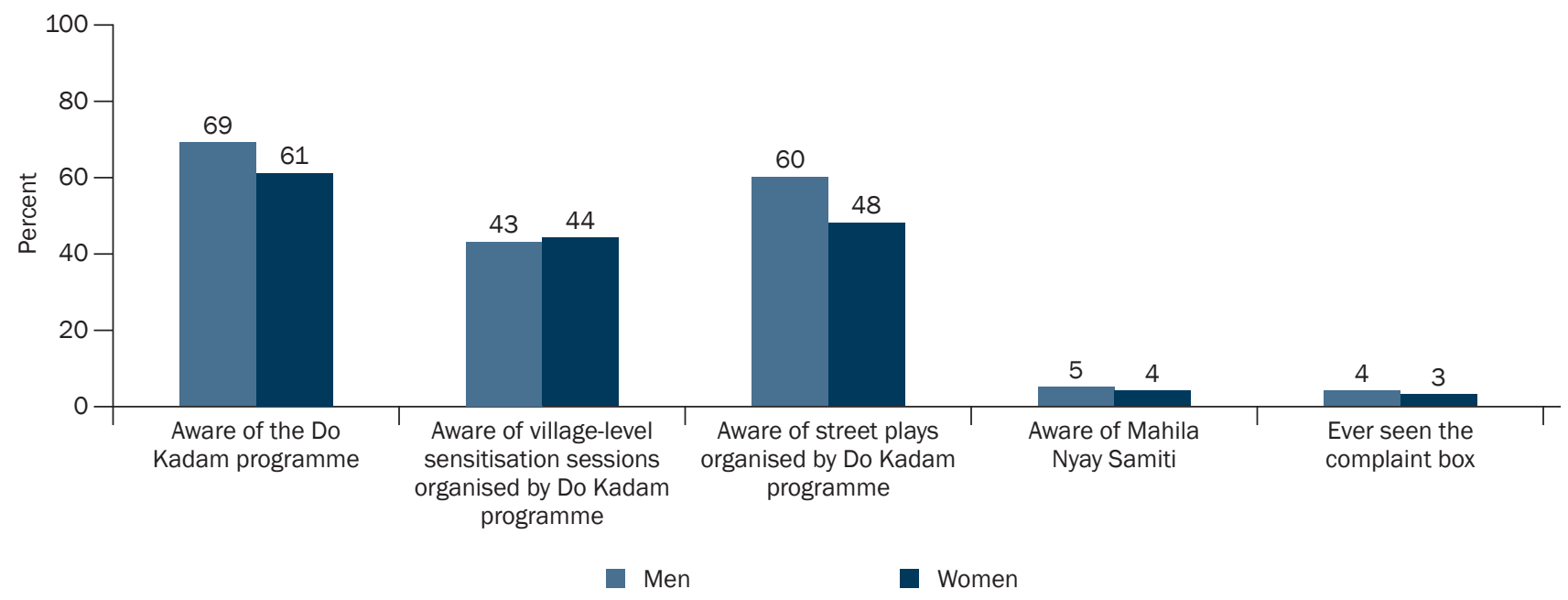

of the sensitisation sessions organised as part of the programme. In contrast, hardly any had heard about the Mahila Nyay Samiti (just 4-5\%) or seen the complaint box (3-4\%), both of which were instituted towards the end of the intervention period.

Two-fifths of men and one-third of women reported having attended at least one village-level sensitisation session or street play. Exposure to these was, however, irregular. While 22-24 percent of men and women indicated that they had attended at least one village-level sensitisation session organised by the Do Kadam programme, just six percent had attended such sessions sometimes or regularly. In addition, 26 percent of women and 35 percent of men had attended street plays organised by the programme. Not a single woman reported that she had lodged a complaint or that she knew someone who had lodged a complaint with the Mahila Nyay Samiti.

As evident from Figure 4, discourses or meetings on violence against women and girls (VAWG) or alcohol abuse organised by PRI members, as reported by community men and women, increased significantly following the introduction of the Do Kadam programme. Likewise, PRI members' intervention in cases of VAWG or alcohol abuse, as reported by men and women from the community, increased steeply ${ }^{3}$.

Figure 3: Participation in the Do Kadam Barabari Ki Ore intervention, married men and women in intervention villages, endline survey

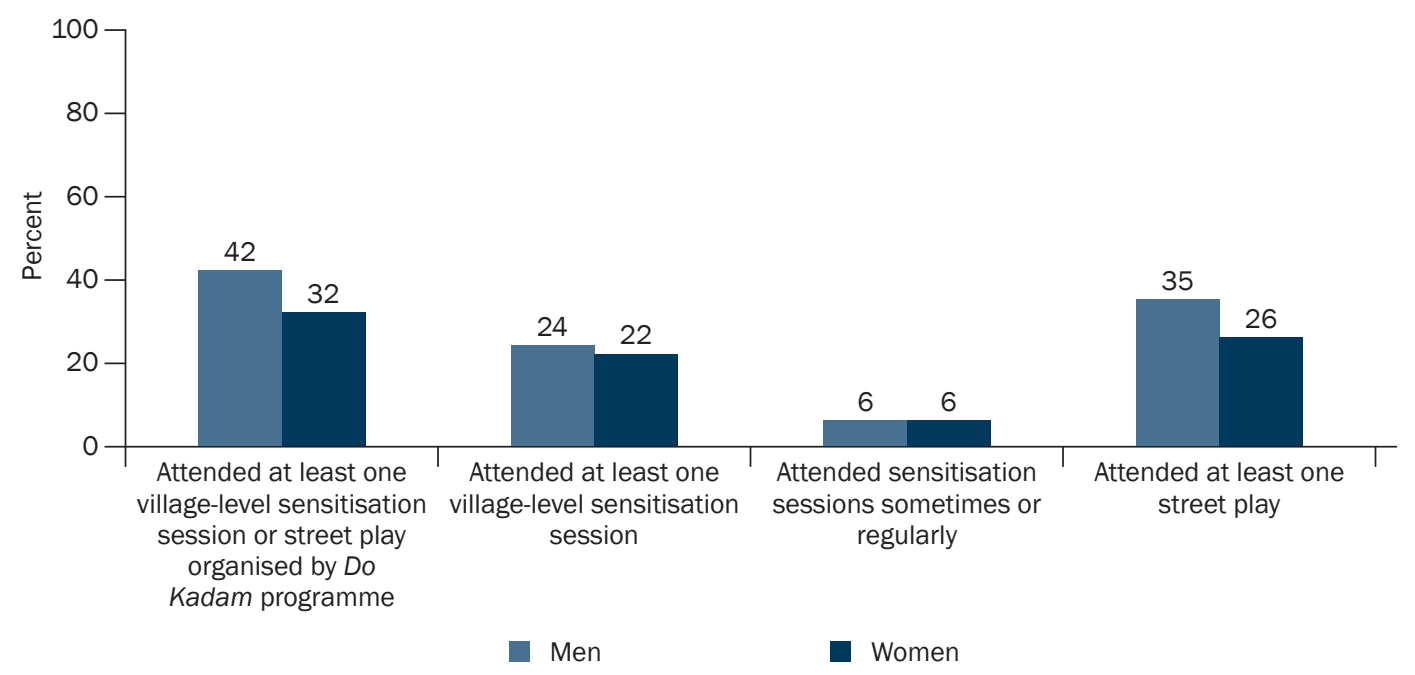

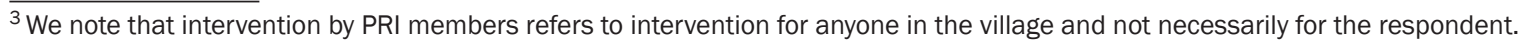


Figure 4: Community members' perceptions about engagement of PRI members on issues related to VAWG and alcohol abuse

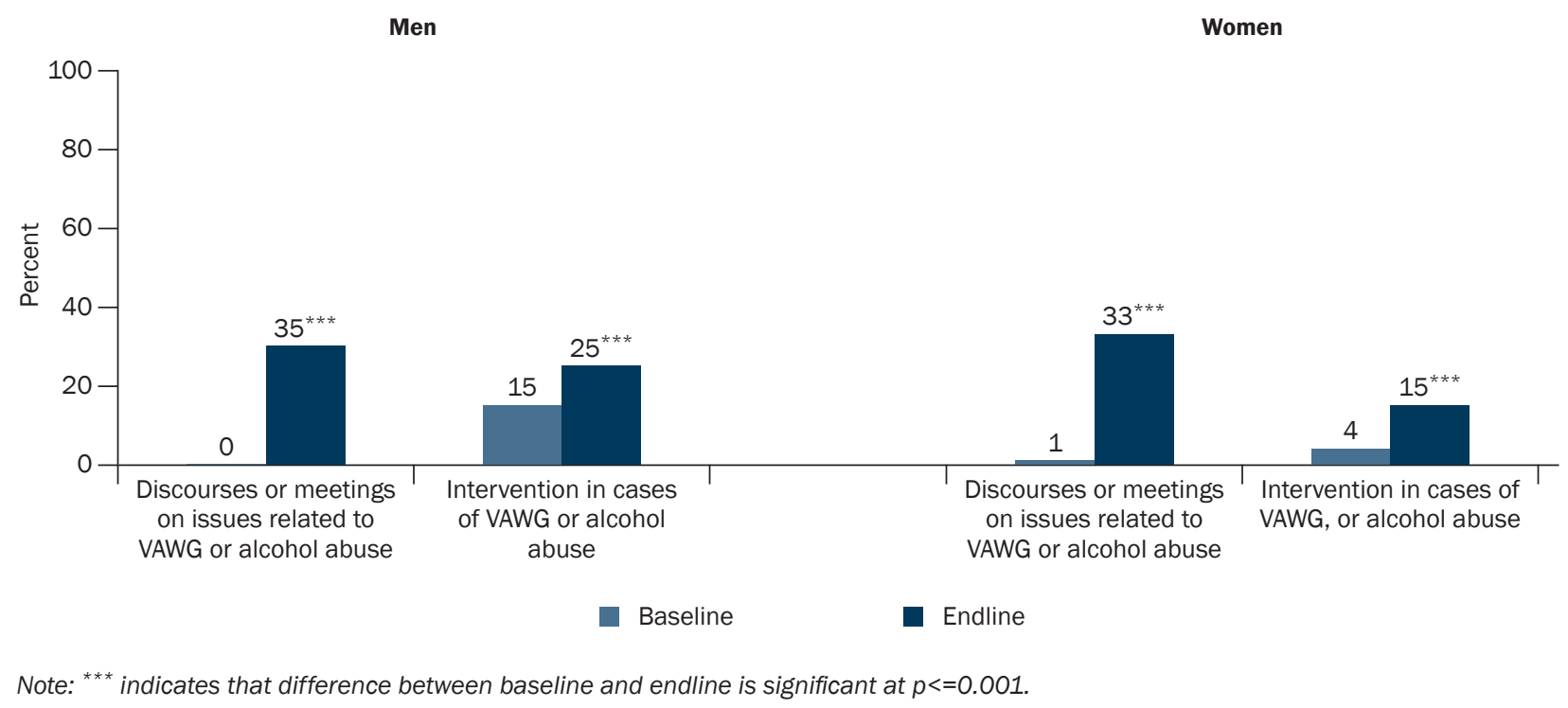

\section{Effect of the intervention}

The effect of the intervention on attitudes and behaviours among PRI members and men and women from the community was assessed.

\section{Changes in PRI members' attitudes and behaviours}

In in-depth interviews, almost all PRI members reported changes in their own gender role attitudes and attitudes about the acceptability of violence against women; most discussed the need to reduce alcohol abuse in their village and maintain closer, more harmonious and violence-free marital relations.

\section{Gender role attitudes became more egalitarian}

PRI representatives acknowledged that while they had largely adhered to traditional gender role attitudes until exposed to the programme, they were now committed to upholding more egalitarian gender role attitudes and some discussed their commitment to spreading these new attitudes in their communities as well, as the narrative below highlights.

Before taking the training, I used to think that whatever was happening was correct but now I feel that it wasn't correct. There is a need for change. A woman should have all the rights at home that a man has. She should also be able to go out of the house by her own choice, she should be able to take decisions related to the home by herself, and she should be able to go out and earn money, She shouldn't require anyone else's permission. For all of this to take place, we need to change the mindsets of men and women, make them more aware, give them information about their rights and duties, and only then will there be equality and a stop to violence against women. [Male, aged 32, completed Class 6, panchayat representative for 3 years, endline, ID18]

\section{Marital violence became less acceptable}

Views about the acceptability of marital violence had also changed, with all PRI members reporting that violence against women should not be tolerated, as can be seen in the following narratives.

Yes there has been a change in this too. Now I think that women are humans and so why do people treat them like animals? We should help them out, we should treat them well and if they ever do make a mistake then we should talk and explain things to them lovingly. In my opinion, talking to one's wife in a loud voice is also a form of violence, and beating her is an even worse offence. [Male, aged 43, completed Class 12 , panchayat representative for 8 years, endline, ID12] 
Yes, I have clearly understood that violence against any woman should not happen under any circumstances. And that if we see such violence in our community, we should make them understand that they should never do this, that they torture more when they are drunk, and that if a husband doesn't drink alcohol he will commit less physical and mental violence. [Female, aged 46, completed Class 8, panchayat member for 8 years, endline, ID06]

\section{Marital relations became more egalitarian and caring than earlier}

PRI representatives, notably male representatives, reported moreover that their relations with their spouse had improved in many ways as a result of the Do Kadam programme exposure. While narratives must be interpreted keeping in mind likely social desirability bias, male PRI representatives identified a host of changes in their marital life, aside from reduced alcohol use and marital violence. They reported that they had stopped emotionally abusing their wife, now spoke with their wife 'lovingly', spent more time with their wife and children, participated in household chores, and acknowledged their wife's agency. We note, however, that female representatives, except one, reported no change in the nature of their marital relations.

Yes there has been an effect on my relationship with my wife too. Now I talk to her lovingly. Compared to before, I give her more respect, I talk to her with respect, and even if she makes a mistake, I don't get angry with her like I used to do before the training. After taking the training, I am more aware of both her rights and of my rights and duties. I have started spending more time with my children, and started behaving well with everyone. I have started helping out more in the house. All in all I now know better what is wrong and what is right, and started behaving better at home and in society. [Male, aged 43, completed Class 12 , panchayat representative for 8 years, endline, ID12]

Yes there has been a change in our relationship. Compared to before, I talk to her more nicely and lovingly.... I no longer get angry with her or shout at her or speak in a loud tone. Now I live more harmoniously, I spend time with my family, I help my children with their schoolwork, I help my wife out with housework. I know that it is also my responsibility to carry out these chores, so I look after the animals, go to the market, help my wife out in cleaning the house. [Male, aged 43, completed Class 15, panchayat representative for 3 years, endline, ID14]

\section{Intervention in cases of VAWG increased and in cases of alcohol abuse remained challenging}

Narratives suggest that prior to the Do Kadam programme, hardly any PRI representative reported that they had intervened in cases of marital violence: several reported that marital violence was a personal matter and women preferred to remain silent about it. By the time of the endline in-depth interview, a few PRI representatives reported that they had intervened in cases of violence in which the women had approached them for help. They reported that the problem was resolved at the level of the panchayat, and that there was no need to approach the police or helpline. Action taken by the panchayat to stop violence against women is described in the following narratives.

Yes, the panchayat intervenes when such matters come to its notice and we speak with both sides to resolve the matter. The panchayat scares and threatens that the offender will be sent to the police. Until now, the cases which have come up like these have been resolved at the panchayat level. The police have never been required, but in the future if the police's help is ever required, it will surely be sought. So far the need has never arisen to go to the helpline or the short-stay home. If their help is ever needed, we will surely go to them as well. Until now people have accepted the decision of the panchayat and resolved the matter in the village itself. [Male, aged 43, completed Class 10, panchayat representative for 8 years, endline, ID12]

There has been a lot of awareness among women through your programme, which is why they have come. Twenty women may have come regarding this issue in the year. I solved their problems through the law or the panchayat and helped them. There is a woman in my ward, RD. Her husband used to hit and abuse her, so we called him and explained. Now they live together nicely. We put social pressure on her husband which is why he doesn't beat or abuse her any more. Yes, now if any woman has experienced violence, then her family and husband are called and we punish them financially or physically. We call them, scold them and make them understand. [Male, aged 43, completed Class 15, panchayat representative for 3 years, endline, ID14] 
While PRI representatives, particularly male representatives reported taking actions to address alcohol abuse, including counselling those abusing alcohol and organising protests to curb the sale of alcohol, they acknowledged obstacles in doing so, including political interference when PRI representatives tried to reduce the sale of alcohol, on the one hand, and community members' own reluctance to stop the practice on the other.

\section{Changes in the attitudes and behaviours of men and women in the community}

Findings indicate that the programme had a mixed effect in changing attitudes and behaviours of community men and women.

\section{Raising awareness of violence-related laws and services for women in distress}

Although the intervention had no effect on raising married men's or women's knowledge about the DV Act, including penalties for violating it, it contributed significantly to enhancing men's and especially women's awareness about services available for women in distress, such as availability of short-stay homes and helplines (Figure 5). Specifically, awareness of support services among men increased by 15 points in intervention arm (23\% at baseline to $38 \%$ at endline) compared to a six-point increase in comparison arm ( $21 \%$ to $27 \%$ ); among women, it increased by 20 points in intervention arm (7\% to $27 \%$ ) compared to a three-point increase in comparison arm (5\% to $7 \%$ ).

Figure 5: Effect of exposure to the Do Kadam programme on awareness of the Domestic Violence Act and services for women in distress

Awareness of the DV Act

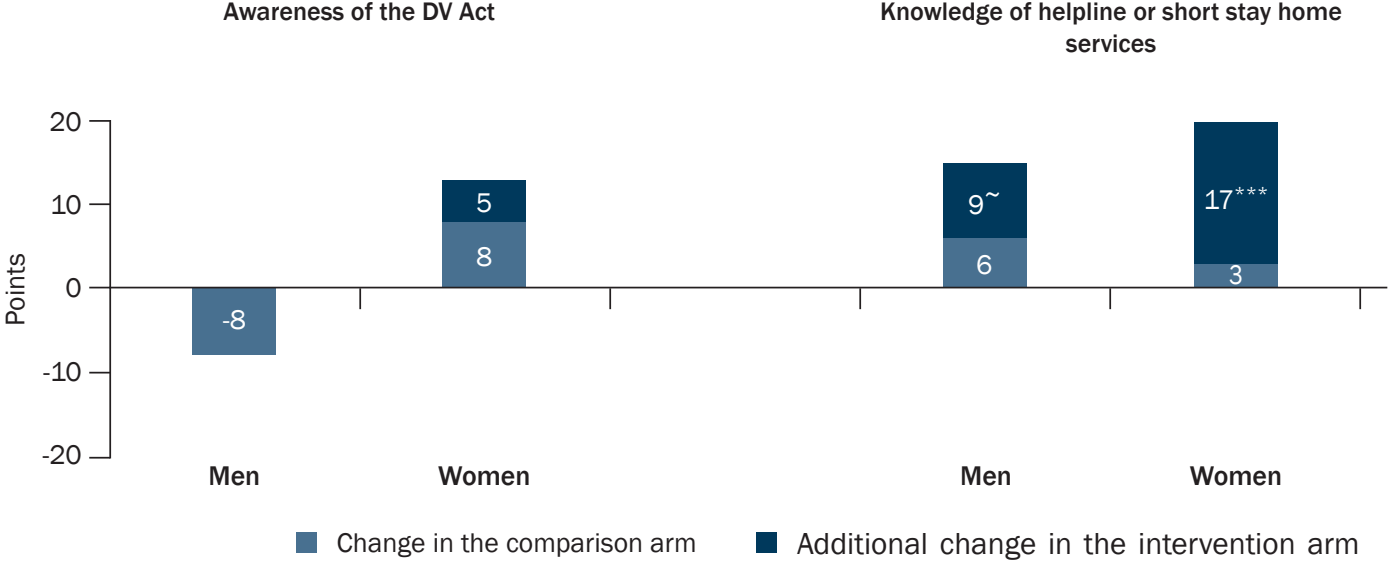

Note: ${ }^{\text {and }}{ }^{* * *}$ indicates that the effect of exposure to the Do Kadam programme is significant at $p<=0.10$ and $p<=0.001$, respectively.

\section{Reversing discriminatory attitudes and behaviours}

Exposure to the Do Kadam programme did not affect gender role attitudes and attitudes about the acceptability of VAWG. Traditional gender norms, as measured by attitudes towards gender roles and violence against women, remained strong and virtually unchanged in both arms in the endline survey.

Neither men's controlling behaviours nor men's perpetration and women's experience of violence within marriage was affected by exposure to the intervention. In the endline survey, as in the baseline survey, large proportions of men reported that they controlled their wife's movements and actions and large proportions of women reported that their husband controlled them. Likewise, marital violence remained widespread in intervention and comparison arms. About one-fifth of men from both arms reported the perpetration of physical violence on their wife in the six months preceding the baseline and endline interviews. Likewise, about a quarter of women in both arms reported the experience of physical violence perpetrated by their husband in the six months prior to the baseline and endline interviews. There was no evidence, moreover, that exposure to the intervention had an effect on men's perpetration and women's experience of sexual and emotional violence, respectively. 
Figure 6: Effect of exposure to the Do Kadam programme on husband's alcohol consumption as reported by women

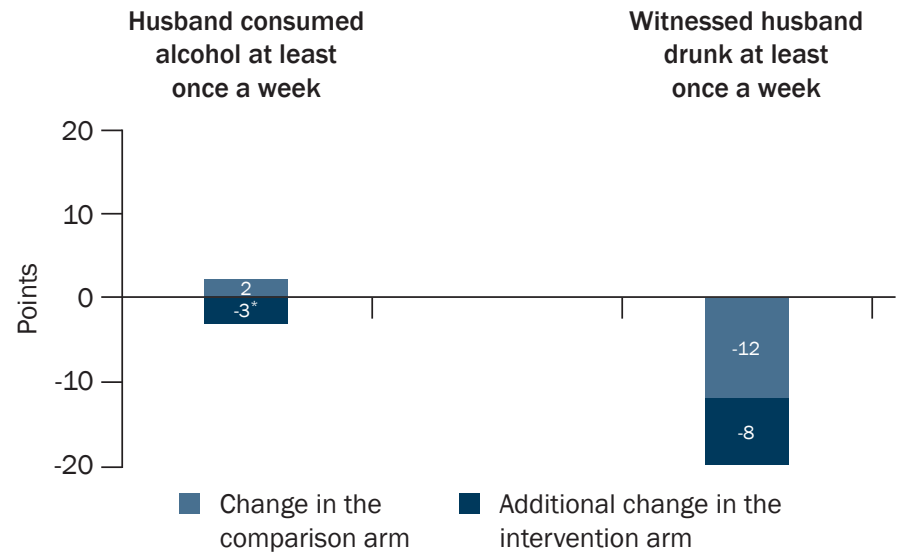

Note: * indicates that the effect of exposure to the Do Kadam programme is significant at $p<=0.05$.

\section{Reducing men's alcohol abuse}

The intervention resulted in a reduction in alcohol abuse among men in the intervention arm, as measured by women's reports of the frequency of their husband's alcohol use, and in their husband's display of drunkenness (Figure 6). While similar proportions of women in comparison arm reported that their husband consumed alcohol once a week or more frequently at baseline and endline (49\% and 51\%), a somewhat smaller proportion so reported at endline than baseline in intervention arm (44\% and $41 \%)$. The percentage of women who reported that they had witnessed their husband drunk at least once in the week declined more steeply in the intervention arm (38\% to $18 \%)$ than in the comparison arm (42\% to $30 \%)$.

\section{Recommendations}

The Do Kadam Barabari Ki Ore programme was designed to work within the existing community leadership structure, that is, locally elected representatives, to foster social change. Such a programme was envisaged to ensure community ownership and sustainability.

\section{Recognise that training PRI members to act as change agents requires sustained efforts}

Our findings have highlighted that PRI representatives themselves hold traditional attitudes, are not necessarily sensitive to the need to change such practices as alcohol abuse and violence against women, and lack the leadership skills necessary to mobilise communities. Yet they remain a powerful and untapped community-level resource for promoting social change. Indeed, strengthening their capacity for promoting social change requires a strong PRI capacity-building phase, accompanied by a strong demonstration phase in which NGOs conduct events and meetings and show locally elected representatives both how to organise a meeting and how to convey messages, and intervene confidently in case of violations. Finally, a transitional mentorship phase is needed, in which the organisation and conducting of events are taken over by PRI representatives themselves, with minimal or no external involvement. While this was the model the Do Kadam programme implemented through C3 and Abhiyan, we recognise that this three-phased approach is likely to be more time consuming than the seven months of activities conducted under the Do Kadam programme.

\section{Integrate a module on gender and violence against women in the larger PRI curriculum}

Given that deep-rooted gender stereotypical norms underpin several social issues that PRI representatives are entrusted to address, and given the findings from this study that exposing PRI representatives to a gender transformative curriculum can help them to adopt gender egalitarian norms, it is important and timely to integrate a module on gender and violence against women in the larger PRI curriculum.

\section{Ensure more intensive leadership training for PRI representatives}

While the PRI department is entrusted with providing leadership in the capacity building of PRI representatives, many PRI representatives have not had an opportunity to build leadership skills, are unaccustomed to communicating in public events, and have not been oriented about their responsibilities with regard to upholding social justice, empowering women, and addressing the needs of the most vulnerable. In this background, it would be useful to provide PRI representatives leadership training within the overall training programmes organised by the PRI 
department, apprise them of the importance of their roles as agents of social change in their communities, and build their skills in community mobilisation, communication, and negotiation, along with efforts, as in the Do Kadam programme, to change attitudes, facilitate exposure to available services, and organise events intended to transmit specific messages relating to social change.

\section{Take steps to ensure more regular exposure}

The finding that exposure to the intervention events-community-level sensitisation sessions and street plays-was irregular, calls for measures to ensure community members' regular participation in the programme. Female study participants who did not attend the programme argued that the location of the event was unsuitable for them or that their husband or family member had denied them permission to attend. Male and female study participants cited competing demands on their time. And finally, not all community members were aware of the programme and the events it organised. Efforts need to be made to better understand and accommodate reasons for modest attendance. PRI representatives may need to reach all community members in their homes, inform them about the intervention, share with them a schedule of events and services that PRI representatives can provide, and convey to them the legitimacy of the programme. If women's hesitation to attend the programme is linked to the presence of men who also attend the programme, separate events may need to be organised for women. Further, given that household chores and other time commitments inhibited many from attending the programme regularly, the programme would need to be more flexible in setting session timings to accommodate these constraints.

\section{Consider a sub-group focus}

In the current programme, events, meetings, and street plays were conducted for the community at large, and messages conveyed were general. It is possible that general messages are more difficult to internalise and adapt to one's own situation; organisers may thus prefer to hold meetings addressing specific groups of community members: men, women, and the young, those assembled at places where liquor is available, those in school, and so on. 


\section{Chapter 1 Introduction}

Violence against women is widespread in India: nationally, one in three (37\%) married women aged 15-49 has experienced physical or sexual violence perpetrated by their husband and among those from the state of Bihar, as many as 59 percent had experienced such violence in 2005-06 (International Institute for Population Sciences and Macro International, 2007; International Institute for Population Sciences, 2016). Although a number of policies, laws and programmes-ranging from the National Policy for the Empowerment of Women 2001 to the Protection of Women from Domestic Violence Act 2005, for example-have been introduced with the intention of empowering women and eliminating violence against women and girls (VAWG), evidence on what works and what does not work to prevent violence against women and girls is limited in India.

In order to fill this gap, the Population Council, together with the Centre for Catalyzing Change (C3) and the London School of Hygiene and Tropical Medicine, and with support from UKaid, implemented the Do Kadam Barabari Ki Ore (Two Steps Towards Equality) programme. The programme comprised the development and evaluation of a number of interventions for the prevention of violence against women and girls in Bihar, which incorporated evidence-based best practices from India and globally. One of the interventions implemented under this programme, situated in Patna district, aimed to orient and engage locally elected leaders-namely, members of Gram Panchayats and Gram Kachehris ${ }^{2}$-in changing community norms relating to the acceptability of violence against women, and preventing violence against women as well as one factor closely associated with the perpetration of such violence, namely alcohol abuse. The Population Council evaluated the acceptability of the intervention and its effectiveness in changing gender norms, particularly those related to wife-beating, among women and men at the community-level as well as in reducing men's perpetration of marital violence, controlling behaviours and alcohol misuse, and women's experience of marital violence. This report describes the project and presents its findings.

\section{Background and rationale}

The need for interventions that focus on community mobilisation has been expressed repeatedly in the global literature. The WHO World Report on Violence and Health pointed out, in 2002, that community and societal strategies to reduce violence had been relatively neglected among programmes (Krug et al., 2002). More recently, a review of available evidence for what works to reduce the prevalence of violence against women and girls suggests that programmes have indeed shifted their focus from trying to achieve change in groups of individuals to trying to achieve change at the community-level. It notes that these community mobilisation interventions aim to reduce violence at the population level through changes in public discourse, practices, and norms related to gender and violence. Typically, they engage many stakeholders and use strategies ranging from group training to public events and advocacy campaigns (Ellsberg et al., 2014).

Perhaps the best documented recent community mobilisation intervention to reduce violence against women is the SASA! study in Kampala, Uganda. The intervention identified and trained local leaders (women and men from the community as well as police, health care providers, and others), who then conducted informal activities within their own social networks, built connections with the community at large, and focused on changing social norms surrounding gender power relations and violence against women. The intervention lasted some 2-3 years, and was implemented in four communities, with an additional four communities serving as comparison areas. Results showed that the intervention had succeeded in reducing the acceptability of partner violence among women (and to a lesser

\footnotetext{
${ }^{1}$ Findings from the NFHS4 suggest that the percentage of women reporting the experience of spousal violence had declined to $45 \%$ by 2015 (International Institute for Population Sciences 2016), a steep decline that requires further investigation.

${ }^{2}$ As per the Bihar Panchayat Raj Act 2006: "Panchayat" means an institution of self-government constituted under Article 243B of the Constitution of India for the rural areas. It indicates moreover that $[T]$ here shall be Gram Kachehri in every Gram Panchayat area for the purposes of discharging the judicial functions as defined under the Bihar Panchayat Raj Act 2006. As per the Act, every Gram Panchayat must have six standing committees, one of which must be the Social Justice Committee.
} 
extent among men), and reducing women's experience of physical and sexual violence (Abramsky et al., 2014). Other successful models are the Tostan programme implemented in villages of Senegal (Diop et al., 2004) and the SHARE intervention in Rakai, Uganda (Wagman et al., 2014).

Opportunities for community mobilisation exist in India as well, and among the most promising potential agents of change are locally elected representatives of Panchayati Raj institutions (PRIs, local self-governance bodies). Local self-government or Panchayati Raj came into being in India with the enactment in 1992 of the 73rd amendment of the Indian Constitution (although it came into force only in 1994). Under this amendment, administrative powers were devolved to the local level, and governance became the responsibility of locally elected representatives. Engaging these locally elected representatives to act as agents of change to challenge patriarchal norms and prevent violence against women is a promising approach. For one, panchayat members are specifically tasked with the responsibility for preparing plans, as well as implementing and monitoring the progress of schemes for economic development and social justice, including poverty alleviation, public health and family welfare, education, and women and child development; they are also expected to play a role in the promotion of cultural and sports activities. Indeed, each Gram Panchayat meets at least once in two months and operates through six standing committees including a Social Justice Committee (intended to promote the welfare of women). Protection of women from violence thus falls directly within its mandate and building the capacity of these elected representatives and instilling in them a sense of accountability for preventing violence is well within the purview of their commitments as locally elected representatives. Second, scope for upscaling is significant, given that similar structures exist in every district of the state and indeed of the country (Government of Bihar, n.d.).

Bihar, the locale for our study, comprises nine percent of India's population: it contains a population of 104.1 million and is the third largest state in the country; 17 percent of the population belong to socially disadvantaged castes and tribes (Office of the Registrar General and Census Commissioner, India, 2013). Bihar offers an appropriate setting for exploring the impact of a community mobilisation intervention on changing attitudes towards and reducing the experience of violence within marriage for several reasons. For one, it is one of the most poorly developed states in the country: 34\% of the state's population was estimated to be living below the poverty line (Planning Commission, 2013), a significant proportion of the population remains illiterate (for example, 52\% of women were illiterate) (Office of the Registrar General and Census Commissioner, 2013), and child marriage is more widespread in Bihar than in any other state in the country: 69 percent of 20-24-year-old women were married before age $18,{ }^{3} 33$ percent below age 15, and 10 percent below age 13 in 2005-06 (International Institute for Population Sciences and Macro International, 2007). Moreover, as mentioned earlier, Bihar ranked highest among all states in India with regard to women's experience of violence within marriage in 2005-064 (International Institute for Population Sciences and Macro International, 2007). Although violence cuts across socio-demographic groups, women with no education, those belonging to scheduled castes, and those belonging to poor households were most severely affected.

Norms justifying partner violence are strongly held by both men and women in Bihar-57 percent of women and men alike justified wife-beating in 2005-06. Violence against women and girls is widely perceived by women and men as acceptable under some circumstances, notably, for example, women's perceived disobedience. Intergenerational transmission of violence is substantial in the state; 20 percent of young men and women in Bihar had witnessed their father beating their mother, and 55 percent and 11 percent, respectively, had experienced violence perpetrated by a parent (International Institute for Population Sciences and Population Council, 2009). Furthermore, alcohol consumption is common among men (35\% and 29\%, respectively, of those aged 15-49 consumed alcohol in 2005-06 and 2015, respectively) (International Institute for Population Sciences and Macro International, 2007; International Institute for Population Sciences, 2016). Finally, seeking help when faced with violence is uncommon: only 21 percent of women in Bihar who had experienced violence sought help (International Institute for Population Sciences and Macro International, 2007), a situation that, in turn, reduces women's ability to prevent further violence (International Institute for Population Sciences and Population Council, 2009; Jejeebhoy, Santhya and Sabarwal, 2013; Jejeebhoy, Santhya and Acharya, 2014).

Table 1.1 presents a comparative profile of socio-demographic indicators in Patna district as compared to Bihar state as a whole. Patna district comprises six percent of the state's population; given that it houses the state capital, it is

\footnotetext{
${ }^{3}$ Findings from the NFHS-4 suggest that the percentage of women aged 20-24 who were married before age 18 had declined to 39 percent by 2015 (International Institute for Population Sciences, 2016), a steep decline that requires further investigation.

${ }^{4}$ Findings from the NFHS-4 suggest that the percentage of married women of reproductive ages reporting the experience of spousal violence had declined to 45 percent by 2015 (International Institute for Population Sciences, 2016), a steep decline that requires further investigation.
} 
far less rural than the state as a whole. Hindus make up a somewhat larger proportion of the population of Patna compared to Bihar as a whole (92\% vs. $83 \%$ ), although percentages belonging to socially disadvantaged castes and religions are similar (16-17\%). Literacy rates are higher among both men and women in Patna district than in the state as a whole. However, the population and child sex ratios are somewhat more adverse in Patna than in Bihar. Of note however is that marriage continues to take place in childhood for considerable percentages in both Patna district and Bihar state: 11-12 percent of girls aged 15-17 in both were married and as many as 36 percent of married girls aged 15-19 in Patna were already mothers, a somewhat larger proportion than in Bihar as a whole (30\%).

Table 1.1: Profile of the study district and state

\begin{tabular}{|c|c|c|}
\hline & Patna district & Bihar \\
\hline Population $^{1}$ & $5,838,465$ & $104,099,452$ \\
\hline Rural $(\%)^{1}$ & 56.9 & 88.7 \\
\hline Scheduled castes and tribes $(\%)^{1}$ & 15.9 & 17.2 \\
\hline Hindu $(\%)^{2}$ & 91.7 & 82.7 \\
\hline Muslim $(\%)^{2}$ & 7.5 & 16.9 \\
\hline Male literacy $(\%)^{1}$ & 78.5 & 71.2 \\
\hline Female literacy $(\%)^{1}$ & 62.0 & 51.5 \\
\hline Overall sex ratio $(F / M)^{1}$ & 897 & 918 \\
\hline Child sex ratio $(0-6$ years $)(F / M)^{1}$ & 909 & 935 \\
\hline Total fertility rate, AHS $2012-13^{3}$ & 2.6 & 3.5 \\
\hline Infant mortality rate, AHS $2012-13^{3}$ & 31 & 48 \\
\hline $15-17$-year-old girls who were ever married $(\%)^{4}$ & 11.2 & 11.6 \\
\hline $15-19$-year-old married girls who were already mothers $(\%)^{5}$ & 35.8 & 29.7 \\
\hline
\end{tabular}

Sources: ${ }^{1}$ Directorate of Census Operations, Bihar, 2014; Office of the Registrar General and Census Commissioner, ${ }^{2} 2015 a,{ }^{3}$ n.d., ${ }^{4} 2015 b,{ }^{5} 2015 c$.

Bihar has an effective and functioning three-tier Panchayati Raj system. ${ }^{4}$ Indeed, while at least one-third of locally elected representatives must be women, in Bihar, women constitute a far larger proportion. As such, they offer opportunities to both build leadership skills among both women and men community leaders, and, correspondingly, through them, reach both women and men in the community. Locally elected representatives must also come from socially disadvantaged castes and tribes (proportionate to their representation in the constituency) and may thus be credible spokespeople for reaching those from different caste groups (Rural Development and Panchayat Raj Department, Government of Tamil Nadu, n.d.).

Locally elected representatives, that is, members of the Gram Panchayat, are directly elected to their posts by the voters of the village. They are from the community and are expected to be familiar with the social and economic concerns and development needs of their areas. The Gram Panchayat is headed by a mukhiya. Local representatives are elected for a period of five years and must hold meetings of the Gram Sabha (all those on the electoral rolls) at least four times a year, during which progress on development programmes is reported. While the Gram Panchayat is responsible for undertaking development work in the village, there are statutory standing committees that are responsible for undertaking specific tasks. One of these is the Standing Committee on Social Justice responsible for specific tasks related to social development, including those relating to violence against women and alcohol abuse.

Community members generally hold locally elected representatives with respect, and as such the PRI as an institution has the potential to serve as a powerful agent of social change. Unfortunately, this potential has been

\footnotetext{
${ }^{4}$ The Gram Panchayat (village-level committee) is headed at the lowest level by a Mukhiya, Panchayat Samiti (committee); at the block level, by a Pramukh and Zila Parishad (district committee); and at the district level by an Adhyaksha.
} 
poorly utilised. For one, notwithstanding a provision for training PRI members to understand laws of relevance to their community, and to discharge their responsibilities, such training is rarely imparted. Second, priorities are rarely set based on social needs. Third, the prominent role elected representatives can play is poorly understood, and PRI members rarely serve as agents of change. Finally, even if the role of the PRI is understood at the communitylevel, women rarely seek justice from these locally elected representatives because of lack of support from family and community members. An intervention that raises PRI members' awareness of social issues-including violence against women-and empowers, sensitises, and mentors PRI members to play a more proactive role in effecting social change would thus fall squarely within the mandate of the $73^{\text {rd }}$ Amendment to the Constitution.

\section{Objectives}

The objective of the evaluation was to assess the feasibility and acceptability of the Do Kadam Barabari Ki Ore model and its impact on changing norms and attitudes that accept men's entitlement to commit violence against their wife. In particular the programme aimed to develop more egalitarian gender role attitudes generally among women and men; reduce alcohol misuse; and reduce the experience (women) and perpetration (men) of violence against women in marriage. Specifically, it assessed:

1. The feasibility of sensitising and training PRI members to act as change agents to transform gender norms among men and women in their communities;

2. The effect of the intervention on generating egalitarian gender role attitudes among PRI members and a reduction in VAWG perpetrated/experienced by them; and

3. The effect of the intervention on changing gender role attitudes, including attitudes about marital violence among men and women at the community-level, and reduction in VAWG and alcohol misuse at the community-level.

\section{Study setting}

Our intervention was based in Patna district. In Patna, not only are structures and facilities for building women's agency and addressing violence against women more likely to exist than in other districts, it also has a strong system of Panchayati Raj institutions. In all, there are 331 Panchayats in Patna district, and 4489 Gram Panchayat members in the district. At least 50 percent of the elected members of Gram Panchayats are female, far more than the mandatory one-third representation of women in panchayats. Gram Panchayats implement several development projects in their villages, although no work had specifically been conducted to address violence against women and girls. Each Gram Panchayat serves a population of 7,000-8,000; in our case, about 4-5 villages. There are approximately 14-16 ward members, that is, elected members of each panchayat (roughly 1 per 500 population).

\section{Intervention}

Our intervention was implemented over a seven-month period, between July 2014 and February 2015. It contained a number of components. For one, it trained and oriented members of the Panchayati Raj institutions to act as change agents to transform gender norms among women and men in their communities; a three-day training workshop was organised as a first step in the programme, and fortnightly refresher sessions were also conducted that prepared locally elected representatives to conduct sensitisation sessions with their communities. Training of PRI members was conducted using a curriculum specially developed by C3 for the intervention; training also sought to mentor PRI members to intervene in violence cases in their community. Following each training session, the locally elected representatives held learning sessions with their communities in which, with help from local NGOs, they sought to transfer their learning to the wider population of men and women in their ward; over the course of the intervention, they also organised community wide campaigns and street plays to highlight issues related to gender and violence. Finally, although the intervention aimed to take steps to revitalise the Social Justice Committee, we experienced challenges and delays in doing so. As an alternative, C3 India supported PRI representatives in establishing a parallel but more informal mechanism, the Mahila Nyay Samiti (Women's Justice Committee) to take on this function. The programme was conducted with inputs from the Department of Panchayati Raj Institutions in the Government of Bihar. The intervention is discussed in greater length in Chapter 3. 


\section{Study design}

A mixed-method evaluation design was used, comprising both quantitative and qualitative methods. We used a quasi-experimental design to assess effect with regard to community members at large- namely married women aged 18-49 and married men aged 18-54-with cross-sectional surveys undertaken in comparison and intervention arms prior to the implementation of intervention activities (baseline) and at its conclusion (endline). A quasi-experimental design was considered optimal. This design enabled us to assess not only whether changes had been experienced among women and men over the course of the intervention, but also whether the change observed in the intervention arm was significantly different from the change observed in similar villages where the intervention did not take place (comparison arm). We could thus assess whether the change in the intervention arm was attributable to the Do Kadam Barabari Ki Ore project. In order to supplement findings from the surveys, we purposively selected 10 male and 10 female survey respondents to explore change in greater depth. These survey respondents were interviewed, in the month following the baseline and endline surveys, based on their response to questions on the perpetration and experience of violence and alcohol use.

We also conducted repeated in-depth interviews with selected PRI members in the intervention arm at around the times of the baseline and endline assessments, to assess their perceptions and experiences with regard to the acceptability and effectiveness of the Do Kadam Barabari Ki Ore PRI project.

Selection of intervention and comparison villages was done in two steps. In the first step, one block-namely, Mashauri, whose indicators were similar to the Patna district average in terms of female literacy and percentage of the scheduled caste/tribe population-was selected for the study. We note that of the blocks identified with indicators similar to the district average, we selected Mashauri because C3 India had worked in the block in a previous project (unrelated to violence against women and girls) and was familiar with local partners in the block. In the next step, two indicators-female literacy and the percentage of the population that belonged to scheduled castes or tribes-were computed for all 18 Panchayats of Mashauri block and compared with block-level indicators. Four Panchayats whose indicators were similar to the average levels of indicators recorded for the block were selected for the study. Two of these Panchayats were then selected for the intervention, and the remaining two as comparison sites. To reduce chances of contamination, we chose the intervention and comparison Panchayats in such a way that they were relatively distant from each other. The two Gram Panchayat areas in which the intervention was conducted contained a total of nine villages and a population of 18,514 according to the 2011 census; the two Gram Panchayat areas comprising the comparison area contained a total of 13 villages and a population of 23,288.

In order to evaluate the effectiveness of the intervention, we required a sample of 375 married men and 375 married women in each of the two arms; our strategy also ensured, for ethical reasons, that men and women from the same household would not be interviewed. Following the selection of intervention and comparison villages, we conducted a baseline assessment, that is, a household listing, in which all households in the study villages were enumerated, followed by a survey of eligible respondents, as specified earlier, in the 22 selected villages. From the household listing exercise, we selected the male sample randomly from odd numbered households and the female sample from even numbered households, thereby ensuring that a woman and her husband from the same household were not interviewed. A total of 1,462 and 1,063 households, respectively, were randomly selected.

For the survey, the field team administered a household schedule in 95-98 percent of selected households, and from these households, invited one (if more than one was available) eligible married woman or man to participate in the survey. In households containing more than one eligible respondent, one was selected randomly using the Kish table. At baseline, the team identified a total of 837 married men and 805 married women. In total, 763 married men aged 18-54 and 767 married women aged 18-49 were interviewed, of a targeted 750 in each group. We completed the baseline data collection in June 2014.

Aside from the survey, we conducted in-depth interviews with selected men and women who had reported various experiences in the course of the baseline survey. We selected women who reported that their husband either never or frequently, respectively, consumed alcohol; and who reported that they had experienced severe, moderate, or no violence in their marital life. Two women from each of these five categories were selected and in all, we selected 10 women. Likewise, we selected 10 men on the basis of their self-reported alcohol consumption practices and their perpetration of marital violence. Finally, of the 52 PRI members who underwent the pre-intervention training programme, one male and one female PRI member who had attended all three days of this training programme were selected for an in-depth interview from each of the nine villages, for a total of 18 PRI representatives. 
The endline assessment was carried out from April-June 2015. Using the household listing information obtained prior to the baseline exercise, a fresh set of households was selected (we acknowledge that some households may have been interviewed at baseline as well although no special effort was made to re-interview those interviewed at baseline). Thus, at endline, field teams successfully interviewed a total of 757 and 766 married men and women, respectively. In-depth interviews were repeated, in addition, with all married men and women and 16 of the 18 PRI representatives who had been interviewed at baseline.

\section{Study instruments}

Six study instruments were developed-a household listing form (only at baseline); a household schedule to collect socioeconomic characteristics of selected households and identify eligible respondents; two survey questionnaires, one each for women and men, to gather information from eligible community members; and two in-depth interview guides to collect insights from PRIs and selected survey male and female respondents, respectively.

Responses to the household listing form and the household questionnaire were gathered from a responsible adult member of all households in the study villages. The household listing form identified all households in the primary sampling units at the time of the baseline, and was used to select households for interview at both baseline and endline. The household questionnaire contained a roster in which age, sex, marital status, schooling status, and duration of residence in the household in the last year of all household members who usually resided in the household were recorded. Details recorded in this roster allowed us to identify the availability of an eligible male or female respondent (at endline, any respondent who had not resided in the household in the period during which the intervention was implemented was considered ineligible for inclusion in the study).

The questionnaire for married women and men was more or less identical at baseline and endline. It focused on respondents' background characteristics, their agency and gender role attitudes, particularly with regard to violence against women and girls. It also focused on women's experiences and men's perpetration of non-consensual sex and physical violence of various forms (from slapping to burning), men's alcohol consumption, knowledge about the Domestic Violence (DV) Act, and among women who had reported the experience of violence, injuries suffered and the nature of help available and sought. At endline, in addition, we probed about whether behaviours and experiences had changed since the project was initiated, as well as their exposure to the meetings and other events held by PRIs and local NGOs, perceptions about the acceptability and effectiveness of the programme, and whether they attributed any change in gender role attitudes or experiences of violence against women to the intervention.

The In-Depth Interview (IDI) guide for married men and women selected from the baseline survey included broad thematic areas to be covered and key questions that served as prompts under each broad theme. At baseline, the in-depth interview focused on the life experiences of the respondent; his/her relations and interaction with his/her spouse; socialisation experiences; perceptions of masculinity and femininity; gender-role attitudes including those relating to violence against women and girls; spousal communication, negotiation and conflict resolution practices; alcohol and substance use practices; and finally, experience and perpetration of emotional, physical, and sexual violence in marriage and the circumstances in which the violence took place. At endline, the IDI guide focused on experiences in the intervening period, and, additionally, on study participants' perspectives about the role of PRIs as change agents and the extent to which they interacted with PRIs on topics related to or experience of violence. If they had any interaction, IDIs focused on the perceived effectiveness and acceptability of PRIs as change agents, and whether PRI-led activities did indeed make gender norms more egalitarian and enable men to denounce violence against women.

The guide for PRIs similarly explored their gender role attitudes, particularly with regard to violence against women, alcohol abuse in their family, experience/perpetration of violence in marriage, and experiences as a locally elected representative and whether they had ever been approached for any matter relating to violence against women. In the follow-up in-depth interview, we also inquired about change in the period since the first interview with regard to attitudes and experiences of violence, perceptions about the acceptability and effectiveness of the intervention, and the extent to which PRIs believed they had been successful in reducing the incidence of violence in their village.

All study instruments were prepared in English, translated into Hindi, and pre-tested. 


\section{Recruitment, training, and fieldwork}

A total of eight young men underwent training prior to the baseline survey. They conducted the household listing and the information they obtained was used for the survey at both baseline and endline. In addition, at baseline, six young women and six young men were trained and they administered the survey instruments. At endline, 15 young women and eight young men did so. These research assistants were graduates in science or social science streams, proficient in Hindi and had 3-4 years of experience in conducting field-based studies. All teams-at both baseline and endline-were trained by Population Council staff members. Training for household listing was completed in two days; for the survey, however, interviewers underwent a 10-day training programme-at the time of both the baseline and endline surveys-that included a combination of classroom sessions, mock interviews, and field practice. Training focused on interviewing methods, details of the questionnaire, and research ethics including issues of confidentiality and privacy. The interviewers were divided into two teams; female interviewers conducted interviews with women, male interviewers with men. Each team had one field editor who was responsible for field editing, backchecks, and quality control of interviews; and one supervisor, responsible for the overall management of fieldwork and team-related logistics as well as assisting in field editing and back-checking.

Finally, two interviewers-one male and one female-were separately trained to conduct in-depth interviews; the same interviewers conducted interviews at baseline and endline.

Principal investigators made frequent visits to monitor and supervise data collection operations. Each team regularly completed quality-control sheets, giving the team, the coordinator, and principal investigators an opportunity to review the quality of ongoing fieldwork. These quality control sheets were designed to provide information on response rates in each village covered and track reporting of violence and interviewer performance.

\section{Ethical considerations}

We recognised that serious ethical concerns could arise in both the survey and in-depth interviews and we adopted suitable precautionary measures. First and foremost, we recognised that women may fear adverse repercussions if they disclosed experiences of marital violence. To allay these fears, we assured all respondents that the data gathered were entirely anonymous; that the interviewers would not share their responses with anyone, including their family members, the authorities, or other influential adults in their community; and that names would never be recorded on the questionnaire.

The interviewers underwent extensive training in ethical issues. Emphasis was laid on explaining the content of the questionnaire, the respondent's right to refuse to participate or answer any question, and informed consent. At the same time, we trained interviewers how to ask sensitive questions regarding violence and alcohol abuse in empathetic and non-judgemental ways, and emphasised the importance of offering to refer those in need to appropriate nearby organisations. Third, before entering a Primary Sampling Unit, the interviewer teams were instructed to apprise community leaders of the study and seek their support for its implementation in the community. This step ensured that community support was forthcoming and enabled team members to easily build rapport within the community. We note that despite the sensitive nature of the questions, not a single Primary Sampling Unit refused permission to our teams on the grounds of study content.

Every effort was made to maintain privacy in the course of the interview. To ensure that the interviews were not overheard by family members or others, the interviewers conducted the interview in a separate room in the respondent's home, asked questions in whispers, called on a co-interviewer designated for this purpose to hold parallel discussions with adults or others interested in listening to the interview, or re-scheduled the interview so as to enable full confidentiality. Interviewers were permitted to skip to relatively non-sensitive sections in case the interview was observed by others. Each team was trained to assign one interviewer to conduct parallel discussion sessions with bystanders, thereby providing privacy to the interview. Finally, the interviewers were instructed that if privacy could not be ensured, the interview must be terminated without asking sensitive questions. Notwithstanding these efforts, we acknowledge that during the interview some women may not have accurately reported the experience, and some men the perpetration, of violence. 
All of the questionnaires were anonymous and names were never recorded. In order to preserve the confidentiality of the respondent, signing the consent form was optional; however, the interviewer was required to sign that she or he had explained the content of the consent form to the respondent. Consent forms were detached and stored separately from the questionnaires. Finally, we also recognised the need for responding appropriately to requests from respondents for help or information related to violence and help-seeking options. Our field staff members were trained and equipped to refer such requests to local NGOs or relevant government authorities in the selected districts as appropriate.

The protocol for this study was approved by the Population Council's Institutional Review Board.

\section{Data processing}

All completed questionnaires were sent to the Population Council's office in New Delhi for office editing and data processing. Completed questionnaires were rechecked and further edited in the office for omissions and consistency. Responses to open-ended questions were scrutinised and common responses were provided codes. For entering the edited data, a special software package was developed using CSPro 5.1. Data were entered twice by different entry operators to minimise entry problems. The raw data were validated and cleaned to remove possible inconsistencies. The analysis of data was carried out using SPSS 18.0 and STATA 13.0. For textual data, a coding scheme was developed. Coded blocks of text related to specific themes, for example, gender role attitudes, experiences of violence, help-seeking practices, and so on, with a focus on assessing changes that took place among individuals over the course of the intervention.

The impact of the intervention was measured by comparing changes in outcome indicators for PRI members as well as women and men in the study communities, as appropriate, in intervention and comparison arms. Specifically, the impact evaluation among women and men at the community-level uses data from the two cross-sectional surveys conducted before the intervention was initiated (at baseline) and after its conclusion (endline), respectively, in intervention and comparison arms. To measure the effect of the intervention among PRI members, we compared their responses to the in-depth interviews conducted at baseline and endline in intervention arm.

\section{Response rates}

Table 1.2 summarises the number of respondents identified and successfully interviewed at baseline and endline. At baseline, of the 1,462 households selected from which to draw male respondents, 1,427 household interviews were successfully conducted (98\%); likewise, of the 1,063 households selected from which to draw the female sample, 1,007 household interviews were successfully conducted (95\%). At endline, the same sampling frame was used to select a new set of households from which we drew male and female respondents. Of the 1,377 households selected for drawing the male sample, 1,355 household interviews were successfully conducted (98\%) and of the 1,077 households selected for drawing the female sample 1,060 household interviews were successfully conducted (98\%).

From these lists of households we drew our sample of men and women to be interviewed individually at baseline and endline. We identified a total of 837 and 844 men at baseline and endline respectively, of whom 88 percent and 90 percent were successfully interviewed. Likewise, we identified 805 and 820 women at baseline and endline, respectively, of whom 95 percent and 93 percent, respectively, were successfully interviewed.

Reasons for non-response are presented in Table 1.2. They show that refusal rates were generally low at both times among both respondents to the household questionnaire and to the individual questionnaires. At the time of both the baseline and endline surveys, the leading reason for non-response was that the respondent was unavailable for interview even after 3-4 visits by the field teams (1-5\% in the case of household interviews for men and women at baseline and endline; $10 \%$ and $7 \%$ for men selected for individual interviews at baseline and endline, respectively; and $4 \%$ and $5 \%$ for women selected for individual interviews at baseline and endline, respectively).

\section{Structure of the report}

The report is divided into seven chapters, including this introductory chapter. In Chapter 2, we present a profile of the lives of married men and women at baseline. In Chapter 3, we describe the objectives, the design, and the key components of the intervention. Drawing from monitoring data, we also describe the exposure of PRIs 
Table 1.2: Response rates at baseline and endline and reasons for non-response for men and women

\begin{tabular}{|c|c|c|c|c|c|c|c|c|}
\hline & \multicolumn{4}{|c|}{ Married men (ages 18-54) } & \multicolumn{4}{|c|}{ Married female (ages 18-49) } \\
\hline & $\begin{array}{l}\text { Households } \\
\text { for male } \\
\text { interviews } \\
\text { at baseline }\end{array}$ & $\begin{array}{c}\text { Men at } \\
\text { baseline }\end{array}$ & $\begin{array}{l}\text { Households } \\
\text { for male } \\
\text { interviews } \\
\text { at endline }\end{array}$ & $\begin{array}{l}\text { Men at } \\
\text { endline }\end{array}$ & $\begin{array}{l}\text { Households } \\
\text { for female } \\
\text { interviews } \\
\text { at baseline }\end{array}$ & $\begin{array}{c}\text { Women at } \\
\text { baseline }\end{array}$ & $\begin{array}{l}\text { Households } \\
\text { for female } \\
\text { interviews } \\
\text { at endline }\end{array}$ & $\begin{array}{c}\text { Women at } \\
\text { endline }\end{array}$ \\
\hline $\begin{array}{l}\text { Selected/ } \\
\text { Identified }\end{array}$ & 1,462 & 837 & 1,377 & 844 & 1,063 & 805 & 1,077 & 820 \\
\hline Interviewed & 1,427 & 736 & 1,355 & 757 & 1,007 & 767 & 1,060 & 766 \\
\hline $\begin{array}{l}\text { Reasons for } \\
\text { non-response }\end{array}$ & & & & & & & & \\
\hline Not at home & 30 & 84 & 16 & 57 & 55 & 35 & 9 & 43 \\
\hline $\begin{array}{l}\text { Respondent } \\
\text { refused }\end{array}$ & 4 & 11 & 6 & 17 & 1 & 1 & 6 & 6 \\
\hline $\begin{array}{l}\text { Partially } \\
\text { completed }\end{array}$ & 0 & 5 & 0 & 0 & 0 & 1 & 1 & 0 \\
\hline Incapacitated & 1 & 1 & 0 & 13 & 0 & 1 & 1 & 5 \\
\hline $\begin{array}{l}\text { Response } \\
\text { rate }\end{array}$ & 97.6 & 87.9 & 98.4 & 89.7 & 94.7 & 95.3 & 98.4 & 93.4 \\
\hline
\end{tabular}

and community members to intervention activities. Drawing on survey data, Chapter 4 describes community members' awareness of and participation in the Do Kadam programme, their interaction with PRI members and their perceptions about PRI members' engagement on issues related to VAWG, alcohol abuse and gender equality before and after the intervention, and changes experienced by those in intervention and comparison arms over the six months preceding the endline interview (a period that overlapped with the implementation of the intervention). Chapter 5 presents PRI representatives' own perceptions about the intervention, their role in implementing it, and the challenges faced in doing so. It also presents findings with regard to their own assessments about whether there had been changes in their practices and attitudes following their exposure to the intervention. In Chapter 6 , we draw on data collected from men and women at baseline and endline, to present findings with regard to the effect of the project on changing attitudes, including about gender roles, the acceptability of marital violence and women's right to refuse sex in marriage. In addition we present findings on changing behaviours, including men's controlling behaviours; and experience and perpetration of marital violence and men's alcohol misuse. Chapter 7 summarises the main findings of the evaluation. 


\section{Chapter 2 Profile}

Drawing on data from the baseline survey, this chapter presents a profile of the lives of married women and men in the study settings. We first present the socio-demographic background characteristics of the sample, followed by a discussion of baseline indicators relating to study participants' knowledge about laws and services related to violence against women, their gender role attitudes and attitudes regarding the acceptability of violence against women and girls, men's controlling behaviour over their wife, and violence perpetrated by men against their wife. Finally, we assess study participants' perceptions about community support, their perceptions about the activities of their Panchayats, and their interaction with Panchayat members.

\section{Background characteristics}

Table 2.1 describes the household characteristics of the married men and women from the intervention and comparison sites who participated in the survey at baseline. As far as household characteristics are concerned, findings suggest that an overwhelming majority (96\%-98\%) of respondents were Hindu and about two in five (38-39\%) belonged to scheduled castes.

Economic status data suggest that the majority of men and women in both the intervention and comparison sites came from resource-poor households; only one in five respondents $(20 \%-21 \%)$ lived in a pucca house (with a roof, walls, and floor made of permanent materials); few had access to a flush toilet ( $16 \%$ of men and $23 \%$ of women) and $72-78 \%$ lived in households with electricity. About half (46\%-51\%) owned agricultural land. Household economic status was measured using a wealth index, composed of household asset data on ownership of selected durable goods, including means of transportation as well as access to a number of amenities. The wealth index was constructed by allocating scores to a household's reported assets or amenities (for details of the scores, see Appendix 1). Index scores, so constructed, ranged from 0 to 56. The household wealth index confirms a situation of considerable poverty: the average household scored only 15 on the wealth index. Scores on the wealth index were, moreover, almost identical in both intervention and comparison sites.

Table 2.1: Selected household characteristics of men and women, ${ }^{1}$ baseline survey

\begin{tabular}{|c|c|c|c|c|c|c|}
\hline \multirow[t]{2}{*}{ Selected characteristics } & \multicolumn{3}{|c|}{ Married men (ages 18-54) } & \multicolumn{3}{|c|}{ Married women (ages 18-49) } \\
\hline & Comparison & Intervention & Total & Comparison & Intervention & Total \\
\hline \multicolumn{7}{|l|}{ Religion and caste (\%) } \\
\hline Hindu & 98.7 & 97.0 & 97.8 & 95.5 & 96.4 & 96.0 \\
\hline Scheduled caste & 41.8 & 35.5 & 38.7 & 39.5 & 35.9 & 37.7 \\
\hline \multicolumn{7}{|l|}{ Household economic status (\%) } \\
\hline Has flush toilet & 13.1 & 19.6 & 16.3 & 21.0 & 24.1 & 22.6 \\
\hline Has electricity & 72.7 & 72.2 & 72.4 & 75.9 & 80.8 & 78.4 \\
\hline \multicolumn{7}{|l|}{ Type of house (\%) } \\
\hline Kachcha & 31.6 & 32.8 & 32.2 & 15.6 & 19.2 & 17.5 \\
\hline Semi-pucca & 49.3 & 43.8 & 46.6 & 66.3 & 59.2 & 62.7 \\
\hline Pucca & 19.0 & 23.4 & 21.2 & 18.0 & 21.5 & 19.8 \\
\hline Owns agricultural land & 44.0 & 47.4 & 45.7 & 51.5 & 49.5 & 50.5 \\
\hline Mean HH wealth index $(0-56)$ & 14.9 & 15.2 & 15.1 & 15.4 & 15.5 & 15.4 \\
\hline Number of respondents & 373 & 363 & 736 & 377 & 390 & 767 \\
\hline
\end{tabular}

Note: ${ }^{1}$ Given spousal age differences, with men 3-5 years older than their wife, we adopted a somewhat higher age range for men than women. 
Table 2.2 presents a socio-demographic profile of married men and women interviewed in the intervention and comparison sites at the time of the baseline survey. Age profiles suggest that men were on average aged 35.3 years and women 30.9 years; the difference in mean ages is attributable to the fact that we interviewed women aged 18-49 and men who were somewhat older, that is, aged 18-54. Differences between respondents in comparison and intervention sites were negligible. On average, women and men both resided in households containing six members, and 37 percent of men and 42 percent of women reported residing with an extended family.

Table 2.2: Selected socio-demographic characteristics of men and women, baseline survey

\begin{tabular}{|c|c|c|c|c|c|c|}
\hline \multirow[t]{2}{*}{ Select characteristics } & \multicolumn{3}{|c|}{ Married men (ages 18-54) } & \multicolumn{3}{|c|}{ Married women (ages 18-49) } \\
\hline & Comparison & Intervention & Total & Comparison & Intervention & Total \\
\hline \multicolumn{7}{|l|}{ Age } \\
\hline Respondent age, mean & 35.3 & 35.2 & 35.3 & 31.1 & 30.7 & 30.9 \\
\hline \multicolumn{7}{|l|}{ Household size and type } \\
\hline Household size, mean & 5.7 & 5.8 & 5.7 & 5.6 & 5.8 & 5.7 \\
\hline $\begin{array}{l}\text { Extended family: Co-resides } \\
\text { with parent }(M) / \text { in-laws }(F)\end{array}$ & 34 & 39.1 & 36.5 & 41.4 & 41.8 & 41.6 \\
\hline \multicolumn{7}{|l|}{ Educational attainment } \\
\hline Mean years of education & 5.9 & 7.0 & 6.5 & 2.8 & 2.8 & 2.8 \\
\hline$\%$ never attended school & 32.4 & $22.0^{+}$ & 27.3 & 64.2 & 63.3 & 63.8 \\
\hline \multicolumn{7}{|l|}{ Economic activity } \\
\hline Ever engaged in paid work & 95.7 & 96.1 & 95.9 & 50.1 & 49.7 & 49.9 \\
\hline Paid work in past 12 months & 94.9 & 95.0 & 95.0 & 48.5 & 46.0 & 47.2 \\
\hline \multicolumn{7}{|l|}{$\begin{array}{l}\text { Main occupation (last } 12 \\
\text { months) }\end{array}$} \\
\hline Cultivator & 20.9 & 18.2 & 19.6 & 1.9 & 0.5 & 1.2 \\
\hline Agricultural labourer & 7.0 & 10.7 & 8.8 & 41.9 & 41.3 & 41.6 \\
\hline Non-agricultural labourer & 39.3 & 30.8 & 35.2 & 0.3 & 0.6 & 0.4 \\
\hline Other & 27.7 & 35.3 & 31.4 & 4.8 & 3.5 & 4.0 \\
\hline \multicolumn{7}{|l|}{ Mass media exposure ${ }^{a}$} \\
\hline Television & 34.3 & 38.0 & 36.1 & 33.4 & 30.5 & 31.4 \\
\hline Newspaper/magazine/books ${ }^{\text {b }}$ & 62.2 & $76.2^{*}$ & 69.6 & 28.7 & 39.5 & 34.2 \\
\hline \multicolumn{7}{|l|}{ Mobile phone access } \\
\hline Has own mobile phone & 81.5 & 80.4 & 81.0 & 38.7 & 33.8 & 36.2 \\
\hline $\begin{array}{l}\text { Can access someone else's } \\
\text { phone }\end{array}$ & 6.4 & 7.4 & 6.9 & 54.9 & 57.9 & 56.4 \\
\hline \multicolumn{7}{|l|}{ Marriage experiences } \\
\hline $\begin{array}{l}\text { Had some say in marriage } \\
\text { decisions }\end{array}$ & 43.9 & 39.1 & 41.5 & 5.3 & 7.0 & 6.2 \\
\hline Met spouse on wedding day & 97.3 & 97.0 & 97.1 & 97.3 & 95.6 & 96.5 \\
\hline Dowry paid & 82.3 & 79.6 & 81.0 & 87.8 & 87.4 & 87.6 \\
\hline $\begin{array}{l}\text { Own family }(\mathrm{M}) / \text { Husband's } \\
\text { family }(\mathrm{W}) \text { satisfied with dowry }\end{array}$ & 64.1 & 62.8 & 63.5 & 53.8 & 50.3 & 52.0 \\
\hline Number of respondents & 373 & 363 & 736 & 377 & 390 & 767 \\
\hline
\end{tabular}

Note: ${ }^{\star}$ Differences between intervention and comparison sites are statistically significant at the 5 percent level; ${ }^{+}$Differences between intervention and comparison sites are statistically significant at the 10 percent level; a Sometimes or often; ${ }^{b}$ Includes those with five or more years of education; i.e., 239 men and 114 women in the intervention sites and 209 men and 108 women in the comparison sites. 
Findings on educational attainment confirm that large proportions of married men and women had never been to school: about one-quarter of men (27\%) and almost two in three women (64\%). While men had attained an average of 6.5 years of education, women had attained less than half this number-just 2.8 years of schooling. We note that while educational attainment levels of women residing in intervention and comparison villages were virtually identical, men in intervention villages were significantly better educated than were those in comparison villages.

Almost all men and about half of all women reported that they had ever worked for wages or income (96\% and 50\%, respectively). Of these, almost all had done so in the year preceding the interview. Occupational distributions show that most men in both intervention and comparison villages had worked as non-agricultural labourers (35\%) or cultivators (20\%), while most women had worked as agricultural labourers (42\%). Economic activity patterns were similar for those in the intervention and comparison villages.

Exposure to mass media was assessed through two indicators: whether or not men and women watched television sometimes or often; and whether those with five or more years of education read newspapers, magazines, or books. Findings suggest relatively limited exposure to television: just 36 percent of men and 31 percent of women reported that they watched TV sometimes or regularly. Use of the print media sometimes or regularly was reported by 70 percent of men and 34 percent of women with five or more years of education. Mobile phone ownership was reported by 81 percent of men and 36 percent of women; far more women (56\%) reported that they did not own their own phone but had access to a phone owned by their husband or other household members. Differences between those in intervention and comparison villages were negligible.

All men and women (99\%-100\%, not shown in Table 2.2) reported having an arranged marriage. While two in five men $(42 \%)$ had a say in the selection of their wife, just six percent of women had any say in the selection of their husband. Irrespective of their say in marriage-related decisions, almost all (97\% of both men and women) reported that they had met their spouse for the first time at their wedding. Dowry payments characterised the majority of marriages ( $81 \%$ of men and $88 \%$ of women reported dowry transactions), and many families were dissatisfied with the amount of dowry paid; indeed, just 64 percent of men and 52 percent of women reported that their/their husband's family was satisfied with the dowry paid.

A comparison of the socio-demographic background characteristics of respondents and their households in the intervention and comparison sites, as described in this section, shows that, by and large, their characteristics were almost identical for all the major indicators.

Table 2.3: Awareness of the Domestic Violence Act and related services, men and women, baseline survey

\begin{tabular}{|c|c|c|c|c|c|c|}
\hline \multirow[t]{2}{*}{ Selected Characteristics } & \multicolumn{3}{|c|}{ Married men (ages 18-54) } & \multicolumn{3}{|c|}{ Married women (ages 18-49) } \\
\hline & Comparison & Intervention & Total & Comparison & Intervention & Total \\
\hline \multicolumn{7}{|l|}{ Knowledge of DV-related law } \\
\hline Heard about the DV Act & 59.8 & 62.3 & 61.0 & 23.6 & 28.5 & 26.1 \\
\hline $\begin{array}{l}\text { In-depth awareness of the DV } \\
\text { Act: Heard about the DV Act } \\
\text { and knows a man can be jailed } \\
\text { for committing violence against } \\
\text { his wife }\end{array}$ & 59.0 & 59.8 & 59.4 & 22.8 & 27.2 & 25.0 \\
\hline \multicolumn{7}{|l|}{$\begin{array}{l}\text { Knowledge of services for } \\
\text { women in distress }\end{array}$} \\
\hline Helpline & 20.9 & 22.6 & 21.7 & 3.7 & 6.4 & 5.1 \\
\hline Short stay home & 3.2 & 4.4 & 3.8 & 1.3 & 1.8 & 1.4 \\
\hline $\begin{array}{l}\% \text { aware of helpline or short } \\
\text { stay home services }\end{array}$ & 21.2 & 23.4 & 22.3 & 4.5 & 7.2 & 5.9 \\
\hline Number of respondents & 373 & 363 & 736 & 377 & 390 & 767 \\
\hline
\end{tabular}

Note: Differences between respondents in intervention and comparison villages not significant. 


\section{Awareness of the DV Act and related services}

The baseline survey inquired about men's and women's awareness of the Domestic Violence (DV) Act as well as services, such as the helpline and the short stay home, for women in distress. Findings, presented in Table 2.3, highlight that awareness was limited, and that far more men than women were aware of the law and of available services. For example, three in five men (61\%) of men, and just one-quarter of women (26\%) had heard about a law that protects women from domestic violence. Almost as many had in-depth knowledge about the Act, that is, were aware of the law and knew that according to this law, men who committed violence against their wife could be prosecuted and jailed (59\% of men, $25 \%$ of women). In contrast, relatively few men and women were aware of services for women in distress, i.e., helpline or short stay homes: 22 percent of men and, just six percent of women. Most of these respondents were aware of the helpline rather than the short stay home. Hardly any respondent, male or female, was aware of short stay homes that provide shelter to women in distress (1\%-4\%).

\section{Attitudes}

Several questions were posed that probed women's and men's attitudes about gender roles, the acceptability of physical violence in marriage, and whether a woman could refuse sex with her husband in certain circumstances. Questions were posed at baseline and we assessed changes in these attitudes at endline.

\section{Gender-role attitudes}

Findings, presented in Table 2.4, suggest, with some exceptions, that attitudes remain gendered. For example, just five percent of men and 15 percent of women believed that a woman does not need her husband's permission for most things; just 16 percent of men and four percent of women believed that household chores are the responsibility of both women and men. Small proportions of women-and somewhat more men-expressed gender egalitarian attitudes on several other issues as well: for example, just 18 percent of women, and 41 percent of men believed it was acceptable for a girl to have male friends, and just 11 percent of women and 57 percent of men agreed that it

Table 2.4: Gender-role attitudes held by men and women, baseline survey

\begin{tabular}{|c|c|c|c|c|c|c|}
\hline \multirow[t]{2}{*}{ Gender attitudes and beliefs } & \multicolumn{3}{|c|}{ Married men (ages 18-54) } & \multicolumn{3}{|c|}{ Married women (ages 18-49) } \\
\hline & Comparison & Intervention & Total & Comparison & Intervention & Total \\
\hline \multicolumn{7}{|l|}{ Respondents agree that: } \\
\hline $\begin{array}{l}\text { Girls should not get married } \\
\text { early }\end{array}$ & 53.4 & $61.4^{*}$ & 57.3 & 76.9 & 79.5 & 78.2 \\
\hline $\begin{array}{l}\text { It is acceptable for a girl to } \\
\text { have male friends }\end{array}$ & 40.8 & 41.3 & 41.0 & 18.8 & 17.2 & 18 \\
\hline $\begin{array}{l}\text { Girls should decide when they } \\
\text { want to marry }\end{array}$ & 58.4 & 56.7 & 63.9 & 63.9 & $55.1^{*}$ & 59.5 \\
\hline $\begin{array}{l}\text { It is not necessary to give a } \\
\text { dowry }\end{array}$ & 53.6 & 59.5 & 56.5 & 10.1 & 12.1 & 11.1 \\
\hline $\begin{array}{l}\text { Women don't need husband's } \\
\text { permission for most things }\end{array}$ & 4.0 & 6.6 & 5.3 & 13.5 & 16.7 & 15.1 \\
\hline $\begin{array}{l}\text { Couples should decide jointly } \\
\text { how money is spent }\end{array}$ & 77.7 & 73.0 & 75.4 & 80.6 & 73.6 & 77.1 \\
\hline $\begin{array}{l}\text { Household chores are not only } \\
\text { a woman's responsibility }\end{array}$ & 16.1 & 16.0 & 16.0 & 3.4 & 4.4 & 3.9 \\
\hline Index of gender attitudes ${ }^{* *}$ & 3.0 & 3.1 & 3.1 & 2.7 & 2.6 & 2.7 \\
\hline Number of respondents & 373 & 363 & 736 & 377 & 390 & 767 \\
\hline
\end{tabular}


was not necessary to give a dowry. More respondents displayed egalitarian attitudes on three issues: that couples should decide jointly about how money should be spent ( $75 \%$ of men, $77 \%$ of women); that girls should not marry early ( $57 \%$ of men, $78 \%$ of women); and that girls should decide when they marry ( $64 \%$ of men, $60 \%$ of women).

An index of gender role attitudes was constructed by summing the number of statements (of a maximum of 7 ) for which women and men expressed egalitarian attitudes. This index takes values between 0 and 7: 0 if respondents did not express egalitarian attitudes regarding any of the seven statements and 7 if they expressed such attitudes in all statements. The average number of statements in which respondents expressed gender egalitarian attitudes ranged from 2.7 among women to 3.1 among men, indicating that attitudes were generally inegalitarian. Differences between those in intervention and comparison sites were negligible.

\section{Attitudes towards acceptability of physical violence against women}

Seven situations were presented to probe respondents' attitudes about the acceptability of marital physical violence. Findings, presented in Table 2.5, suggest that marital physical violence is widely accepted and justified. Responses suggest that women were far more conservative and gendered (or perhaps less likely to provide socially desirable responses) than were men. For example, women were more likely than men to justify marital violence if the wife engages in extramarital relations (96\% versus $71 \%$ ), if the wife goes out without informing the husband (53\% versus $34 \%$ ), if the wife disobeys her husband (65\% versus $50 \%$ ), if the wife makes a mistake (65\% versus $33 \%$ ), and if the wife does not care for the children properly (44\% versus $31 \%$ ). Hardly any respondent agreed, conversely, that a man is justified in beating his wife if she gives birth only to girls $(0 \%-1 \%)$ and if she refuses to have sexual relations with her husband ( $5 \%$ of men and no women).

Table 2.5: Attitudes towards physical violence within marriage held by men and women, baseline survey

\begin{tabular}{|c|c|c|c|c|c|c|}
\hline & \multicolumn{3}{|c|}{ Married men (ages 18-54) } & \multicolumn{3}{|c|}{ Married women (ages 18-49) } \\
\hline & Comparison & Intervention & Total & Comparison & Intervention & Total \\
\hline \multicolumn{7}{|l|}{ Physical violence in marriage } \\
\hline \multicolumn{7}{|l|}{ Respondents agree that: } \\
\hline $\begin{array}{l}\text { Women should tolerate violence } \\
\text { for family's sake }\end{array}$ & 77.2 & 78.0 & 77.6 & 75.1 & $83.1^{*}$ & 79.1 \\
\hline \multicolumn{7}{|l|}{$\begin{array}{l}\text { Acceptable to be physically } \\
\text { violent in following situations }\end{array}$} \\
\hline $\begin{array}{l}\text { Wife engages in extramarital } \\
\text { relations }\end{array}$ & 70.5 & 72.2 & 71.3 & 95.8 & 96.2 & 96.0 \\
\hline $\begin{array}{l}\text { Wife goes out without informing } \\
\text { husband }\end{array}$ & 36.7 & 32.0 & 34.4 & 48.8 & $57.4^{*}$ & 53.2 \\
\hline Wife disobeys husband & 54.2 & 46.6 & 50.4 & 61.3 & $68.7^{*}$ & 65.1 \\
\hline Wife makes a mistake & 31.1 & 34.4 & 32.7 & 65.5 & 64.9 & 65.2 \\
\hline $\begin{array}{l}\text { Wife does not care for children } \\
\text { properly }\end{array}$ & 33.5 & 29.2 & 31.4 & 40.3 & 46.9 & 43.7 \\
\hline Wife gives birth only to girls & 0.5 & 0.8 & 0.7 & 0.3 & 0.3 & 0.3 \\
\hline Wife refuses to have sex & 5.9 & $4.7^{*}$ & 5.3 & 0.3 & 0.5 & 0.4 \\
\hline $\begin{array}{l}\text { Index, attitudes towards physical } \\
\text { violence }^{* *} \text { (range } 0-7 \text { ) }\end{array}$ & 2.3 & 2.2 & 2.3 & 3.1 & 3.3 & 3.2 \\
\hline Number of respondents & 373 & 363 & 736 & 377 & 390 & 767 \\
\hline
\end{tabular}


We created an index reflecting the acceptability of marital physical violence, by summing the number of statements (of a maximum of 7 ) for which women and men expressed attitudes justifying the practice. This index takes values between 0 and 7: 0 if the respondent did not justify violence in any of the seven situations indicated in Table 2.5 and 7 if the respondent justified violence in all situations. The average number of situations in which respondents held attitudes justifying marital physical violence ranged from 2.3 among men to 3.2 among women, suggesting that large proportions of respondents held attitudes justifying violence.

In in-depth interviews, men and women agreed that marital violence is justified in some circumstances (eight men and six women); several suggested that the husband should first explain to the wife and if she continued to 'misbehave,' violence against her was justified. For example:

Yes, when women fight with their husbands daily for no reason, there is always trouble in the home. Then in such a situation, she should be beaten up. Aside from this, if a wife does not listen to her husband or if she does not do household work on time or if she goes here and there without telling her husband then in all such situations, a husband should explain to his wife by talking to her first, but if she does not listen to him then there is nothing wrong in beating her. [Male, aged 38, no education, ID31]

Yes, sometimes there are situations when it is right for a husband to beat his wife. When a woman does not do household work on time then he should first explain to her, but if she does not listen then it is right to beat her. Similarly, if she does not listen to her husband or if she goes somewhere without telling him, the husband is right to do violence on her because when there is a husband at home she should ask him before going anywhere. Also, if she keeps relations with someone other than her husband then it is right to also do violence against her. [Male, aged 23, no education, ID33]

Like if she hadn't cooked food properly then husband can hit her... Hitting is not right, he can talk to her or maybe scold her. If she goes out without her husband's permission then he should not hit her; he should make her understand not to go out without telling him, but hitting is wrong... If she is having an extramarital affair then he should hit her. [Female, aged 24, no education, ID24]

No, it is not okay to hit a wife, if the wife goes to someone's house without asking her husband he should explain to her and not hit her. Even if she has not done the housework he should say, 'you haven't done this work so do it like this.' If he makes her understand then she will do it but if not, he should hit.... She may become worse by hitting so that's why he should make her understand.... But in case she still doesn't listen, it would be okay to hit. He should scold her and if she doesn't listen then hit. [Female, aged 30, no education, ID36]

If the wife does something wrong and the husband hits her then he is right.... If she has an affair and her husband hits her he is correct in doing so.... If she doesn't do housework, the husband should explain, but if she doesn't, then the husband will hit but that is not correct. He should make her understand.... If she goes to someone's house without her husband's permission, he shouldn't hit. He should first ask her where she went and why, then explain to her but not hit her. [Female, aged 32, completed Class 10, ID22]

\section{Behaviour outcomes}

The Do Kadam programme sought to change behaviours, notably men's alcohol abuse; men's controlling behaviours over their wife; men's perpetration of emotional, physical, and sexual violence against their wife; women's experience of marital violence, and their reactions and/or help-seeking practices. Findings highlight the vulnerable position of married women.

\section{Alcohol and drug misuse}

Alcohol and drug consumption was reported by considerable proportions of men, and hardly any women. For example, as seen in Table 2.7, three in four men, and hardly any women reported alcohol consumption in the four weeks preceding the interview, and more than one quarter of men reported alcohol consumption most days (27\%). In a separate set of questions, we asked women about their husband's alcohol use around the time of the interview. Women's responses on their husband's alcohol use by and large resembled men's responses about their own 
practices, with 70 percent reporting that their husband did indeed consume alcohol and 30 percent reporting that he did so daily. Two-fifths of all women reported that their husband had been drunk at least once a week in the year preceding the interview, and one-quarter $(25 \%)$ reported that their husband had been drunk almost every day.

Drug use was also reported: 14 percent of women reported that their husband consumed drugs, and five percent reported that he did so daily in the year preceding the interview.

In-depth interviews undertaken at baseline confirmed the extensiveness of alcohol consumption among men. Of the 10 women who participated in in-depth interviews, four reported that their husband drank frequently. Likewise, of the ten men interviewed, eight reported that they did indeed consume alcohol. Narratives of both men and women suggest that alcohol consumption among men was normal and even justifiable to relieve men of the fatigue that accompanies hard work. For example:

Yes, he gets tired when he comes home from work so he drinks, 3-4 pouches [term used for a half-litre of country liquor sold in a sealed plastic bag] daily, when he is tired. He comes home then, eats his food and goes to sleep. He doesn't abuse. [Female aged 45, no education, ID21]

Yes, he drinks every day. In the night and not during the day. [Female, aged 18, no education, ID28]

Yes, in a week I drink alcohol around 2-3 times but it is not necessary. Sometimes it happens that I consume alcohol for the whole week and sometimes I don't drink for two months. I consume alcohol only when I feel like it and only when I have money. Whenever I feel physically tired then I have to consume alcohol to get rid of that tiredness. [Male, aged 43, no education, ID32]

Yes, I consume alcohol. I believe that if I do not consume alcohol then I will not be able to work because my work is of this nature. I drive day and night and I get only 2-3 hours of sleep because it is not easy to drive a police car. Whenever I get any information from anywhere, I have to go and drive the car whether it

Table 2.7: Alcohol and drug consumption, men and women, baseline survey

\begin{tabular}{|c|c|c|c|c|c|c|}
\hline & \multicolumn{3}{|c|}{ Married men (ages 18-54) } & \multicolumn{3}{|c|}{ Married women (ages 18-49) } \\
\hline & Comparison & Intervention & Total & Comparison & Intervention & Total \\
\hline \multicolumn{7}{|l|}{ Alcohol consumption, self-reports } \\
\hline Never & 22.3 & 28.1 & 25.1 & 97.9 & 97.4 & 97.7 \\
\hline $\begin{array}{l}\text { Less than once/week in the last } \\
\text { month }\end{array}$ & 50.7 & 44.9 & 47.8 & 2.1 & 2.3 & 2.2 \\
\hline 1-7 days/week in the last month & 27.1 & 27.0 & 27.0 & 0.0 & 0.3 & 0.1 \\
\hline \multicolumn{7}{|l|}{$\begin{array}{l}\text { Women's responses about } \\
\text { husband's alcohol consumption }\end{array}$} \\
\hline \multicolumn{7}{|l|}{ Frequency of alcohol consumption } \\
\hline Never & & & & 26.8 & 31.3 & 29.1 \\
\hline $1-3$ times a month or less & & & & 23.6 & 23.6 & 23.6 \\
\hline One to 3 times a week & & & & 14.1 & 18.7 & 16.4 \\
\hline Daily & & & & 34.5 & 25.4 & 29.9 \\
\hline $\begin{array}{l}\text { Husband drunk in the last } 12 \\
\text { months }\end{array}$ & & & & 29.7 & 20.8 & 25.2 \\
\hline \multicolumn{7}{|l|}{ Everyday or nearly every day } \\
\hline At least once a week & & & & 42.2 & 38.0 & 40.0 \\
\hline At least once a month & & & & 52.3 & 47.9 & 50.1 \\
\hline At least once in the year & & & & 64.2 & 60.0 & 62.1 \\
\hline \multicolumn{7}{|l|}{ Husband uses drugs } \\
\hline At least once in the last year & & & & 13.3 & 14.9 & 14.1 \\
\hline Daily & & & & 7.7 & 4.4 & 5.1 \\
\hline Number of respondents & 373 & 363 & 736 & 377 & 390 & 767 \\
\hline
\end{tabular}


is daytime or night. I drink alcohol while on duty and drive after drinking only but I do not drink so much that I become extremely intoxicated and am unable to drive. With me, even the policemen consume alcohol. [Male, aged 38, completed Class 9, ID31]

Yes, I drink alcohol around 3-4 times in a week. After working throughout the day I get tired and I have to drink alcohol to get rid of this fatigue. I drink only one-quarter of a bottle of alcohol (180 ml) and after drinking, I sleep quietly and next morning I go to work... After consuming alcohol, there is no change in my behaviour because I do not consume alcohol for intoxication and I don't even drink in abundance. After consuming alcohol I behave in the same way as I do without consuming alcohol. [Male, aged 32, no education, ID36]

\section{Men's controlling behaviours}

We explored men's controlling behaviours through questions posed to men about whether they restricted their wife's behaviour and to women similarly about whether their husband restricted their behaviour in specific ways. Findings are presented in Table 2.8. With regard to men's control over their wife, findings were mixed: between one-third and two-thirds of men and women reported that they/their husband insisted on knowing where their wife was at all times ( $38 \%$ of men; $37 \%$ of women), became angry if the wife spoke to another man (33\% and $27 \%$, respectively), and expected the wife to obtain her husband's permission in order to seek health care for herself (69\% and 55\%). Many fewer reported that they/their husband prevented the wife from seeing her friends ( $15 \%$ and $7 \%$, respectively) or natal family ( $2 \%$ and $16 \%$, respectively).

Table 2.8: Men's controlling behaviours over their wife, men and women, baseline survey

\begin{tabular}{|c|c|c|c|c|c|c|}
\hline & \multicolumn{3}{|c|}{ Married men (ages 18-54) } & \multicolumn{3}{|c|}{ Married women (ages 18-49) } \\
\hline & Comparison & Intervention & Total & Comparison & Intervention & Total \\
\hline \multicolumn{7}{|l|}{$\begin{array}{l}\text { Responses regarding men's } \\
\text { behaviour towards their wife }\end{array}$} \\
\hline $\begin{array}{l}\text { Tries to prevent wife from seeing } \\
\text { friends }\end{array}$ & 15.5 & 14.6 & 15.1 & 5.8 & $7.4^{*}$ & 6.6 \\
\hline Restricts contact with natal family & 0.8 & 3.9 & 2.3 & 15.1 & 15.9 & 15.5 \\
\hline $\begin{array}{l}\text { Insists on knowing wife's } \\
\text { whereabouts at all times }\end{array}$ & 31.9 & $43.5^{*}$ & 37.6 & 34.0 & 39.5 & 36.8 \\
\hline $\begin{array}{l}\text { Gets angry if wife speaks with } \\
\text { another man }\end{array}$ & 29.5 & 35.5 & 32.5 & 25.2 & 28.2 & 26.7 \\
\hline $\begin{array}{l}\text { Expects wife to seek permission } \\
\text { to seek health care }\end{array}$ & 70.0 & 67.5 & 68.8 & 50.4 & $60.0^{*}$ & 55.3 \\
\hline Index on controlling behaviour ${ }^{* *}$ & 1.5 & 1.7 & 1.6 & 1.3 & 1.5 & 1.4 \\
\hline Number of respondents & 373 & 363 & 736 & 377 & 390 & 767 \\
\hline
\end{tabular}

Notes: *Differences between the intervention and comparison sites are statistically significant at the 5 percent level; ${ }^{\star \star}$ Range $0-5$; $0=$ no controlling behaviour; $5=$ most controlling behaviour; Cronbach's alpha: men 0.65; women 0.71.

An index of controlling behaviours was created that summed the number of situations we probed about men's control over their wife. This index takes values between 0 and 5: 0 if controlling behaviour was not perpetrated (men) or experienced (women) in any of the five situations, and 5 if controlling behaviours were reported in all five. The average number of situations in which respondents reported the men's controlling behaviours was identical for men and women (1.4-1.6), suggesting that on average, men exhibited controlling behaviours over their wife in relatively few situations.

In in-depth interviews, we explored notions of men's control over their wife by exploring study participants' perspectives about men's entitlements and their role as their wife's 'guardian.' The findings indicate that all ten men 
agreed that men are the guardian of their wife, and argued that women are weaker, that men are the breadwinners and protectors of their family, and that women must look up to their husband. A few linked 'guardianship' with earnings, and suggested that where women work, both may be considered the guardians of each other.

The first right that a man has is to go out and earn money and feed his family properly and fulfill all their needs.... In married life, his wife should do all household work properly; she should not go here and there without her husband's permission. She should not do anything without her husband's permission.... Related to sexual relations, I would like to say that a husband can have relations with his wife according to his own wish, because he is doing it with his own wife only and not a stranger. So what is wrong in it? In my opinion, having relations with your own wife against her wish is also not wrong.... How many children and how much of a gap they should have should also be decided by the husband only because he has to feed them in future.... Yes, he is called a guardian because the day he gets married to her he becomes her owner. He feeds her and fulfils all her needs, that's why he is considered her guardian. I also completely agree with this. This is right. On the day of marriage, the girl's parents give their daughter to the other person and once she comes to her husband's place, she relies only on him. [Male, aged 28, completed Class 8, ID34]

It should not be that a husband is having sexual relations according to his own wish only because that will be considered rape. How many children and when to have those children are also decisions to be made by both of them..... A husband is called a guardian because after marriage a wife comes to her husband's home and relies on him alone. A husband only earns money and feeds her and fulfils all her needs. A wife is completely dependent on her husband. So whatever she does, she does only after asking him and does not do anything without his permission. That's why a husband is called the guardian. It is right and I agree with this. [Male, aged 27, no education, ID37]

In contrast, many women-five of ten-believed that marital relations should be more equal, and that men should not control their wife or be their guardian, but acknowledged that in their society, this was not the case. For example:

Men alone can't decide; both husband and wife have to discuss it and this right should belong to both. The wife should be the guardian and not the husband......yes, the husband brings money home. The husband will waste the money or spend it doing things with friends whereas the wife will be careful with money, so she should be the guardian. [Female, aged 45, no education, ID21]

Both should have equal rights at home.... Whether it is regarding money in the house, educating the children, both should have equal rights.... Everything should be decided by both and the husband shouldn't be the only one to have these rights... Both should be each other's guardians, it should not be the husband only who is the guardian. Both should decide everything together. But in our society it is like this; the husband is always the guardian. [Female, aged 40, completed Class 15, ID27]

\section{Domestic and marital violence}

In this section, we discuss not only the extent of perpetration by men/experience by women of marital violence, practices that the intervention sought to change, but also the cycle of violence reported by men and women, and women's reactions and help-seeking practices, issues that the intervention did not directly address. We also describe men's and women's reports of violence perpetrated against their wife/them by other family members.

\section{Marital violence}

Table 2.9 presents findings relating to reports of men and women about violence perpetrated by them/their husband against their wife/them (Panel A) and by other family members on their wife/them (Panel B). As evident from Panel A, marital violence was widespread: four in five men and women reported that they (men)/their husband (women) had abused their wife/them emotionally ( $86 \%$ of men, $79 \%$ of women), three in five reported the perpetration (men) and experience (women) of physical violence (62\% and 58\%, respectively); and about three in four men ( $73 \%$ ) and four in five women (79\%) reported the perpetration (men) and experience (women) of sexual violence at least once in their married life. 
Table 2.9: Reports of men and women on violence perpetrated by husband and other family members on women, baseline survey

\begin{tabular}{|c|c|c|c|c|c|c|}
\hline & \multicolumn{3}{|c|}{ Married men (ages 18-54) } & \multicolumn{3}{|c|}{ Married women (ages 18-49) } \\
\hline & Comparison & Intervention & Total & Comparison & Intervention & Total \\
\hline \multicolumn{7}{|l|}{ A. Marital violence } \\
\hline \multicolumn{7}{|c|}{$\begin{array}{l}\text { Ever perpetrated (men)/Experienced } \\
\text { (women) violence within marriage: }\end{array}$} \\
\hline Emotional violence & 87.4 & 83.7 & 85.6 & 80.6 & 77.4 & 79.0 \\
\hline Physical violence & 65.4 & 58.4 & 62.0 & 57.8 & 58.2 & 58.0 \\
\hline Sexual violence & 79.4 & $65.6^{*}$ & 72.6 & 82.2 & 76.2 & 79.1 \\
\hline \multicolumn{7}{|c|}{$\begin{array}{l}\text { Perpetration (men)/Experience } \\
\text { (women) of violence within marriage } \\
\text { in the six months preceding the } \\
\text { interview }\end{array}$} \\
\hline Emotional violence & 81.5 & $65.6^{*}$ & 74.0 & 72.7 & 70.8 & 71.7 \\
\hline Physical violence & 21.7 & 19.8 & 20.8 & 24.9 & 24.6 & 24.8 \\
\hline Severe physical violence ${ }^{1}$ & 0.8 & 2.8 & 1.8 & 13.8 & 12.6 & 13.2 \\
\hline Sexual violence & 43.7 & $25.9^{*}$ & 34.9 & 41.6 & 42.8 & 42.2 \\
\hline \multicolumn{7}{|c|}{$\begin{array}{l}\text { Perpetration (men)/Experience } \\
\text { (women) of violence during } \\
\text { pregnancy }\end{array}$} \\
\hline $\begin{array}{l}\text { Physical violence ever dur } \\
\text { pregnancy }\end{array}$ & 9.0 & 7.5 & 8.3 & 32.6 & 33.0 & 32.8 \\
\hline $\begin{array}{l}\text { Physical violence during l } \\
\text { pregnancy }\end{array}$ & 3.7 & 3.3 & 3.5 & 24.3 & 23.3 & 23.8 \\
\hline \multicolumn{7}{|c|}{$\begin{array}{l}\text { Perceived reasons for violence }{ }^{2} \\
\text { among those who had experienced it }\end{array}$} \\
\hline Husband drunk & & & & 56.1 & 53.5 & 54.8 \\
\hline Money & & & & 17.5 & 14.9 & 16.2 \\
\hline Family & & & & 19.3 & 16.7 & 18.0 \\
\hline Wife disobedient & & & & 11.4 & 25.4 & 18.4 \\
\hline \multicolumn{7}{|c|}{$\begin{array}{l}\text { B. Violence perpetrated by other } \\
\text { family members }\end{array}$} \\
\hline \multicolumn{7}{|c|}{$\begin{array}{l}\text { Family members ever perpetrated } \\
\text { violence against wife (men)/ } \\
\text { respondent (women) }\end{array}$} \\
\hline Emotional violence & 68.4 & 58.4 & 63.5 & 62.6 & 64.6 & 63.6 \\
\hline Physical violence & 7.8 & 8.5 & 8.2 & 11.9 & 12.8 & 12.4 \\
\hline Sexual violence & 0.3 & 0.6 & 0.4 & 0.0 & 0.8 & 0.4 \\
\hline Number of respondents & 373 & 363 & 736 & 377 & 390 & 767 \\
\hline
\end{tabular}

Note: ${ }^{\star}$ Differences between the intervention and comparison sites are statistically significant at the 5 percent level; ${ }^{1}$ Severe physical violence includes punching, beating, choking or threatening with knife; ${ }^{2}$ Multiple responses possible.

Even in the six months preceding the interview, violence was widespread. The perpetration and experience, respectively, of emotional abuse was reported by three in four men and women (72\%-74\%); 21 percent of men, and 25 percent of women, respectively, reported physical violence, and 35 percent and 42 percent, respectively, reported sexual violence. While hardly any men reported that they had perpetrated severe physical violence (punching, beating, choking, or threatening with knife) against their wife (2\%), considerably more women reported 
the experience of such violence (13\%). Violence continued, moreover, even during pregnancy, although gender differences were particularly wide in reporting of this practice: while just $8 \%$ of men admitted perpetrating physical violence on their wife during pregnancy, and just four percent reported doing so during the last pregnancy, as many as one in three (33\%) and one-quarter (24\%) of women reported experiencing physical violence during any and their last pregnancy, respectively.

Leading reasons offered by women for the violence experienced included the husband's alcohol abuse (55\%), financial problems, family conflict, and the wife's self-perceived 'disobedience' (16\%-18\%). While differences between women in intervention and comparison villages were negligible for the most part, we note that those in intervention villages were considerably more likely than those in comparison villages to report that it was their 'disobedience' that had provoked the violence.

\section{Violence perpetrated by other marital family members}

Panel B shows that violence was perpetrated by other marital family members as well, and that such violence was, for the most part, in the form of emotional abuse. Indeed, some two-thirds of men and women reported that other family members had perpetrated emotional abuse against their wife/them ( $64 \%$ of both men and women). In contrast, considerably fewer reported the perpetration of physical violence (8-12\%) and hardly any reported the perpetration of sexual violence against women by other family members $(0.4 \%)$. Differences between those in intervention and comparison villages were not observed.

\section{Intergenerational cycle of violence}

The intergenerational cycle of violence was evident (Table 2.10). Many respondents-53 percent of men and 35 percent of women-had witnessed their father beating their mother, 71 percent and 53 percent had witnessed their father emotionally abusing their mother, and 56 percent of men and 30 percent of women reported that they had themselves been beaten in childhood by their parents. At the same time, many women (86\%) reported that their children had observed their husband perpetrating physical violence against them, and almost half reported that their children had witnessed it on several occasions. Finally, almost three in five women reported that they and/or their husbands had perpetrated physical violence against their children in the six months prior to the interview.

Table 2.10: Cycle of violence, men and women, baseline survey

\begin{tabular}{|c|c|c|c|c|c|c|}
\hline & \multicolumn{3}{|c|}{ Married men (ages 18-54) } & \multicolumn{3}{|c|}{ Married women (ages 18-49) } \\
\hline & Comparison & Intervention & Total & Comparison & Intervention & Total \\
\hline \multicolumn{7}{|l|}{ Childhood violence } \\
\hline $\begin{array}{l}\text { As a child, witnessed father } \\
\text { beating mother }\end{array}$ & 58.0 & 48.6 & 53.0 & 35.0 & 35.8 & 35.4 \\
\hline $\begin{array}{l}\text { As a child, witnessed father } \\
\text { shouting at mother }\end{array}$ & 74.5 & 67.5 & 71.1 & 48.9 & 56.1 & 52.5 \\
\hline Beaten in childhood by parents & 58.6 & 54.1 & 56.4 & 28.9 & 30.3 & 29.6 \\
\hline \multicolumn{7}{|l|}{$\begin{array}{l}\text { Own children's witnessing of } \\
\text { violence }\end{array}$} \\
\hline \multicolumn{7}{|l|}{$\begin{array}{l}\text { Children witnessed parental } \\
\text { violence }\end{array}$} \\
\hline At least once & & & & 91.2 & 81.6 & 86.4 \\
\hline Several times & & & & 50.0 & 41.2 & 45.6 \\
\hline \multicolumn{7}{|l|}{$\begin{array}{l}\text { Respondents' perpetration of } \\
\text { violence against children }\end{array}$} \\
\hline $\begin{array}{l}\text { Mother and/or father beat child } \\
\text { in last six months }\end{array}$ & & & & 56.8 & 60.5 & 58.7 \\
\hline Number of respondents & 373 & 363 & 736 & 377 & 390 & 767 \\
\hline
\end{tabular}




\section{Response to violence}

Women who reported a recent experience of physical violence were probed about their responses in terms of communication of the experience to others, and help sought from informal networks, formal sources of support, and more specifically, from PRI representatives. As Table 2.11 shows, the majority of women-55 percent, ranging from 61 percent of those in comparison villages to 50 percent of those in intervention villages-had not shared their experience with anyone, largely because women believed that violence must be tolerated and that marital problems should not be shared with others. One-fifth (21\%) of women who had experienced violence had informed their own parents, and somewhat fewer had discussed their experience of violence with their in-laws (18\%). Even fewer had informed their neighbours or friends (15\% and $5 \%$, respectively).

Indeed, just one-quarter, one-fifth, and one-seventh of women who had experienced violence obtained help from their husband's family, their own parents, and neighbours, respectively. Just half of all women who had experienced violence reported that a family member, neighbour, or friend had indeed helped them; we note that a few women reported that although they had not discussed their experience with anyone, a neighbour or community member had intervened on their behalf.

Table 2.11: Help-seeking experiences by women who experienced physical violence recently, ${ }^{1}$ baseline survey

\begin{tabular}{|c|c|c|c|}
\hline & Comparison & Intervention & Total \\
\hline \multicolumn{4}{|l|}{ Approached any informal source for help } \\
\hline \multicolumn{4}{|l|}{ Person with whom respondent shared her violence experience* } \\
\hline Friends & 3.5 & 6.1 & 4.8 \\
\hline Parents & 17.5 & 24.6 & 21.1 \\
\hline Husband's family & 19.3 & 15.8 & 17.5 \\
\hline Neighbours & 11.4 & 19.3 & 15.4 \\
\hline No one & 60.5 & 50.0 & 55.3 \\
\hline \multicolumn{4}{|l|}{ Person from whom respondent received help* } \\
\hline Parents/siblings & 15.8 & 22.8 & 19.3 \\
\hline Husband's family & 25.4 & 27.2 & 26.3 \\
\hline Neighbours/friends & 11.4 & 15.8 & 13.6 \\
\hline No one & 52.6 & 45.6 & 49.1 \\
\hline \multicolumn{4}{|l|}{ Approached any formal source for help } \\
\hline \multicolumn{4}{|l|}{ From: } \\
\hline Police & 0.0 & 2.6 & 1.3 \\
\hline Lawyer & 0.0 & 0.9 & 0.4 \\
\hline Doctor/medical professional & 23.7 & 15.8 & 19.7 \\
\hline Community group & 4.4 & 0.9 & 2.6 \\
\hline PRI member & 2.6 & 3.5 & 3.1 \\
\hline Any of the above & 26.3 & 19.3 & 22.8 \\
\hline Number of women who reported recent episodes of physical violence ${ }^{2}$ & 114 & 114 & 228 \\
\hline \multicolumn{4}{|l|}{ Why respondent told no one ${ }^{*}$} \\
\hline Fear of more violence & 14.5 & 19.3 & 16.7 \\
\hline Ashamed & 18.8 & 21.1 & 19.8 \\
\hline It is husband's right to beat & 8.7 & 15.8 & 11.9 \\
\hline Should tolerate & 60.9 & 49.1 & 55.6 \\
\hline What happens in marriage should not be made public & 52.2 & 59.7 & 55.6 \\
\hline $\begin{array}{l}\text { Number of women who reported recent episodes of physical violence } \\
\text { and did not tell anyone }\end{array}$ & 69 & 57 & 126 \\
\hline
\end{tabular}

Note: ${ }^{1}$ Up to one year; ${ }^{2} N=114$ in comparison villages; 114 in intervention villages; 228 in total; " Multiple responses. 
Few women (just 23\%) had approached any formal source of support for women in distress. As many as one-fifth (20\%) had sought help from a health care provider, and just 1\%-3\% had approached the police, a lawyer or a PRI representative for help, suggesting that women hesitated to seek care for any reason other than medical, or were unaware of the other sources of help for which they were eligible.

Key reasons for not sharing their experience with or seeking help from informal or formal sources included perceptions that it is a woman's duty to tolerate violence perpetrated against her by her husband (56\%), that what happens between a woman and her husband should not be shared with anyone else (56\%), and that discussing such matters would bring shame to the respondent or her family (20\%). In addition, 17 percent desisted from sharing their experience with anyone for fear of incurring more violence.

Women who had experienced any domestic violence-perpetrated by their husband or any other family memberwere asked, finally, whether they had ever had thoughts of leaving the marriage, and whether they had ever thought about committing suicide. Findings, presented in Table 2.12, suggest that large proportions had thought about both: 20 percent had thought about leaving the marriage and 30 percent about committing suicide. Differences between women residing in intervention and comparison arms were negligible.

Table 2.12: Percentage of women reporting ever having thoughts of leaving the marriage and of committing suicide, baseline survey

\begin{tabular}{lccc}
\hline & Comparison & Intervention & Total \\
\hline Ever thought of leaving marriage & 19.1 & 20.7 & 19.9 \\
Ever thought of suicide & 31.4 & 27.9 & 30.0 \\
$\begin{array}{l}\text { Number of women who had ever experienced } \\
\text { violence within marriage }\end{array}$ & $\mathbf{3 4 0}$ & $\mathbf{3 4 8}$ & $\mathbf{6 8 8}$ \\
\hline
\end{tabular}

As mentioned in Chapter 1, in-depth interview participants were selected according to their responses to questions related to the perpetration (men) and experience (women) of marital violence and alcohol use. In-depth interviews confirm the prevalence of violence against women as reported by both men and women, and the fear of violence reported by women. Five of the ten men interviewed admitted that they perpetrated physical violence on their wife in a number of circumstances, although just one man reported perpetrating sexual violence on his wife. At the same time, several of those who had not done so reported that there had been 'no need' to do so as their wife was wellbehaved and obedient. For example:

Sometimes it happens that I get angry with her and I give her 2-4 slaps. Whenever she makes a mistake, for example, doesn't look after the children properly or hits the children then I get angry and I beat her up.... 15-20 days ago when I came back home, she had not cooked food, the children were also hungry and were crying. I got angry and told her that she stays at home throughout the day, so why couldn't she cook the food on time? Then she got annoyed and talked back to me so I got angry and I beat her up.... But I have never forced her to have sex. Whenever we have physical relations, it is with both our consent. It has never happened that I forced her to have sexual relations with me. [Male, aged 37, no education, ID35]

Yes, this happens sometimes. Sometimes a situation arises that makes me get angry with her and I slap her 2-4 times but this does not happen often. This happens rarely. This happened a month ago, I came back home tired at around $9 \mathrm{pm}$. I got in a little late and I was drunk. As soon as I reached home, she started arguing with me about why I got in so late, why I consumed alcohol, and she said that I do not care for the family, etc. Then I got angry and I beat her up.... No, I have never forced her to have sex. [Male, aged 32, no education, ID36]

No, I have not perpetrated any kind of violence against my wife, ever. We both live with love and togetherness. She has also never done anything that would force me to slap her. [Male, aged 28, completed Class 9, ID38] 
Six of the ten women, in contrast, reported that they had been beaten by their husband, and four reported that they had been forced by their husband to engage in sexual relations. In addition, two women who reported that they had not experienced any violence acknowledged that they feared that their husband would beat or abandon them. For example:

I am afraid sometimes. If I say something, then he starts hitting me, that's why I don't ask for anything when he is angry. He hits me every day, he hit me yesterday as well. Everyday, he drinks and abuses me. If after he has drunk alcohol and comes home from work and I ask for money, then he doesn't give it to me, and starts to hit. He abuses/swears. And yes, he forces me to have sex, and hits me for that also. [Female, aged 18, no education, ID28]

Yes I am afraid of him. Because when he comes from outside, I fear he might hit me or that he has come home drunk...... No he doesn't drink but I fear in case he has drunk.....If I have to ask him if I can go to my parent's house, first I see how his mood is and if I can ask; when he is angry then I will be hit so I see first and then ask. Regarding money also I ask him only when his mood is good. Yes sometimes, in a bad mood he slaps me, and sometimes he forces sex on me. And this is the case in all homes. [Female, aged 24, no education, ID25]

No he never hits me. And when we have sex, it happens with both our consent. It is true that if he comes home tired from work then I won't talk much, and when he is calm, then I will talk. That he will get angry and hit.... Yes I see if he is talking properly then I say; otherwise, if he is angry, I don't. [Female, aged 32, completed Class 10, ID22]

\section{Interaction with PRI representatives}

In general, the responsibilities of PRI representatives include facilitating the provision of entitlements to community members, addressing general infrastructural development issues, holding regular community-level meetings, addressing community-level conflicts, and making efforts towards social change in their communities.

Interaction with PRIs in the six months prior to the interview was reported by large proportions of men (87\%) and two in five women (41\%). Most had interacted with a ward member ( $79 \%$ of men; $32 \%$ of women) who was more likely to reside in their village than were the mukhiya and sarpanch; even so, large proportions of men (55\% and $76 \%$ in comparison and intervention arms) and about one quarter of women (21-28\%) reported some interaction with the mukhiya or sarpanch. Far fewer had attended a meeting or any other function organised by PRIs ( $8 \%$ and $2 \%$ of men and women, respectively), and hardly any had ever discussed the topic of violence against women with a PRI representative $(0.1 \%-0.5 \%)$.

At baseline, hardly any men or women reported that, as far as they were aware, their PRI members held any meetings on such topics as women's roles, safety, alcohol abuse or violence against women $(0.1 \%-0.5 \%)$ and just 12 percent of men and 3 percent of women reported that their PRI members had intervened in cases of women's concerns and alcohol abuse. Hardly any respondents $(0 \%-0.3 \%)$ reported that their PRI members had helped women access services for women in distress. Just 1-2 percent believed that the sale of alcohol had become more restricted in the six months preceding the interview because of PRI intervention.

Narratives from in-depth interviews with men and women suggested that PRI representatives rarely held meetings or community events, and that the community-level events that took place in their village, if any, were not organised by Panchayat members. A few women also suggested that Panchayat-organised events were rarely attended by women, and that only those the Panchayat members favoured were invited to attend. For example:

In our village, the Panchayat doesn't organise any programmes. The 15th of August and 26th of January are celebrated at the school level only and the Panchayat plays no role in that. Other festivals like Durgapuja, Dussehra, Chatt Puja, etc. are celebrated by the villagers at their level only and in this also,the Panchayat does not have any contribution. [Male, aged 37, completed Class 15, ID30]

No, there is no panchayat (bhavan), in Bhaiswa, nothing happens so hardly anyone goes there, they don't really do anything, so why would anyone go there? [Female, aged 45, no education, ID21] 
Table 2.13: Panchayati Raj Institutions related engagement and participation in PRI activities, men and women, baseline survey

\begin{tabular}{|c|c|c|c|c|c|c|}
\hline & \multicolumn{3}{|c|}{ Men } & \multicolumn{3}{|c|}{ Women } \\
\hline & Comparison & Intervention & Total & Comparison & Intervention & Total \\
\hline \multicolumn{7}{|l|}{$\begin{array}{l}\text { PRI-related engagement, past six } \\
\text { months }\end{array}$} \\
\hline Interacted with a PRI member & 84.5 & $90.4^{*}$ & 87.3 & 37.1 & 44.1 & 40.7 \\
\hline $\begin{array}{l}\text { Interacted with mukhiya or } \\
\text { sarpanch }\end{array}$ & 55.2 & $75.8^{* * *}$ & 65.4 & 20.7 & 28.0 & 24.4 \\
\hline $\begin{array}{l}\text { Interacted with ward/panch } \\
\text { member }\end{array}$ & 77.2 & 81.5 & 79.3 & 29.7 & 33.8 & 31.8 \\
\hline Have attended a PRI function & 5.1 & 11.0 & 8.0 & 1.1 & 2.1 & 1.6 \\
\hline $\begin{array}{l}\text { Ever discussed experience of } \\
\text { domestic violence with PRI } \\
\text { member }\end{array}$ & 0.3 & 0.0 & 0.1 & 0.3 & 0.8 & 0.5 \\
\hline \multicolumn{7}{|c|}{$\begin{array}{l}\text { PRI meetings organised on the } \\
\text { following topics, past six months, } \\
\text { as reported by men and women }\end{array}$} \\
\hline Rights of women and girls & 0.3 & 0.0 & 0.1 & 0.3 & 0.3 & 0.3 \\
\hline $\begin{array}{l}\text { Support services for women in } \\
\text { distress }\end{array}$ & 0.3 & 0.0 & 0.1 & 0.0 & 0.0 & 0.0 \\
\hline Alcohol misuse & 0.0 & 0.0 & 0.0 & 0.3 & 0.8 & 0.5 \\
\hline Village safety & 0.3 & 0.0 & 0.1 & 0.0 & 0.5 & 0.3 \\
\hline Any of the above & 0.3 & 0.0 & 0.1 & 0.3 & 0.8 & 0.5 \\
\hline \multicolumn{7}{|c|}{$\begin{array}{l}\text { Interventions made by PRI } \\
\text { representatives, past six months, } \\
\text { as reported by men and women }\end{array}$} \\
\hline $\begin{array}{l}\text { In situation where women } \\
\text { mistreated }\end{array}$ & 5.1 & 9.9 & 7.5 & 0.3 & 3.3 & 1.8 \\
\hline $\begin{array}{l}\text { Help women access services fo } \\
\text { women in distress }\end{array}$ & 0.0 & 0.6 & 0.3 & 0.0 & 0.0 & 0.0 \\
\hline Alcohol misuse & 8.3 & 9.1 & 8.7 & 0.5 & 1 & 0.8 \\
\hline Reduction in alcohol sale & 1.3 & 2.5 & 1.9 & 1.1 & 1.5 & 1.3 \\
\hline Any of the above & 9.1 & 14.6 & 11.8 & 1.1 & 4.4 & 2.7 \\
\hline Number of respondents & 373 & 363 & 736 & 377 & 390 & 767 \\
\hline
\end{tabular}

Note: ${ }^{*}$ Difference between respondents in intervention and comparison villages significant at $p<0.05$; ${ }^{\star \star \star}$ difference significant at $p<0.001$.

On the 26th of January or the 15th of August. Nothing else....Those who are given a card from the mukhiya, only they go. They call those whom they like that's all... No, only men are called. They go. No, women do not go at all. It is an exception if there are some women who go and stand there to get sweets. [Female, aged 32, completed Class 10, ID22]

Women who had experienced violence were also asked whether they had shared their experiences with a PRI representative, the police, or any other source of help. Not a single woman reported that she had sought help from a formal source. For example:

What would I say to the panchayat. I don't say anything to anybody. [Female, aged 30, no education, ID23] No I have never told anyone except my gotani and never discussed with a panchayat member. [Female, aged 24, no education, ID25] 


\section{Summary}

Findings presented in this chapter underscore deeply entrenched unequal gender role attitudes, including about the acceptability of marital violence. They also underscore widespread gender disparities and power differences in marital life, including men's controlling behaviour over their wife, and physical, emotional, and sexual violence perpetrated by men against their wife. Men's alcohol abuse was noted by large proportions of women, and often associated by them with their violent behaviour. Two in five women reported that their husband was drunk at least once a week. Women who experienced violence rarely shared their experience with or sought help from a family member, neighbour, or friend, and rarely obtained help from them. Likewise, women who experienced violence very rarely approached formal sources of help, such as the police, the helpline, or the short stay home; many had thought about leaving the marriage, and somewhat more had thought about committing suicide as a means of escaping violence. Knowledge about the DV Act and the fact that a man could be jailed for violations, and awareness of helpline and short stay home services available to women who experience violence was limited, and more men than women reported awareness of the Act and of the services. Finally, contact with PRI representatives was reported by most men and fewer than half of all women; while about one in ten men reported that a PRI representative had intervened in cases of violence or alcohol abuse, hardly any women were familiar with meetings held by PRI representatives on social issues, or interventions made by PRI representatives to stop marital violence or alcohol abuse. In-depth interview findings support those of the survey: they underscore the extent to which inegalitarian gender norms, men's alcohol abuse, marital violence, and the fear of violence among women shape the lives of men and women in the community. 


\section{Chapter 3}

\section{Do Kadam Barabari Ki Ore: The intervention}

In light of the limited evidence on promising approaches to counter the vulnerability of women and girls to violence, the Centre for Catalyzing Change (C3) and the Population Council designed, implemented and assessed the effectiveness and acceptability of a model intended to effect change in norms and practices by engaging and empowering locally elected representatives from two Panchayat areas of Patna district, Bihar. The Gender Violence and Health Centre at the London School of Hygiene and Tropical Medicine provided input into the design of the evaluation. While the organisations worked in partnership, C3 was primarily responsible, along with its local partner NGO, Abhiyan, for programme design and implementation, and the Population Council for programme evaluation.

In this chapter, we briefly describe the objectives, the design of the intervention and the key components of the intervention. Drawing on project monitoring data collected by $\mathrm{C} 3$, we also describe the extent to which various stakeholders participated in the intervention activities. Finally, we discuss the challenges faced in implementing the intervention.

\section{Objectives of the Do Kadam Barabari Ki Ore intervention}

The goal of the intervention was to engage locally elected representatives to work towards changing notions of masculinity and modifying lifestyle factors among men. The intervention targeted all members (male and female) of the Gram Panchayat and Gram Kachehri of nine villages in the two panchayat areas of Masaurhi block of Patna district in Bihar. Specifically, the study objectives were:

- To assess whether PRI members could be sensitised and trained to act as change agents to change gender norms among men and women in their communities.

- To assess whether an intervention focusing on PRI members could contribute to more egalitarian gender role attitudes among PRI members and a reduction in VAWG perpetrated/experienced by them.

- To test the effect of the intervention on changing gender role attitudes, including attitudes about marital violence among men and women at the community-level, and reduction in VAWG and alcohol misuse at the communitylevel.

- To test the effect of the intervention on the number of cases of alcohol misuse and perpetration of marital violence in which PRIs and other community members intervened.

Activities were implemented across nine villages of Masaurhi block, Patna district, and were conducted over approximately seven months; for the most part, activities were initiated in July 2014 and were concluded at the end of January 2015.

\section{Main components of the intervention programme}

The Do Kadam programme addressed two categories of participants: male and female locally elected representatives, and, through them, married men and women in the community more generally. We recognised that locally elected representatives were likely no different from the communities from which they were drawn, and may have been as likely as other community members to hold gendered norms, justify men's entitlement to commit violence against women, and misuse alcohol. The intervention programme was therefore two-pronged: it focused on sensitising and building capacity at the PRI level and preparing PRI members to act as change agents in their communities; and through them, changing norms and behaviours at the community-level. Below we discuss the main components of each of these two prongs. 


\section{Developing a curriculum for sensitising PRI members and building their capacity to address VAWG and alcohol abuse in their constituencies}

C3 developed a training curriculum with 14 sessions for the training of the PRI members (Gram Panchayat [GP] and Gram Kachehri [GK]); the curriculum drew on C3's previous experience working with elected women representatives as well as other projects implemented under the Do Kadam programme, notably with members of self-help groups. The curriculum included three basic segments:

1. The PRI structure and the roles and responsibilities of PRI members: In this segment of the curriculum, the focus was on the role of the Gram Panchayat in addressing social issues, especially protecting women from violence, not only through established structures such as the Social Justice Committee, Ward Sabhas, and Gram Sabha, but also through more informal mechanisms including meetings to change attitudes, and exercise of authority in case of violence or substance abuse.

2. Understanding issues related to VAWG: In this segment, efforts were made to sensitise PRI representatives about gender, patriarchy, and violence against women; to change their own notions of masculinity and femininity and reverse prejudice and discrimination; to change their attitudes about the acceptability of unequal gender roles, violence against women and girls, and alcohol abuse; to expose them to laws and policies supporting women; as well as to enhance their commitment to reducing VAWG and alcohol abuse in their constituencies. Sessions also focussed on the actions PRI representatives could take to reduce VAWG and alcohol abuse. The thematic focus of sessions encompassed, for example, domestic violence, positive masculinities, equality between sons and daughters, equal relationships in marriage, the link between domestic violence and alcohol abuse, and legal provisions and support services for women.

3. Leadership development and development of communication skills: In this segment, the curriculum included participatory exercises intended to raise PRI representatives' confidence and skills in organising meetings at the community-level and overcoming apprehensions about addressing community members; build their communication and public-speaking skills and capacity to communicate on gender issues and VAWG; convey to them the kinds of messages to impart in order to change attitudes and practices among their constituents about alcohol misuse and violence; and empower them to take action and intervene in individual cases of VAWG and/or alcohol abuse.

Based on this curriculum, a structured plan was developed for 14 sensitisation sessions with their communities that would be led by the GP/GK members over a period of seven months. A takeaway booklet was also developed for use by PRIs that summarised the key messages and actions to be taken.

\section{Sensitising PRI members and building their capacity}

Male and female PRI members received training through an initial three-day workshop followed by fortnightly training sessions for the entire seven months of the intervention. Sessions followed the curriculum described above. A total of 14 sessions were held, as planned, starting with a three-day orientation and followed by more focused interactions that addressed a particular issue and built PRI representatives' skills and confidence in conveying messages imparted in the particular session to the community at large. Training was facilitated by the C3 team using participatory methodology including interactive games, role-play, and case studies to provoke discussion. An external resource person led the session on legal provisions. Each training session for PRI representatives lasted two hours.

The two intervention Panchayats included 52 Gram Panchayat and Gram Kachehri members (Table 3.1), of whom, 27 or more than half were women. All of these 52 elected representatives attended at least one session; 41 attended more than half of all sessions (that is, 8-14 sessions), and 12 members attended almost all (12 or more) of 14 fortnightly sessions conducted over the seven months during which the intervention was implemented. Although arrangements were made for gender-specific training sessions, in case women representatives appeared hesitant to undergo training along with men, this proved unnecessary, and all PRIs from each Panchayat were trained in a single group. Initial feedback from PRI representatives highlighted their lack of confidence about speaking in public about sensitive issues such as VAWG. As a result, training emphasized, as discussed above, leadership and communication skills, and ways of delivering messages to their constituents. Mock sessions were conducted in which PRI representatives were encouraged to speak about the issues that they learned in the training session, and trainers from C3 and Abhiyan played the role of community members and asked questions and sought help. 
The theme for each community-level sensitisation session was linked to the corresponding training session. Each session concluded with planning for the next community-level sensitisation session and PRI representatives were supported in planning and organising the next community-level sensitisation session, and prepared agendas, talking points, the venue and date for these sessions.

Aside from these sessions, exposure visits were held for PRI members in order to provide PRI representatives firsthand information on services and programmes available to support women in distress and those in need of help to address alcohol problems, build their confidence about imparting what they had learned in these visits to the community at large, and support them to refer individual cases. As such, in a total of four batches, PRI members visited health facilities, the women's police station (Mahila Thana), the helpline (crisis centre), a short stay home (shelter), an alcohol de-addiction centre and the Bihar Gram Swaraj Society (mandated to support functioning of PRIs). During these visits, PRI representatives had an opportunity to interact with service providers and understand their options in referring women from their constituencies who approached the Panchayat. At the helpline, PRI representatives learned how women should approach the helpline and the kinds of action that the helpline was empowered to take on behalf of women who experience violence. At the Mahila Thana, PRI representatives interacted with the head of the police station or the Station House Officer (SHO) about the process of filing first information reports (FIRs), and about laws on domestic violence, sexual harassment, dowry and the rights of women at a police station.

In all, about $80 \%$ of PRI representatives participated in at least one exposure visit.

\section{Supporting PRI representatives to hold regular sensitisation sessions in their constituency}

Following their exposure to each training session, PRI representatives, with support from the local NGO partner, Abhiyan and C3, held community-level sensitisation sessions in their wards to build awareness of community members on issues addressed in the last training session that PRI members had attended. Aside from sensitisation sessions, PRI representatives were supported to hold community wide campaigns and such events as street theatre, film shows and local rallies, including a prabhat pheri (community rallies in the morning) on ending gender discrimination, VAWG and alcohol abuse related domestic violence. Discussions were facilitated using visual aids, including illustrated messages displayed on a flex banner.

Monitoring data show that 63 percent of PRI members participated in organising and delivering community-level sessions. They were more enthusiastic and confident, however, about organising sensitisation sessions, delivering introductory remarks, and responding to queries than in delivering the session and speaking about violence and alcohol related matters, citing their lack of sufficient knowledge and shyness about public speaking as reasons for their hesitation. As a result, the $\mathrm{C} 3$ and Abhiyan team played a considerable role, at least in initial months, in delivering programme sessions and facilitating community-level discussion.

Community sensitisation sessions were held ward-wise and attracted an audience of, on average, 32 community members. In order to attract and engage community members, nukkad nataks (street plays) were sometimes staged and film shows held. Programme implementers noted that nukkad nataks and other community events drew larger crowds, including men who would stay on for the discussions following the main presentation, than did a community sensitisation sessions without entertainment. While street plays drew the largest crowds, film shows, held in enclosed spaces, accommodated smaller audiences but were able to engage men and women in more in depth discussions following the film show. In separate events to reach boys and young men, PRI representatives held sessions in coaching centres and held smaller meetings for young men.

In addition, 46 PRIs took at least one action to prevent violence against women and 41 PRIs counseled community members to reduce alcohol abuse in community. By the second month of the intervention, PRI representatives reported that women from the community had approached them on violence and/or alcohol issues, and that they had counselled, supported and referred them as appropriate. Several complained or expressed frustration that the women they had referred to available services had experienced delays and non-responsiveness at the Mahila Thana and in some cases even at the helpline. Difficult cases were brought to PRI representatives' training sessions, and action to be taken was discussed there.

PRI representatives also perceived that conveying messages to men about alcohol consumption and control over sale and purchase of alcohol was difficult. Several strategies were explored: male GP/GK members addressed group meetings of men and held meetings at locations frequented by men. Monitoring data suggest that male attendance 
Table 3.1: Extent of participation in the intervention programme as per monthly monitoring reports

\begin{tabular}{|c|c|}
\hline & Number \\
\hline \multicolumn{2}{|l|}{ PRI attendance in capacity-building sessions } \\
\hline Number of PRI representatives from the two Panchayat areas & 52 \\
\hline Number of PRI representatives attending at least one training session & 52 \\
\hline Number of PRI representatives attending at least half (more than 7 ) training sessions & 41 \\
\hline Number of PRI representatives attending 12 or more of 14 fortnightly training sessions & 12 \\
\hline Percent of PRI representatives who made exposure visits & 79 \\
\hline \multicolumn{2}{|l|}{ Community-level sensitisation sessions and campaigns } \\
\hline Number held in each panchayat area/ward & 14 \\
\hline Percent of PRI representatives participating in organising and delivering community-level sessions & 63 \\
\hline Average attendance at sensitisation sessions and campaigns (held at ward level) & 32 \\
\hline \multicolumn{2}{|l|}{ Referrals made by PRI representatives } \\
\hline Number of PRI representatives reporting at least one action to prevent violence against women & 46 \\
\hline Number of PRI representatives who counselled community members to reduce alcohol abuse & 41 \\
\hline \multicolumn{2}{|l|}{ Mahila Nyay Samiti } \\
\hline Meetings held in each panchayat & 2 \\
\hline
\end{tabular}

was relatively sparse, and many men cited work priorities or tended to be hostile or defensive during the course of discussions. A few successes were achieved however. In one ward, action against alcohol abuse was initiated by one female ward member who was able to mobilise the community and also engage with the local police station; in another, members submitted a memorandum to the District Collector for closure of alcohol outlets in residential areas. They faced a number of challenges, including the non-responsiveness of the authorities on the one hand, and the lack of cooperation from several male PRI representatives on the other.

Revitalising the Social Justice Committee of each Gram Panchayat: The original intention was to revitalise the Social Justice Committee in each panchayat; the committee is expected to address and promote social issues including the elimination of VAWG and alcohol abuse. Unfortunately, although Social Justice Committees have been constituted, meetings are not held, and some people listed as committee members have not been informed of their selection. Although the Abhiyan and C3 teams made efforts with block authorities to ensure the establishment and regular meetings of this and other committees, their efforts were unsuccessful. As an alternative, C3 supported PRI representatives in establishing a parallel but more informal mechanism, the Mahila Nyay Samiti (Women's Justice Committee) to address concerns that would ordinarily have been addressed by the Social Justice Committee. The intention was for this committee to act as an informal forum both for raising awareness about violence against women and girls, and as a facility for redressal of cases of domestic violence and sexual harassment in public spaces. Membership in the Mahila Nyay Samiti included PRI members as well as teachers' helpers (Tola Sevak) ${ }^{5}$ and self-help group (SHG) leaders.

Over the course of the intervention, two meetings were held of the Mahila Nyay Samiti in each GP, in which committee members discussed individual cases and referred them as appropriate to other services, such as the helpline and the Mahila Thana. The Samiti also set up a complaints box with financial support from the Panchayat's contingency fund, however, as of the end of the project, community members had not begun to make use of this service.

\section{Challenges faced in implementing intervention activities}

We faced a number of challenges when implementing the intervention. Perhaps the biggest challenge was the disconnect between the mandated functions of the Panchayats and elected representatives and the reality. While

\footnotetext{
${ }^{5}$ Tola sevaks are teachers' helpers, attached to schools in Bihar in hamlets with at least 50 children belonging to socially disadvantaged groups, namely Scheduled Castes (SCs) and Schedled Tribes (SCs/STs); their role is to support the primary education of children in these communities.
} 
Gram Panchayat and Gram Kachehri meetings are supposed to be held at regular intervals, several committees did not meet regularly and where they met, many members, especially women, did not attend. Others, such as the Social Justice Committee, did not meet at all. Complex caste, class, and gender dynamics interfered with the ability of PRI representatives to act jointly to ensure appropriate governance and financial allocations. At the same time, many representatives did not consider social issues a priority. Thus, the $\mathrm{C} 3$ and Abhiyan teams were required to activate the panchayats, build the capacity of locally elected representatives, raise interest among PRI representatives and engage them as a group and even establish a parallel committee to perform the duties of the Social Justice Committee.

A second challenge was the lack of preparedness among PRI representatives to take on social issues in their constituencies, and their lack of confidence and skills in public speaking and in organising and leading sensitisation sessions with their communities and other public events. Indeed, Abhiyan and C3 team members played a far more prominent role than intended in highlighting the topic of the day and initiating discussion among the audience. While women representatives were more committed to the programme than were their male counterparts, they were shyer and more likely to lack communication skills and self-confidence about delivering sessions. Despite the fact that the $\mathrm{C} 3$ and Abhiyan teams focused their attention on capacity-building of PRI representatives in these areas, and although several members did indeed demonstrate confidence and skills in leading sessions by the end of the intervention, findings from the process documentation suggest that many PRI representatives did not have the skills or confidence, even by the end of the intervention, to carry out activities without the support of mentors.

Finally, it proved challenging to encourage regular attendance in the sensitisation sessions and to engage community members on topics perceived as the norm in their settings without also engaging them in activities in which they were interested, such as, for instance, jobs, loans, and skill-building opportunities. Men in particular were uninterested in attending sessions devoted to adopting gender equal attitudes and positive masculinities, reducing alcohol consumption, and banning/closing alcohol shops. Hence even when they attended sensitisation sessions or other events, community members frequently did not attend the entire event or participate in the discussion. Although C3 and Abhiyan teams, as well as PRI representatives, made regular efforts to encourage community members to attend the events, attendance was erratic and tended to be greater for entertainment types of activities than for regular sensitisation sessions.

We also concede that the community-level activities we designed have not attracted community members fully, and prior efforts may have been needed to identify the kinds of activities that may have appealed to communities. Perhaps single-sex events and/or events directed at different groups, for example, farmers or parents of school-going children, or addressing specific themes of interest, such as, for example, livelihoods opportunities and social sector programmes for which community members may be eligible, or venues where subgroups typically assemble, for example, meetings called by members of various mandals or meetings held by frontline health workers for women with young children, would have been a better entry point through which to approach the topic of inegalitarian gender roles and violence against women.

These challenges underline the message that the intervention programme operated in less than ideal situations, and that programme implementers need to be alert to the need for modification to accommodate 'real life' situations.

\section{Summary}

In summary, the intervention programme comprised several elements - the preparation of a curriculum to engage PRI representatives on topics related to notions of masculinity, VAWG and alcohol consumption; capacity-building and sensitisation of PRI representatives on topics related to gender roles, VAWG, and alcohol abuse; supporting PRI representatives to impart these new ideas, through sensitisation sessions with their communities and other events, at the community-level; and the establishment of a mechanism, the Mahila Nyay Samiti, intended to provide a platform for redressal of grievances brought by community members to PRI representatives-implemented over a seven-month period. While the training programme attracted almost all of the PRI representatives, and communitylevel sensitisation sessions and events were attended by considerable numbers of men and women, several implementation challenges were experienced. These ranged from the weak PRI structure at the panchayat level, the unpreparedness of PRI representatives for organising meetings and speaking in public forums, and the lack of commitment to social issues displayed by several PRI representatives; to the difficulty in sustaining the interest of community members, men in particular, in changing norms and behaviours relating to gender power relations, violence against women and girls, and alcohol abuse. 


\section{Chapter 4}

\section{Awareness and experiences of the Do Kadam project among men and women}

Drawing on data collected from men and women from the community as well as in-depth interviews with selected survey respondents from the intervention arm, this chapter describes study participants' experiences of the Do Kadam project, their interaction with PRI members and their perceptions about PRI members' engagement on issues related to VAWG, alcohol abuse and gender equality before and after the intervention. It also presents findings with regard to the assessments of community members from both intervention and comparison arms about whether there had been changes in their life in the year preceding the endline interview, roughly paralleling the period of the intervention.

\section{Awareness about the intervention programme: Community members, intervention arm}

We focus here on the responses of 364 men and 394 women from the nine intervention villages, and ten men and ten women among these respondents who, were also interviewed in-depth. In the endline survey, we inquired about respondents' awareness of the Do Kadam programme and its activities. We acknowledged that some community members may not recognise the project name, hence, we asked a detailed question about the project: In the past year, a programme was implemented, namely Do Kadam Barabari Ki Ore, in which PRI members/Abhiyan/ C3 organised meetings, street plays, etc. Have you heard about this programme? In response to this question, 69 percent of men and 61 percent of women residing in intervention villages reported awareness of the Do Kadam programme. We note, in contrast, that the monitoring data reported in Chapter 3 indicated that women had participated in the activities more often than men. More specifically, about two in five were aware of the communitylevel sensitisation sessions organised as part of the project (43-44\% of all respondents), although just 16-17 percent knew that these sessions were held fortnightly or monthly. Considerably more were aware of the street plays than the sensitisation sessions ( $60 \%$ and $48 \%$ of men and women, respectively), perhaps because street plays were loudly announced and widely perceived as entertainment. In contrast, hardly any had heard about the Mahila Nyay Samiti (just $4 \%-5 \%)$ or seen the complaint box $(3 \%-4 \%)$, both activities that were implemented towards the end of the intervention period.

Table 4.1: Awareness of the Do Kadam intervention, men and women in intervention villages, endline survey

\begin{tabular}{lcc}
\hline Intervention knowledge & $\begin{array}{c}\text { Married men } \\
\text { (ages 18-54) }\end{array}$ & $\begin{array}{c}\text { Married women } \\
\text { (ages 18-49) }\end{array}$ \\
\hline Knowledge of the Do Kadam intervention & 68.9 \\
Know of the Do Kadam intervention & & 61.2 \\
Aware of village-level sensitisation sessions organised by the & 43.4 \\
Do Kadam programme & & 44.2 \\
Aware that village-level sensitisation sessions were held fortnightly & 16.1 \\
or monthly & 59.9 \\
Aware of street plays organised by Do Kadam & 4.7 & 17.2 \\
Heard about Mahila Nyay Samiti & 48.2 \\
Ever seen complaint box & 4.4 \\
Number of respondents & $\mathbf{3 6 4}$ & 3.5 \\
\hline
\end{tabular}




\section{Experience of the intervention programme: community members, intervention arm}

With regard to community members' exposure to the Do Kadam programme, overall 42 percent of men and 32 percent of women reported having attended at least one village-level sensitisation session or street play. Exposure was, however, irregular. Specifically, 22-24 percent of men and women indicated that they had attended at least one village-level sensitisation session organised by the Do Kadam programme, but just six percent of men and women reported that they had attended such sessions sometimes or regularly. In addition, 26 percent of women and 35 percent of men had attended street plays organised by the programme. In contrast, not a single woman had herself lodged a complaint or was acquainted with someone who had lodged a complaint in the Mahila Nyay Samiti (Table 4.2).

Table 4.2: Participation in the Do Kadam intervention, men and women in intervention villages, endline survey

\begin{tabular}{lrr}
\hline Intervention participation & $\begin{array}{c}\text { Married men } \\
\text { (ages 18-54) }\end{array}$ & $\begin{array}{c}\text { Married women } \\
\text { (ages 18-49) }\end{array}$ \\
\hline Attended at least one village-level sensitisation session or street play & 42.3 & 32.0 \\
organised by Do Kadam intervention & 24.2 & 21.8 \\
Attended at least one village-level sensitisation sessions & 6.0 & 6.2 \\
Attended sensitation sessions sometimes or regularly & 35.4 & 26.1 \\
Attended at least one street play & - & 0.0 \\
Lodged complaint with Mahila Nyay Samiti & $\mathbf{3 6 4}$ & $\mathbf{3 9 4}$ \\
Number of respondents & & \\
\hline
\end{tabular}

Questions were posed to survey respondents who had not attended Do Kadam village-level sensitisation sessions regarding their reasons for non-attendance. About three-quarters of men $(75 \%)$ and women $(71 \%)$ reported no specific reason for their lack of attendance. Leading reasons cited by men and women differed, as seen in Table 4.3. Men cited two reasons: the timing was unsuitable or they lacked time $(20 \%)$ and conflict with work-related responsibilities (8\%). Women who had not attended any intervention activity cited a wider range of reasons for their lack of attendance: about one-tenth (9\%) of those reported that the location of the meeting or event did not suit them-it was either too far away from their home, or in a place where they were not permitted to go. A similar proportion (8\%) reported that the time was inconvenient for them. One in 20 cited household and/or work responsibilities (6\%), and almost as many, respectively, reported that their husband and/or other household members ( $4 \%$ each) refused to give them permission to attend the meeting or event. Very few men and women $(1 \%-3 \%)$ reported that there were no benefits to attending the meetings or events.

Respondents who had attended an intervention-related activity were asked whether such topics as violence against women and girls, alcohol abuse, equality of women and men, laws to prevent violence, support services for women

Table 4.3: Reasons for not attending village-level sensitisation sessions held by the Do Kadam intervention, endline survey

\begin{tabular}{lcc}
\hline $\begin{array}{l}\text { Reasons for not attending the village-level } \\
\text { sensitisation sessions }\end{array}$ & $\begin{array}{c}\text { Married men } \\
\text { (ages 18-54) }\end{array}$ & $\begin{array}{c}\text { Married women } \\
\text { (ages 18-49) }\end{array}$ \\
\hline Time did not suit/lack of time & 19.6 & 7.5 \\
Location did not suit & 0.0 & 9.1 \\
Household/family farm/wage-work responsibilities & 7.6 & 5.9 \\
Husband refused & - & 4.2 \\
Other family members refused & 0.0 & 3.9 \\
No perceived benefit & 0.7 & 2.9 \\
No specific reason cited & 74.6 & 71.4 \\
Number of respondents who had not attended Do Kadam & & \\
village-level sensitisation sessions & $\mathbf{2 7 6}$ & $\mathbf{3 0 8}$ \\
\hline
\end{tabular}


and girls who experience violence and so on were discussed during the village-level sensitisation sessions that they attended (Table 4.4). Recall of thematic issues addressed was widespread. Almost all those who had attended one or more sessions organised by the intervention programme reported that VAWG (86\%-90\%) and alcohol abuse (93\%-96\%) had been addressed in these sessions; about three-quarters (73-74\%) reported that gender equality was discussed. Several discussed more specifically the nature of the messages relating to VAWG: laws ( $57 \%$ of men, $40 \%$ of women), actions men can take to prevent violence (34\% and 19\%, respectively), actions PRI representatives can take against VAWG ( $28 \%$ and $42 \%$, respectively), and support services for women and girls who experience violence ( $32 \%$ and $14 \%$, respectively). While several also mentioned issues related to the safety of women in public places (33\%$44 \%$ ), very few mentioned such topics as the Social Justice Committee and its role in the protection of women (5-8\%).

Table 4.4: Topics addressed in intervention-related village-level learning sessions and street plays, endline survey

\begin{tabular}{|c|c|c|}
\hline & $\begin{array}{l}\text { Married men } \\
\text { (ages 18-54) }\end{array}$ & $\begin{array}{l}\text { Married women } \\
\text { (ages 18-49) }\end{array}$ \\
\hline \multicolumn{3}{|l|}{ Topics discussed in village-level sensitisation sessions } \\
\hline Violence against women and girls & 89.8 & 86.0 \\
\hline Alcohol abuse & 95.5 & 93.0 \\
\hline Equality of women and men & 72.7 & 74.4 \\
\hline Laws to prevent violence & 56.8 & 39.5 \\
\hline Actions men can take to prevent violence & 34.1 & 18.6 \\
\hline Actions PRI members can take against violence & 28.4 & 41.9 \\
\hline Support services for women who experience violence & 31.8 & 14.0 \\
\hline Social Justice Committee and its role & 8.0 & 4.7 \\
\hline Safety of women in public places & 44.3 & 32.6 \\
\hline $\begin{array}{l}\text { Number who attended one or more village-level } \\
\text { sensitisation sessions }\end{array}$ & 88 & 86 \\
\hline \multicolumn{3}{|l|}{ Topics addressed in street plays ${ }^{1}$} \\
\hline Violence against women and girls & 82.2 & 65.1 \\
\hline Alcohol misuse & 85.3 & 79.6 \\
\hline Early marriage & 48.1 & 58.3 \\
\hline Support services for women who experience violence & 4.7 & 15.9 \\
\hline Number who attended one or more street plays & 129 & 103 \\
\hline
\end{tabular}

Note: ${ }^{1}$ Multiple responses permitted; percentages add up to more than $100 \%$.

Community members who had attended one or more street plays also recalled that violence against women and girls and alcohol abuse were key themes enacted ( $82 \%$ of men and $65 \%$ of women and $80 \%-85 \%$, respectively). About half reported that street plays had discussed the evils of child marriage, and just five percent of men and 16 percent of women reported that at least one street play had addressed support services for women who experience violence, such as the helpline, the Mahila Thana (female police station), and the short stay home.

In-depth interviews also explored men's and women's acquaintance with the programme. Just four of the ten men and three of the ten women who participated in in-depth interviews reported exposure to the Do Kadam programme. Those who had heard about the programme had typically been exposed to village-level sensitisation sessions and street plays (nukkad nataks). Narratives suggest moreover that men had greater exposure to the programme and were better aware of its contents than were women. Those who had attended themselves or who reported that a family member had attended a village-level sensitisation sessions or event were able to recall its contents and messages clearly, for example:

In the meetings, they told us about quarrels between a mother-in-law and her daughter-in-law. They told us the age at which we should marry our daughters. They showed us some nukkad drama.... I have learned about girls' education and I have learned that we should only marry our girls when they are 18 years old. And they told us about the daughter-in-law and mother-in-law quarrel, that it does happen all the time. [Male, aged 34, completed Class 8, ID34] 
There was only one meeting that took place, but only women went to that meeting. [Male, aged 37, no education, ID35]

Yes I have heard about this programme, though I haven't participated in it. I heard that this programme talks about how all children-girls and boys-are equal.... A nukkad natak was held four times....in this natak, they told us that everyone should vote, as well as about the benefits of having a daughter, and that the daughter shouldn't be killed in the stomach [aborted]. [Male, aged 27, no education, ID37]

Yes. I heard about the programme. It was about if a woman is facing any violence, she should not sit silent but should take some action. They showed us in the telecast that there was a girl who was working and her brother did not like it and made her leave the job, but later the girl's employer went to her parents' house. He met them and persuaded the girl's brother to let her rejoin.... Then she joined again.... I just watched that nukkad drama. It was about women. Like if a woman is alone then people harass her. It was not the Panchayat that organised the programme in which we were told about women's rights but the Do Kadam people did that.... People think that it was good.... It was organised for women, it was good. [Male, aged 45, completed Class 9, ID38]

Yes there was a play about drinking alcohol and abuse. I did not go to watch it... My daughter went to watch it, and all the people from the village also went to watch it. I have heard of the Do Kadam programme, they spoke of it in the play....My daughter came back and told me about it....It was said that a husband and wife can be equals and can go through life at an equal level. At any and every place, both can do their work together. This play happened 2-3 times, meaning it was performed in 2-3 different places. Near the Gram Panchayat office, it happened on 'Durga Sthaan' and at 'Dibara.' All they said about alcohol was that if someone does drink and abuse, then they should go to the head of the village, and to tell him about it. [Female, aged 32, completed Class 10, ID22]

The Nukad Natak took place, they discussed things like you should not fight with each other. Yes, it was informative and educative... the nukkad natak also showed that people should not take alcohol as it leads to violence. These types of things were discussed there.... did not like any of it and returned very early.... No I didn't learn anything from this drama. Panchayat members didn't discuss women's rights, and don't do anything for victims of violence. [Female, aged 24, no education, ID25]

Just one man, and not a single woman was aware about the Mahila Nyay Samiti.

Yes there is a Mahila Nyay Samiti which has been opened recently. They persuade women to inform them if a man uses physical violence against them. [Male, aged 34, completed Class 8, ID34]

\section{Community members' interaction with PRI representatives and their perceptions about PRI representatives' engagement on issues related to violence against women, alcohol abuse and gender equality, before and after intervention}

As mentioned earlier, the mandated responsibilities of PRI representatives include facilitating the provision of entitlements to community members, addressing general infrastructural development issues, holding regular community-level meetings, addressing community-level conflicts and making efforts towards social change in their communities, including in such areas as child marriage, women's empowerment, violence against women and alcohol abuse, in their constituencies.

In addition to examining community members' interaction with PRI representatives and participation in the intervention activities, we assessed in a more general way changes in community members' perceptions about PRI representatives' engagement on issues related to violence against women, alcohol abuse, and gender equality. We start by assessing the extent to which intervention-community members reported any change in their interaction with PRI members, irrespective of whether this contact arose from the generic activities of the PRI representatives, or the activities conducted through the Do Kadam programme. Findings presented in Figure 4.1 confirm that the large majority of men had interacted with a PRI representative in the previous six months and percentages remained largely unchanged between baseline and endline (90\% at baseline; $89 \%$ at endline). Far fewer women had interacted with a PRI representative in the previous six months, and the proportion of women who interacted remained fairly unchanged between baseline and endline (44\% to 39\%). 
Figure 4.1: Interaction with PRI representatives in previous six months, as reported by men and women from intervention areas, baseline and endline surveys
Men

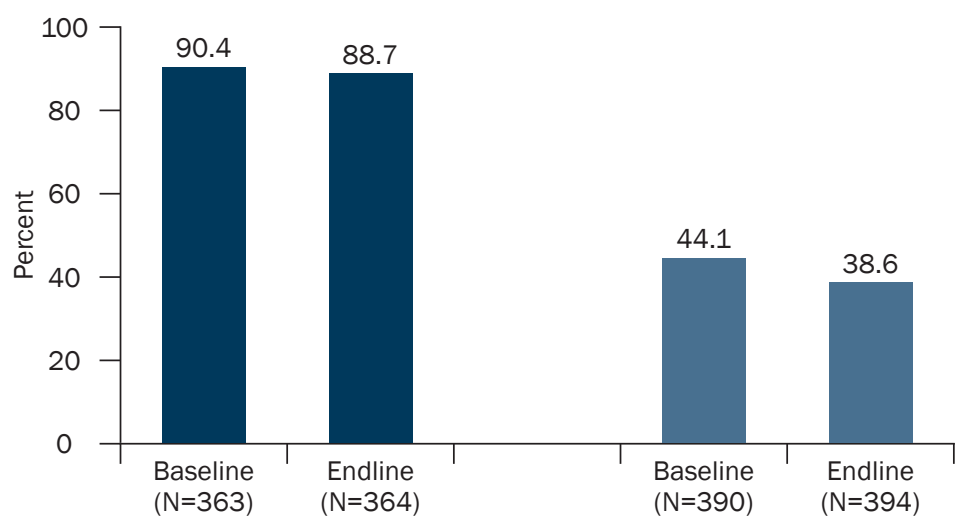

Figure 4.2: Percentage of men and women from intervention areas reporting that their PRI representatives held meetings in which domestic violence and gender equality were discussed in the previous six months, baseline and endline surveys

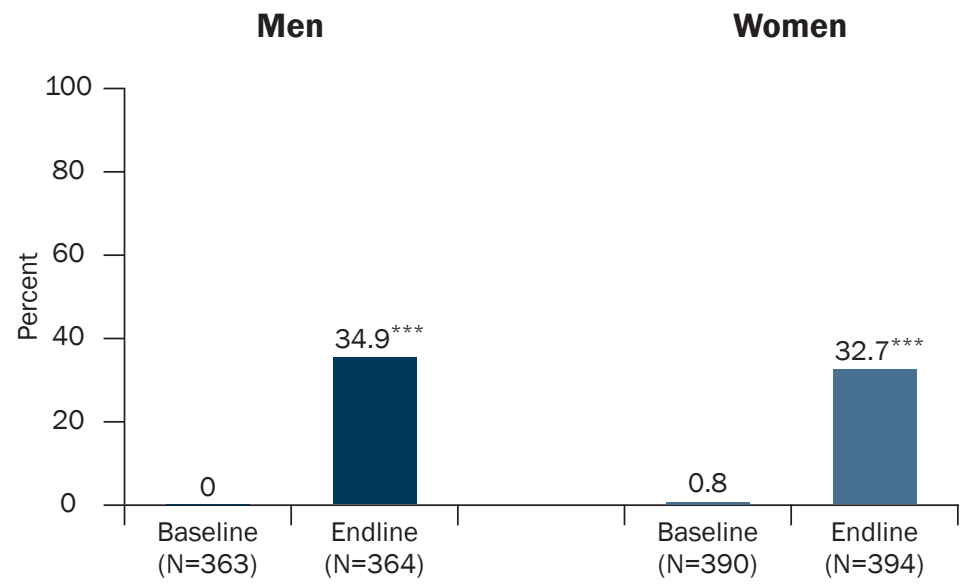

Note: ${ }^{* *}$ Indicates that the difference between baseline and endline is significantly different at $p<=0.001$.
We also inquired at baseline and endline in the intervention community about any meetings held by PRI representatives in which such social issues as domestic violence and gender equality had been discussed, irrespective of whether these meetings had been held as part of the generic duties of PRI representatives or as part of the Do Kadam programme. As evident from Figure 4.2, at baseline, hardly any study participants reported that a PRI representative from their Panchayat had held discourses or meetings on domestic violence or gender equality $(0 \%-0.8 \%$ of men and women alike). By endline, percentages increased significantly among both men and women: 35 percent of men and 33 percent of women reported that a $\mathrm{PRI}$ representative had held meetings in which domestic violence, alcohol abuse or gender equality had been discussed.

We also asked intervention community members whether their PRI representatives had intervened in cases of domestic violence or alcohol abuse or any other issue related to gender roles. Again, as evident from Figure 4.3 , findings show a steep increase in the percentage of men and women who reported any such intervention by PRI representatives in their villages. The proportion of men and women who reported any intervention by their $\mathrm{PRI}$ representatives increased significantly from baseline to endline, by ten percentage points (from 15\% to 25\%) for men and by 11 percentage points (from $4 \%$ to $15 \%$ ) for women.

Participation in meetings and other events led by PRI representatives in the intervention areas also increased significantly in the period between the baseline and endline surveys. We explored participation in two ways: (1) participation in events organised by PRI representatives as fulfilment of their general responsibilities, such as a community-level meeting, celebration of a national day, a

cleanliness drive and so on; and (2) participation in events organised by PRI representatives as part of their general responsibilities or the Do Kadam programme. Findings presented in Figure 4.4 show that there was a significant increase in percentages reporting participation in one or more of these events organised by PRI members in the six months preceding the base- and endline interviews. For example, percentages of men reporting participation in such events increased from 11 percent to 25 percent, and women from two percent to 13 percent.

When we included community members' participation in activities organised by PRI members as part of the Do Kadam programme, percentages reporting participation in PRI-led events increased hugely for both men (to 50\%) and women (to $33 \%$ ). 


\section{Changes as perceived by men and women in the six months prior to the endline interview: intervention and comparison arms}

At the endline, we probed study participants in both intervention and comparison arms about changes they had experienced or observed in the six months prior to the interview, a period overlapping with the months during which the Do Kadam intervention was implemented. Findings are summarised in Table 4.5. They suggest that a larger proportion of study participants from the intervention than the comparison arm perceived positive changes in their life or their community in the six months prior to the interview.

Figure 4.3: Percentage of men and women from intervention areas reporting that their $\mathrm{PRI}$ representatives had intervened in cases of domestic violence or alcohol abuse in previous six months, baseline and endline surveys

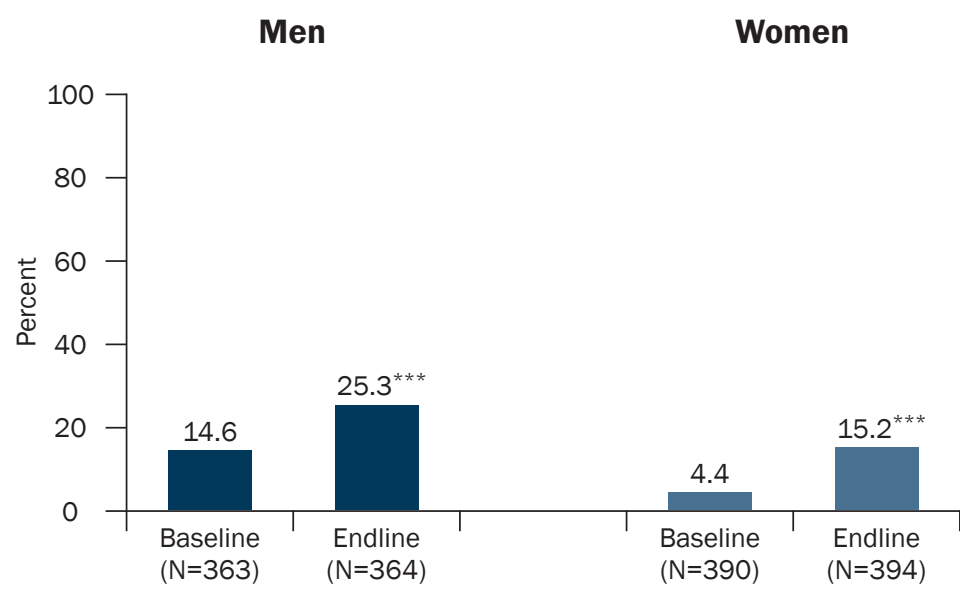

Note: ${ }^{* *}$ Indicates that the difference between baseline and endline is significantly different at $p<=0.001$.
Study participants in the intervention arm were significantly more likely to report that they were better informed about selected matters now than earlier, compared to their counterparts in the comparison arm. Overall, moreover, improvements in awareness were more likely to be reported by men than women. For example, men and women in the intervention arm were more likely than those in the comparison arm to report that they were better informed about the importance of respecting women and girls ( $42 \%$ vs. $17 \%$ of men; $26 \%$ vs. $4 \%$ of women). Similarly, a larger proportion of study participants in the intervention arm than the comparison arm reported that they were better informed now than earlier about laws relating to domestic violence ( $24 \%$ vs. $12 \%$ of men; $17 \%$ vs. $3 \%$ of women), as well as services for women who experience domestic violence (18\% vs. $7 \%$ of men; $11 \%$ vs. $2 \%$ of women). Likewise, they reported that they were more conscious than before about the ill effect of alcohol (55\% vs. 34\% of men; 33\% vs. $8 \%$ of women).

Figure 4.4: Community members' participation in PRI organised events in fulfilment of their generic responsibilities or the Do Kadam programme in the previous six months, as reported by men and women in intervention area, baseline and endline surveys

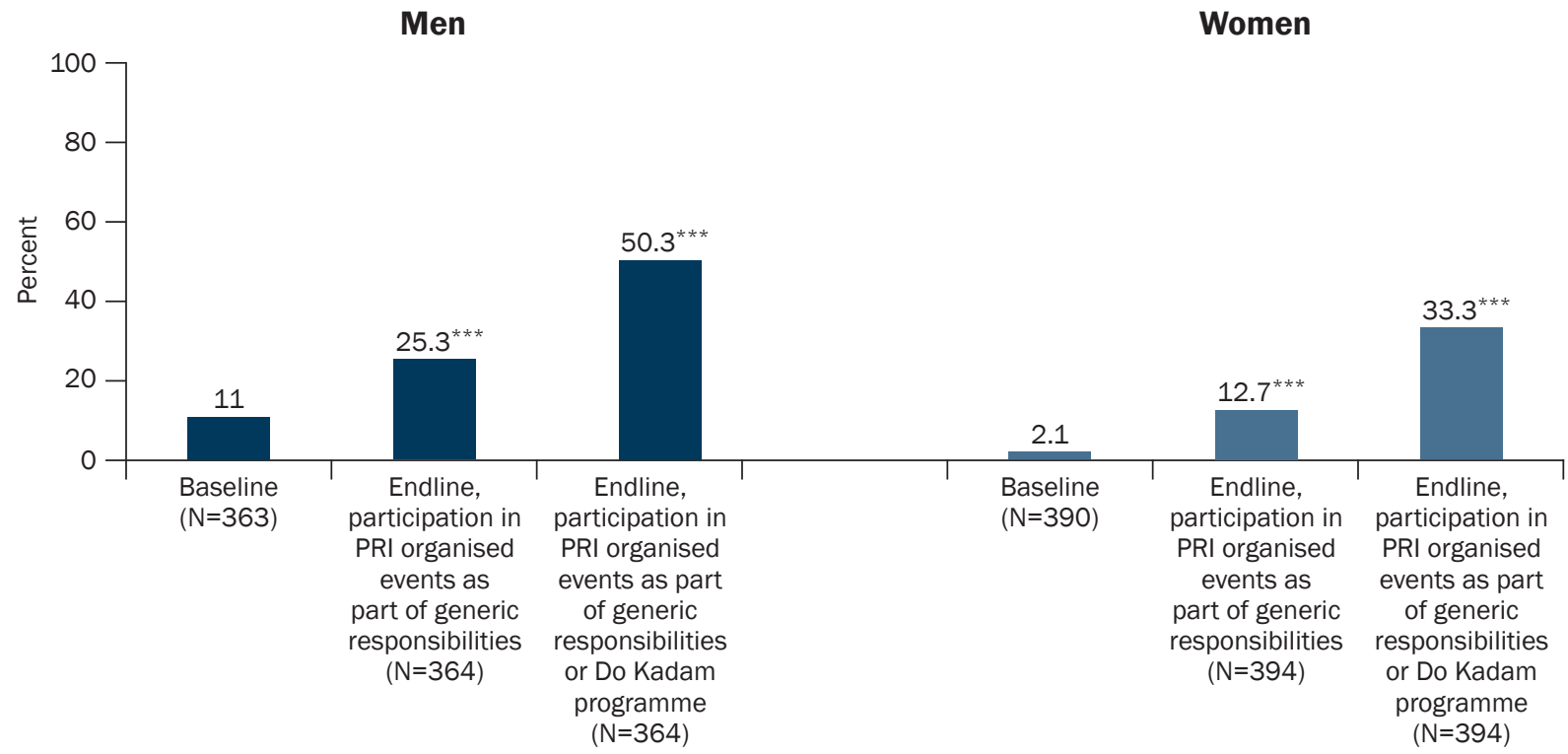

Note: ${ }^{* * *}$ Indicates that the difference between baseline and endline is significantly different at $p<=0.001$. 
Table 4.5: Perceptions of men and women about changes experienced in the six months preceding the interview in comparison and intervention villages, endline survey

\begin{tabular}{|c|c|c|c|c|c|c|}
\hline \multirow{2}{*}{$\begin{array}{l}\text { Self-perceived changes in the six } \\
\text { months preceding the interview }\end{array}$} & \multicolumn{3}{|c|}{ Married men (ages 18-54) } & \multicolumn{3}{|c|}{ Married women ages (18-49) } \\
\hline & Comparison & Intervention & Total & Comparison & Intervention & Total \\
\hline \multicolumn{7}{|l|}{ Changes in awareness } \\
\hline $\begin{array}{l}\text { More informed about respecting } \\
\text { women and girls }\end{array}$ & 17.3 & $41.8^{* * *}$ & 29.1 & 4.0 & $26.1^{* \star *}$ & 15.4 \\
\hline $\begin{array}{l}\text { Knowledge about DV-related laws } \\
\text { improved }\end{array}$ & 11.7 & $24.2^{* * *}$ & 17.7 & 2.7 & $17.3^{* * *}$ & 10.2 \\
\hline $\begin{array}{l}\text { Knowledge about DV-related } \\
\text { services improved }\end{array}$ & 7.4 & $17.9^{* * *}$ & 12.4 & 2.4 & $11.2^{* * *}$ & 6.9 \\
\hline $\begin{array}{l}\text { More conscious of ill effect of } \\
\text { alcohol }\end{array}$ & 34.4 & $54.7^{* * *}$ & 44.1 & 8.3 & $32.7^{* * *}$ & 20.9 \\
\hline \multicolumn{7}{|l|}{ Improvements in own life } \\
\hline $\begin{array}{l}\text { More confident of seeking support if } \\
\text { faced with violence }\end{array}$ & & & & 8.9 & $25.9^{* * *}$ & 17.6 \\
\hline $\begin{array}{l}\text { Relationship with spouse has } \\
\text { improved }\end{array}$ & & & & 26.6 & 35.3 & 31.1 \\
\hline \multicolumn{7}{|l|}{$\begin{array}{l}\text { Perceptions of community-level } \\
\text { changes }\end{array}$} \\
\hline More difficult to obtain alcohol & 7.4 & 8.5 & 7.9 & 4.6 & $7.1^{*}$ & 5.9 \\
\hline $\begin{array}{l}\text { Violence against women has } \\
\text { decreased }\end{array}$ & 22.9 & $32.1^{*}$ & 27.3 & 8.1 & $16.5^{*}$ & 12.4 \\
\hline Number of respondents & 393 & 364 & 757 & 372 & 394 & 766 \\
\hline
\end{tabular}

Note: ${ }^{*}$ and ${ }^{* * *}$ indicate that the difference between the intervention and comparison arms is significantly different at $p \leq 0.05$ and $p \leq 0.001$, respectively.

Women were also asked about changes in their own life over the course of the previous six months, specifically, in their confidence about seeking services if faced with violence on the one hand, and improvements in their relationship with their husband on the other. Findings suggest that those in the intervention arm were significantly more likely than their counterparts in the comparison arm to report confidence in seeking support if they experienced violence ( $26 \%$ vs. $9 \%$ ), and slightly more likely to report improvements in their marital relationship (35\% vs. $27 \%)$.

Finally, study participants were asked about their perceptions of changes at the community-level in the availability of alcohol and the prevalence of violence against women. Men in the intervention arm were no more likely than their counterparts in the comparison arm to perceive that it had become more difficult than before to obtain alcohol in their community ( $9 \%$ vs. $7 \%$ ); few women in both arms so perceived ( $7 \%$ vs. $5 \%$ ). In contrast, perceptions about declines in violence against women were expressed by significantly more study participants from the intervention than comparison arm, and more men than women perceived that violence against women at the community-level had declined ( $32 \%$ vs. $23 \%$ of men; $17 \%$ vs. $8 \%$ of women).

\section{Summary}

Findings presented in this chapter indicate that almost three-quarters of men and three-fifths of women in the intervention arm were aware of the Do Kadam project. Awareness of activities varied considerably both by gender and by type of activity. Men were more likely than women to report awareness, and more study participants reported awareness of community-level sensitisation sessions and especially street plays than other activities. Relatively few study participants reported interventions by PRI representatives in cases of violence against women or alcohol abuse. 
Participation in community-level sensitisation sessions and street plays was also reported by more men than women, both in the survey and in in-depth interviews. In the survey, for example, more than one-third of men had attended a street play and one-quarter a sensitisation session organised by the programme, compared to about one-fifth of women. Reasons for not attending such sessions and events differed for men and women. The most prominent reasons expressed by men related to time conflicts, namely that the timing of events was unsuitable and that their work responsibilities conflicted with the timing of events. Many women, while expressing similar reasons, reported that the location of the event was unsuitable for them, that is, either too far away or in too public a place; many also reported that their husband or other family members had not permitted them to attend. At the same time, large proportions of men and women who attended sensitisation sessions and street plays could recall their messages, notably those relating to violence against women and alcohol abuse. In in-depth interviews, too, those who had any exposure to the programme indicated that violence was a key theme of sensitisation sessions and nukkad nataks, along with other social issues such as child marriage and gender-biased sex selection.

With regard to such process indicators as interaction with PRI representatives and PRI representatives' discourses or interventions on issues related to gender equality, violence against women and alcohol abuse, findings confirmed that discourses delivered by PRIs on such social issues had increased significantly during the intervention period. The intervention also succeeded in increasing participation of community members in meetings and other events organised by PRI representatives as part of their regular duties, and significantly more so in sensitisation sessions and events held by PRI representatives as part of the Do Kadam programme.

Findings suggest that a larger proportion of study participants in the intervention than comparison arm perceived positive changes in the six months prior to the interview. Specifically, study participants in the intervention arm were more likely than their counterparts in the comparison arm to report they were better informed about violence-related matters and more conscious about alcohol misuse than before. Women from the intervention arm, moreover, were more likely than their counterparts from the comparison arm to report confidence about seeking help in case of violence and improvements in marital relations. Moreover, while somewhat larger proportions of men and women in the intervention than comparison arm perceived that violence against women had declined at the community-level, few men and women from both the intervention and comparison arms perceived any change in the ease with which alcohol could be procured in their community. 


\section{Chapter 5 \\ Perspectives and experiences of PRI representatives}

Drawing on findings from in-depth interviews with PRI representatives from the intervention arm, this chapter describes PRI representatives' experiences and perceptions of the Do Kadam project. It also presents findings with regard to their own assessments about whether there had been changes in their practices and attitudes following their exposure to the intervention. As mentioned earlier, in-depth interviews were held with nine male and nine female PRI representatives prior to the introduction of the Do Kadam programme and interviews were repeated with all nine male and seven of the female representatives at its conclusion.

\section{Profile of PRI representatives}

Most PRI members were serving in their first or second term and had held their position for at least three years preceding the baseline interview: of the nine male PRI members interviewed, six were serving in their first term and three in their second. Among women, four were serving in their first term and five in their second or third term. Male PRI representatives tended to be older than females: their ages ranged from 32 to 62 years, compared to women, whose ages ranged from 27 to 50 . Educational attainment levels of male PRI representatives were considerably higher than in the community more generally: just two had not completed high school, most had completed Class 10 or 12 (five) and two were graduates. Among women, five had also completed Class 10 or 12, and of the remaining four, two had never been to school and two had some primary education.

At baseline, most PRI representatives perceived their role as overseeing the infrastructural development of their constituency, notably with regard to water, roads, and electricity; ensuring that entitlements such as Aadhaar cards (unique identity cards) and ration cards, and pensions and other schemes were received; and resolving land disputes and other community-level conflicts.

I have been a panchayat representative for the last three years... I look after all matters related to roads, electricity, water, etc. in the village. Laying sewers in the lanes of the village, installing a hand pump, cleaning up the village. I also undertake duties such as providing people with ration cards, Aadhaar cards, old age and widow pensions etc. [Male, aged 37, completed Class 5, Panchayat representative for three years, baseline, ID10]

My responsibilities are to see that there is proper implementation of the Indira Awas Yojana, proper construction of drains, proper filling of land papers, etc. in our village. [Female, aged 40, no formal education, Panchayat representative for one year, baseline, ID2]

\section{Capacity building for the Do Kadam programme: Experiences of PRI representatives}

All PRI representatives interviewed at endline reported that they had attended the training programme and subsequent sessions. Indeed, most PRI representatives reported that this was the very first training programme they had ever attended (one male and one female had been exposed to an NGO-led programme earlier). They recalled that the programme comprised an initial three-day training programme followed by fortnightly sessions, during which they were informed about gender equality, violence against women, and the evils of alcohol abuse. A few reported that they had also been educated about their roles and responsibilities as locally elected representatives. For example:

Yes I participated. We received a lot of information about violence against women. We were told about Do Kadam Barabari Ki Ore, that both men and women are equal. We were told about gender discrimination, female education, sexual abuse, female freedom, dowry, etc.... Mostly it was about women and about alcohol abuse. We were taught that there should not be any difference between a boy and a girl.... I 
attended all the classes. We selected Tuesdays, every 15 days. I learned that we should ban violence, we should ban alcohol, and treat girls and boys equally. And if you have problems, there is the women's police station, there are counsellors, and lot of other facilities where women can get help and which save women. [Male, aged 48, completed Class 10, Panchayat representative for three years, endline, ID13]

Yes, I participated and it was a three-day training programme. We were told about equality between boys and girls, that we should stop alcohol, that there shouldn't be any violence against women, everyone should live in harmony. Yes, I learned new things, like women should make a group and help in stopping alcohol, everyone should live in harmony. [Female, aged 50, completed Class 2, Panchayat representative for 8 years, endline, ID05]

Most PRI representatives reported that in addition to the training programme and other sessions they attended, they had received a handbook on social matters, gender equality, violence against women and alcohol abuse. PRI representatives were fairly unanimous in describing the booklet as very useful ( 8 of 9 men, 6 of 7 women):

I explained to people from the booklet and gave it to them to read and understand. It was very useful. I read this and explained to people that it is important to believe in equality, Do Kadam Barabari Ki Ore, everyone has equal rights: men, women, girls, and boys. [Male, aged 33, completed Class 10, Panchayat representative for 3 years, endline, ID17]

Yes, I got a book and its title is Two Steps Toward Equality. I have a copy and I write in it, there are pictures in it. They show everything-how to sit, how to talk, etc.-and I have done whatever it asks you to do. [Female, aged 44, completed Class 10, Panchayat representative for 13 years, endline, ID07]

Fewer reported that they had gone on the exposure visits organised by the Do Kadam programme to observe the facilities available for women in distress. Indeed, just four of the nine men and four of the seven women reported having attended the exposure visits. Those who attended the visits reported that this was their first exposure to these facilities, and appeared generally to have benefitted from the exposure. For example:

We were taken to the women's police station, the women's helpline, etc. I knew about them before but had never been to any such facility. So I visited these facilities for the first time because of this programme. I was very happy. [Male, aged 43, completed Class 15, Panchayat member for 3 years, endline, ID14]

I went to the women's police station and the helpline, and to the women's shelter home. I went to all these places for the first time. Before this I didn't know anything about them. [Female, aged 40, no formal education, Panchayat member for one year, endline, ID02]

\section{Do Kadam programme activities conducted by PRI representatives at the community-level}

Once trained, PRI members held meetings and other events, together with Do Kadam organisers, for their constituencies, in which they made efforts to raise awareness and change attitudes and behaviours with regard to violence against women, gender discrimination, and alcohol abuse. Most male PRI representatives ( 8 of 9 ) and just one (of 7 ) female representative reported that they conducted these meetings and events to deliver messages from the Do Kadam programme. A few suggested that while earlier meetings used to address village development matters, over the previous few months, gender equality, marital violence, and alcohol abuse were also discussed. For example:

There is a meeting every month. About what development is taking place in the village, where there is a need for a canal, where a handpump is needed. Since the Do Kadam programme has begun, we also discuss violence against women and how one should behave in marriage. Sometimes 100, 90 people attend, sometimes 50. [Male, aged 43, completed Class 12, Panchayat member for 8 years, endline, ID12]

Yes, we organised the session, we discussed education, how to be free from alcohol, domestic violence. Both men and women participated, sometimes 20-25, not necessarily the same people. After we talked, people asked, 'What is the point of talk, why don't we do something to stop selling alcohol? The government has opened alcohol shops everywhere and they should be closed.' Then we told them that if people stop buying from these shops they will automatically shut down.... [Male, aged 38, completed Class 12, Panchayat representative for 3 years, endline, ID16] 
After getting a gathering of people together, we provide them with pictures, which tell them the things they should not do. We discuss violence against women and alcohol. About 50-70 people took part in these meetings, including men and women. [Male, aged 32, completed Class 6, Panchayat representative for 3 years, endline, ID18]

In meetings, we told them that one shouldn't tease girls, and that if they do then there will be a case against them and a sentence of six years. About dowry, about not hitting anyone or your wife, and then about alcohol. [Female, aged 40, no formal education, Panchayat member for one year, endline, ID02]

PRI representatives also discussed the street plays organised as part of the Do Kadam project. Seven of the nine male PRI representatives, and six of the seven female representatives had taken part in organising the plays and assembling community members. Male PRI representatives' narratives were overwhelmingly positive, most believed that these nukkad nataks resulted in some self-reflection among spectators about attitudes and practices. For example:

Plays were basically about violence against women and consumption of alcohol. People loved watching them and the plays helped to change people's thinking. They said the plays were nice and they will try and improve themselves and improve the village. [Male, aged 62, completed Class 10, Panchayat representative for eight years, endline, ID11]

It showed how after drinking, men cannot eat properly, they hit their wife, cannot look after their children and can't live properly in society. All this was depicted, and whatever they were showing was correct. These things shouldn't happen in society. [Male, aged 43, completed Class 12, panchayat representative for eight years, endline, ID12]

Female PRI representatives, in contrast, were more sceptical about the effect of the nukkad nataks on changing attitudes and behaviours, for example:

Nataks have taken place three times. These Nukkad Nataks showed the husband washing his own clothes and cleaning the house with a broom because his wife was ill. It also talked about drinking and teasing, that both sons and daughters should be given the same respect, not to let them get married during childhood.... They liked to watch these Nukkad Nataks but it made no difference. [Female, aged 30, completed Class 10, Panchayat representative for three years, endline, ID12]

Fewer PRI representatives were aware of the Mahila Nyay Samiti, introduced towards the end of the programme by organisers because the Social Justice Committee was not operational in project areas. Just six of the nine male, and four of the seven female PRI representatives had heard about the committee, but their narratives suggest that they were not fully aware about the committee's role. For example:

They have meetings and explain to women and they get written investigations done for women who experience violence. [Male, aged 48, completed Class 10, Panchayat representative for three years, endline, ID13]

There is a committee, but I have no knowledge about it. [Female, aged 30, completed Class 10, Panchayat representative for nine years, endline, ID03]

Aside from empowering PRI representatives to hold community-level meetings and other events, the Do Kadam programme also strengthened PRI representatives' capacity and commitment to intervene in cases of marital violence and alcohol abuse. Narratives suggest that prior to the intervention, hardly any PRI representative reported that they had intervened in cases of marital violence: several reported that marital violence was a personal matter and women preferred to remain silent about it:

Women complain that their husband comes home drunk and hits them. Then I sit both of them down, explain to them, and resolve the matter. These kinds of disputes come to me very rarely because most women feel that this is a matter belonging within the home and if they tell outsiders about this then their family itself will be insulted and shamed. [Male, aged 43, completed Class 15, Panchayat representative for three years, baseline, ID14] 
No I have never received a complaint regarding violence against a woman, The reason for this is that once a woman has endured violence she thinks why should she take the matter outside the house and spread what happens in her home outside. This would only end up disgracing her own home and disrespecting her husband's dignity. Therefore she stays quiet and doesn't tell anyone anything. If no one comes to me, how can I help them? [Male, aged 43, completed Class 10, Panchayat representative for eight years, baseline, ID12]

No woman has come to me about experiencing violence.... Even if I talk to women about violence, women say it is their personal matter, and why am I interfering. [Female, aged 30, completed Class 10, Panchayat representative for 10 years, baseline, ID01]

Yes, women have shared their experiences of violence with me. They tell me that their husband calls them names, swears at them, beats them, that they feel like killing themselves, etc. But what can I do, apart from listening to them quietly? One women told me that her husband came home drunk and then beat her and slapped her hard on her face. If I take any step to resolve this on my own, neighbours will say that because she won the election, she is interfering in out personal matters. [Female, aged 46, completed Class 8 , Panchayat representative for eight years, baseline, ID6]

By endline, a few PRI representatives reported that they had intervened in cases of violence in which the women had approached them for help, and agreed that the problem was resolved by the Panchayat and that there was no need to approach the police or helpline. For example:

Yes, the Panchayat intervenes when such matters come to its notice and we speak with both sides to resolve the matter. The Panchayat scares and threatens that the offender will be sent to the police. Until now, the cases which have come up like these have been resolved at the panchayat level. The police have never been required, but in the future if the police's help is ever required, it will surely be sought. So far the need has never arisen to go to the helpline or the short stay home. If their help is ever needed, we will surely go to them as well. Until now people have accepted the decision of the Panchayat and resolved the matter in the village itself. [Male, aged 43, completed Class 10, Panchayat representative for eight years, endline, ID12]

There has been a lot of awareness among women through your programme, which is why they have come. Twenty women may have come regarding this issue in the year. I solved their problems through the law or the panchayat and helped them. There is a woman in my ward, RD. Her husband used to hit and abuse her, so we called him and explained. Now they live together nicely. We put social pressure on her husband which is why he doesn't beat or abuse her any more. Yes, now if any woman has experienced violence, then her family and husband are called and we punish them financially or physically. We call them, scold them and make them understand. [Male, aged 43, completed Class 15, Panchayat representative for three years, endline, ID14]

Yes, if a husband beats his wife and if they come to us, we go with them and file a case. But only if she goes to the panchayat can we do anything for her. [Female, aged 40, no formal education, Panchayat representative for one year, endline, ID02]

The intervention also called upon PRI representatives to address alcohol abuse in their constituencies. While PRI representatives reported taking actions to address alcohol abuse, including counselling those abusing alcohol and organising protests to curb the sale of alcohol, they acknowledged obstacles in doing so, including political interference when PRI representatives tried to reduce the sale of alcohol on the one hand and community members' own reluctance to stop the practice on the other. For example:

People who understood that alcohol is bad were with us and told everyone to stop, but people who were against us put the blame on us, saying that we are wrong. So I think it has become easier to get alcohol in our villages, alcohol consumption is increasing daily. [Male, aged 62, completed Class 10, Panchayat representative for eight years, endline, ID11]

Yes we stopped the sale of alcohol for some days, but then those who consume alcohol became vocal. There was no support for us. Nitishji's government earns tax from alcohol shops so he made it easy to start these shops just so he could earn tax. He didn't think about the public. If he is creating this mess, what can we PRI members do. The police will support the government, not us. [Male, aged 48, completed Class 10, Panchayat representative for three years, endline, ID13] 


\section{Perceptions about changes in their own attitudes and behaviours}

In in-depth interviews, PRI representatives discussed the effect of their exposure to the Do Kadam programme on their own attitudes and behaviours with regard to gender roles, marital violence, alcohol abuse, and their own marital relations. Almost all of the PRI representatives reported changes in their own gender role attitudes and attitudes about the acceptability of violence against women; most discussed the need to reduce alcohol abuse in their village and maintain closer and more harmonious and violence-free marital relations.

\section{Gender role attitudes}

PRI representatives acknowledged that they had largely adhered to traditional gender role attitudes until exposed to the programme They were now committed to upholding more egalitarian gender-role attitudes and some discussed their commitment to spreading these new attitudes in their communities as well. For example:

Before taking the training, I used to think that whatever was happening was correct but now I feel that it wasn't correct. There is a need for change. A woman should have all the rights at home that a man has. She should also be able to go out of the house by her own choice, she should be able to take decisions related to the home by herself, and she should be able to go out and earn money, She shouldn't require anyone else's permission. For all of this to take place, we need to change the mindsets of men and women, make them more aware, give them information about their rights and duties, and only then will there be equality and a stop to violence against women. [Male, aged 32, completed Class 6, Panchayat representative for three years, endline, ID18]

My view changed when I attended the programme. Before I used to think that women shouldn't go out of the house. But now I think that women and men are equal and both can go out. [Male, aged 33, completed Class 10, Panchayat representative for three years, endline, ID17]

Yes there has been a change in my views. I feel now that women too should get the same rights as men in society as well as within the home. Women can also take decisions, they can go out of the house to earn a living. They can go out of the house on their own accord. They should have a say in society as well. In the Panchayat too, women should be heard and their opinions taken seriously. Men should change their way of thinking and should encourage women to move ahead. [Male, aged 62, completed Class 10, Panchayat representative for eight years, endline, ID11]

Now I believe that men can no longer treat women like the soles of their shoes; they should treat them as equals because men and women are two sides of the same coin, two wheels of the same car, and as long as one wheel isn't fine, the car won't run properly. Women also deserve a life of dignity. [Male, aged 38, completed Class 12, Panchayat representative for three years, endline, ID16]

Yes, my thinking has definitely changed. Whether it's a boy or a girl, I don't differentiate between the two. We cannot survive without daughters. Everyone should speak courteously, shouting at each other is wrong. Now, if anyone comes to my house for help, I run to help that person, even if they come while I am eating my food. Before I could never imagine doing such a thing. Now I think that violence against women should be stopped totally, and the reasons why it takes place should also be prevented [e.g., alcohol]. [Female, aged 44, completed Class 10, Panchayat representative for 13 years, endline, ID07]

Yes, my thinking has changed after attending the programme. I think a husband and a wife should communicate better and keep harmonious relations with each other. [Female, aged 46, completed Class 8 , Panchayat representative for eight years, endline, ID06]

Yes, my views have changed. I believe men should learn to behave nicely with their wife. [Female, aged 40, no formal education, Panchayat representative for one year, endline, ID02]

Both a boy and a girl come from the same womb, so they should both be equal. Earlier, we thought that the man had more rights and authority at home, and without his permission his wife could not go anywhere, but now I think they should be equal. [Female, aged 30, completed Class 10, Panchayat representative for nine years, ID03] 


\section{Attitudes about the acceptability of marital violence}

Views about the acceptability of marital violence also changed, with all of the PRI representatives reporting that violence against women should not be tolerated. Two male representatives stressed that even shouting at one's wife constituted violence, and expressed a view that women should not tolerate violence. For example:

Yes there has been a change in this too. Now I think that women are humans and so why do people treat them like animals? We should help them out, we should treat them well and if they ever do make a mistake then we should talk and explain things to them lovingly. In my opinion, talking to one's wife in a loud voice is also a form of violence, and beating her is an even worse offence. [Male, aged 43, completed Class 12, Panchayat representative for eight years, endline, ID12]

Yes there has been a major change. Since this training, I explain to people that we should not inflict any form of violence on women. In my opinion, men who are violent should be severely punished because women also have the complete right to live a full life. At the same time, women should never endure and tolerate violence, they should raise their voices against this. [Male, aged 33, completed Class 10, Panchayat representative for three years, endline, ID17]

Yes, I have clearly understood that violence against any woman should not happen under any circumstances. And that if we see such violence in our community, we should make them understand that they should never do this, that they torture more when they are drunk, and that if a husband doesn't drink alcohol he will commit less physical and mental violence. [Female, aged 46, completed Class 8, Panchayat member for eight years, endline, ID06]

\section{Alcohol-related attitudes and practices}

Most PRI representatives agreed that alcohol abuse was a key concern in their constituencies, and several suggested a need to ban the sale of alcohol in their village (6 of 9 male and 4 of 7 female PRI representatives). These representatives recognised the link between alcohol abuse and violence against women, and argued that if alcohol is difficult to access, violence against women will reduce. A few male PRI representatives attributed their own change in alcohol consumption to their exposure to the Do Kadam programme. For example:

Earlier I used to drink a lot and my brain would stop working after drinking. But now I don't drink as much as before... it has changed. Sometimes, when I think that earlier I used to drink alcohol and misbehave with my wife, I feel very sad. I think that I did wrong things, but now I stay away from alcohol and that is a good thing for me. In my view, it is very important for the panchayat to take the help of the police and close down all liquor shops. [Male, aged 32, completed Class 6, Panchayat representative for three years, endline, ID18]

Yes my views have changed. Now I believe women should not be beaten up, and men should not consume alcohol because this leads to beating up of women which is wrong. After the training I understood all this. [Female, aged 40, no formal education, Panchayat representative for five years, endline, ID08]

After the training I understood that there should be some provision to prevent the sale of liquor in our village. The environment of the village is ruined because of alcohol. A meeting should be organised to ban the consumption and sale of liquor in our village. [Female, aged 40, no formal education, Panchayat representative for one year, endline, ID02]

\section{Changes in marital relations}

PRI representatives, notably male representatives, reported moreover that their relations with their spouse had improved in many ways as a result of the Do Kadam programme exposure. While narratives must be interpreted keeping in mind a likely social desirability bias, male PRI representatives identified a host of changes in their marital life, aside from reduced alcohol use and marital violence. They reported that they had stopped emotionally abusing their wife (all 9), and now spoke with their wife 'lovingly' (6), spent more time with their wife and children (6), participated in household chores (7), and acknowledged their wife's agency (decision making, mobility, control over economic resources (4). For example: 
Yes there has been an effect on my relationship with my wife too. Now I talk to her lovingly. Compared to before, I give her more respect, I talk to her with respect, and even if she makes a mistake, I don't get angry with her like I used to do before the training. After taking the training, I am more aware of both her rights and of my rights and duties. I have started spending more time with my children, and started behaving well with everyone. I have started helping out more in the house. All in all I now know better what is wrong and what is right, and started behaving better at home and in society. [Male, aged 43 , completed Class 12 , Panchayat representative for eight years, endline, ID12]

Yes there has been a change in our relationship. Compared to before, I talk to her more nicely and lovingly.... I no longer get angry with her or shout at her or speak in a loud tone. Now I live more harmoniously, I spend time with my family, I help my children with their schoolwork, I help my wife out with housework. I know that it is also my responsibility to carry out these chores, so I look after the animals, go to the market, help my wife out in cleaning the house. [Male, aged 43, completed Class 15, Panchayat representative for three years, endline, ID14]

Now I do not talk to her in a loud voice, I speak to her lovingly and we explain our problems to each other. This has had a positive effect on the children as well because children learn whatever they see happening in front of them. Earlier my wife used to ask my permission before doing anything, now she too has changed and does what she wants, but I do not get angry about this, I also let my daughter go out, because my views have changed and my fear that my daughter shouldn't be let out of the house has changed. [Male, aged 38, completed Class 12, Panchayat representative for three years, endline, ID16]

Earlier I used to say horrible things to her in anger but now, after taking part in this programme, I don't do this as much, I was taught this is also a form of violence. Earlier I never helped her with household chores, now I do-we were told that the responsibility for household chores isn't solely that of the wife. I spend more time at home, I also give my wife the freedom to do whatever she wishes. Being a panchayat member I have to teach all these things to people in the village. [Male, aged 32, completed Class 6, Panchayat representative for three years, endline, ID18]

In contrast, among female PRI representatives, four of seven interviewed at endline noted that marital violence had stopped over the last year, but none of these women attributed the decline to the Do Kadam programme. Rather, they felt it was the fact that their children were growing up and the husband was more inhibited about committing violence; that a daughter-in-law had entered their family; or simply because they were older. Indeed, just one of seven female panchayat members attributed any change in her marital relations-her ability to speak freely to her husband-to the Do Kadam programme:

Yes, I asked my husband to stop drinking and eat sweets instead. Neighbours say bad things about him, that he drinks, behaves badly, etc. Before I could never say these things to him but now [after attending the Do Kadam programme] I do. [Female, aged 46, completed Class 8, Panchayat member for eight years, ID06]

The day my daughter in law came into this house, the beating stopped... No one did anything, he changed on his own, because of the presence of the daughter in law. [Female, aged 40, no formal education, Panchayat member for five years, ID08]

\section{Perceptions about changes in community attitudes and behaviours}

In contrast with the changes PRI representatives noted in their own attitudes and behaviours, relatively fewer identified corresponding changes at the community-level. Even so, we note that a few IDI participants did notice that gender role attitudes had changed, and marital violence and alcohol abuse had declined. Some noted other changes, for example, in dowry and child marriage practices, and investments in children's education, and attributed these to exposure to the Do Kadam programme. For example:

Earlier, women used to be threatened with dowry, child marriage used to happen, now all these things have decreased. [Male, aged 38, completed Class 12, Panchayat representative for three years, endline, ID16]

Yes, men have changed, they have stopped beating their wife now, this is the change I have seen in men. We told them to stop drinking as it increases violence, and it affects their children. [Male, aged 32, completed Class 6, Panchayat representative for three years, endline, ID18] 
Yes now people think that it is more important to educate children, and that the money that we spent on alcohol should be spent on our children's education. [Male, aged 38, completed Class 12, Panchayat representative for three years, endline, ID16]

Like men used to force women after getting drunk to do things [sex] that they didn't want to do. This kind of behaviour has changed and alcohol abuse is reduced to an extent. Alcohol should not be sold near the village. We organised a protest for reducing alcohol abuse which we took to the panchayat level. Because of this, a lot of people quit drinking. [Male, aged 37, completed Class 15, Panchayat representative for three years, endline, ID15]

Most female PRI representatives suggested that there had been no change in community-level behaviours. There were however two exceptions. Both women noted that improvements had taken place in alcohol or violence-related behaviours over the previous year, and both attributed the improvement to the Do Kadam programme. For example:

Baseline response: After drinking, men use abusive language, beat women.

Endline response: Yes, they still do eve-teasing to women and girls under the influence of alcohol. But after watching the natak they have started to understand, and now this has decreased somewhat. [Female, aged 50, completed Class 2, ID05]

Baseline response: Yes, this is common. Many men consume alcohol and then misbehave. This happened just a few days ago.

Endline response: Yes, people still wander around and verbally abuse people. But after watching the nukkad nataks, people have changed their thinking and violence has reduced. [Female, aged 30, completed Class 10, ID03]

\section{Perceptions about the Do Kadam programme}

Several male and female PRI representatives did however appreciate the programme and expressed regret that it had ended ( 8 of 9 male, and 4 of 7 female representatives). Several suggested that it had not continued long enough to result in sustained changes in attitudes and behaviours and needed to be continued in order for improvements in community awareness and attitudes reinforced against alcohol abuse and violence against women. One female PRI representative called for a special focus on the young, especially boys. In her words:

To make the project powerful, it is necessary to make the panchayat administration stronger. For example, if a woman files a complaint and no action is taken, her heart breaks. Only the Do Kadam organisers can show the way to seek justice and help us take correct action. [Male, aged 48, completed Class 10, Panchayat representative for three years, endline, ID13]

The programme should be continued. When it is stopped early, everything falls back to the way it was. If it is continued there will be more awareness and more change among people. [Male, aged 38, completed Class 12, Panchayat representative for three years, endline, ID16]

Yes, the programme made a difference and now that it has stopped, the drinking has also increased as before. When the programme was on, we used to hold a demonstration so people were scared that they may be punished if they drink, but now it has stopped so there is no fear among people and they have started to drink again as much as before. [Male, aged 37, completed Class 5, Panchayat representative for three years, endline, ID10]

Yes, the programme should continue. If it does it will benefit the village and the panchayat. If it continues for six months, some change will happen, people will learn to live in peace. [Female, aged 50, completed Class 2, Panchayat representative for eight years, endline, ID05]

There may not have been a big difference now, but it will be possible in the future. Change is possible, so the programme [Do Kadam] should be continued. There has been a small change today, it will become bigger in future. Meetings should be continued at regular intervals. In meetings, you should talk to the young, old, children, and women-everyone-and make them understand. Particularly young boys who are taking liquor and engaging in other bad habits. [Female, aged 46, completed Class 8, Panchayat member for eight years, endline ID06] 


\section{Summary}

Findings presented in this chapter indicate that all of the PRI representatives attended the Do Kadam training programmes. Several male and female representatives had participated in organising community-level meetings and street plays, and a few reported personal experience intervening in cases of alcohol abuse or marital violence, or holding protests to ban the sale of alcohol in their constituencies. Most narratives were hugely positive, and described in detail the content and messages of the training programmes, meetings and street plays.

As in the case of the community members reported in Chapter 4, PRI representatives noted considerable changes in their own gender role attitudes, attitudes about marital violence, and attitudes about alcohol abuse. While the possibility of providing socially desirable responses cannot be discounted, several male representatives also reported that they had reduced their alcohol misuse, had stopped committing violence against their wife, and generally experienced more egalitarian marital relations, helping their wife with housework, spending more time with family, acknowledging their wife's right to make decisions, move around freely, and control money. Female PRI representatives were less likely to have recognised these changes in their marital life or, if recognised, to have attributed them to the Do Kadam programme.

Few PRI representatives commented on changes in gender-role attitudes, marital violence, and alcohol abuse at community-level. Although some did note these changes, several implied that the programme needed to be implemented for a longer period in order to have resulted in sustained changes in attitudes and behaviours. Some suggested that if the programme were not continued, the community would regress into pre-programme violenceand alcohol-related practices. At least one female PRI representative called for a focus on the young, and notably young men and boys, among whom alcohol abuse had already been initiated. 


\section{Chapter 6 \\ Effect of the intervention programme among community members}

This chapter presents findings with regard to the effect of the intervention on community members' awareness about violence-related matters; gender role attitudes; and attitudes justifying intimate partner violence, men's controlling behaviour over their wife; and experience (women) and perpetration (men) of intimate partner violence. We supplement these findings with qualitative findings on changes, if any, in attitudes and practices noted by community members from intervention villages, in their narratives at base- and endline, respectively.

\section{Methodology}

To ascertain the degree of change in indicators attributable to exposure to the intervention programme, we used difference-in-differences (DiD) estimators (Ashenfelter 1978; Ashenfelter and Card 1985). The DiD method contrasts the difference in average outcomes in the intervention group before and after exposure to the intervention, with the difference in average outcomes in the comparison group at baseline and endline. In this way, the model isolates the effect of exposure to the intervention by cancelling out the effect of other factors external to the intervention that both sites may have experienced in the period between the baseline and endline surveys-a key assumption of the $\mathrm{DiD}$ model is that other factors external to the intervention that have the potential to affect outcome measures (such as the introduction of new programmes for changing gender attitudes among men and women or programmes for preventing violence against women and girls) affect both the intervention and comparison sites in a similar way. The model also isolates the effect of any pre-existing differences between the intervention and comparison groups. Mathematically, a simple DiD estimator can be represented as $\left(\mathrm{Yt}^{1}-\mathrm{Yt}^{0}\right)-\left(\mathrm{Yc}^{1}-\mathrm{Yc}^{0}\right)$, where, $\mathrm{Yt}^{0}$ and $\mathrm{Yt}^{1}$ are the outcome measures at baseline and endline for those from the intervention sites, and $\mathrm{Yc}^{0}$ and $\mathrm{Yc}^{1}$ are the outcome measures at baseline and endline for those from the comparison sites.

Because non-randomised allocation may result in imbalances in demographic characteristics as well as unobservable differences between treatment arms, baseline demographic characteristics and variables potentially associated with the outcomes were first compared for balance across arms to identify any potential covariates. All data were analysed separately for men and women. Using a combined dataset of baseline and endline data, linear regression was performed to produce means of key outcomes and estimate intervention effect using a DiD approach. We estimate the intervention effect on the following outcome indicators: (i) awareness of violence-related laws and services; (ii) gender-role attitudes and attitudes towards physical and sexual violence within marriage among men and women; (iii) women's experience of emotional, physical or sexual violence; (iv) men's controlling behaviours; and (v) men's alcohol misuse. Standard errors were adjusted for the clustered design of the survey and DiD estimators are presented with $p$ values of statistical tests of significance.

Demographic characteristics and other covariates were not included in the DiD analysis, as no evident differences emerged in the baseline comparison. Checks were performed to confirm that multivariate regression based DiD analysis controlling for potential regressors associated with outcomes produced estimates similar to the simple DiD model.

\section{Effect of exposure to the intervention programme on awareness of violence- related laws and services for women in distress}

One of the objectives of the Do Kadam project was to enhance awareness about the Domestic Violence Act, the fact that perpetrators of intimate partner violence could be prosecuted and jailed, and the availability of services, such as the helpline and short stay home, for women in distress. Findings pertaining to study participants' awareness of these issues at baseline and endline are summarised in Figures 6.1 and 6.2.

As evident from Figure 6.1, in-depth knowledge about the Domestic Violence Act (that is, awareness that the Act exists and that a man may be prosecuted and jailed for violations) was far from universal, and gender differences 
continued to be wide. Among men in the intervention arm, knowledge levels remained unchanged between baseline and endline (60\%); in contrast, surprisingly, among men from the comparison arm, significantly fewer reported knowledge of the law at endline than at baseline (51\% versus 59\%). Although larger proportions of men in intervention than comparison arms reported that they were better informed about laws related to domestic violence now than earlier (see Table 4.5), similar differences were not observed among men when we compared responses at baseline and endline.

Fewer women-one in five-reported knowledge about the Domestic Violence Act and the fact that a man may be prosecuted and jailed for violations (23\% of those in the comparison arm and $27 \%$ of those in the intervention arm). The increase in awareness was significant in both groups, but larger among those in the intervention arm (from $27 \%$ to $40 \%$ ) than in the comparison arm (from $23 \%$ to $31 \%$ ).

Figure 6.1: Percentages of men and women in comparison and intervention villages reporting in-depth knowledge of the Domestic Violence Act, baseline and endline surveys

Men

Women

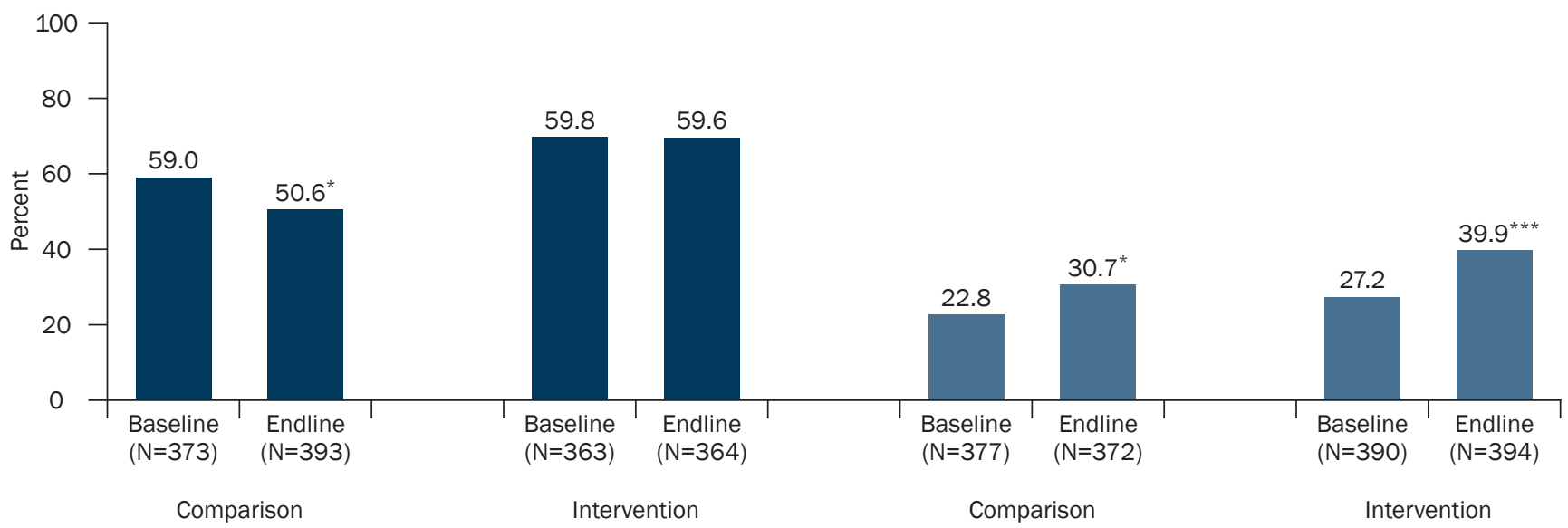

Note: *Indicates that the difference between baseline and endline is significantly different at $p \leq 0.05 ;{ }^{* * *}$ indicates that the difference between baseline and endline is significantly different at $p \leq 0.001$.

Figure 6.2: Percentages of men and women in comparison and intervention villages reporting knowledge of services for women who experience violence (helpline and short stay home), baseline and endline surveys

Men

Women

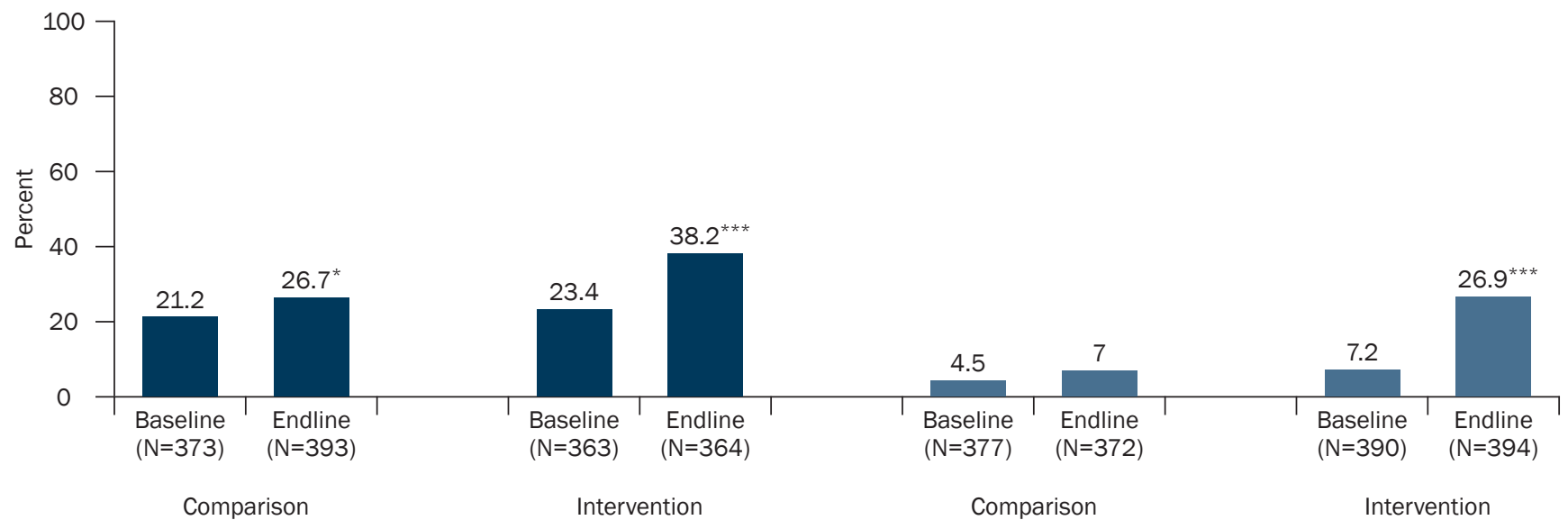

Note: ${ }^{*}$ Indicates that the difference between baseline and endline is significantly different at $p<=0.05 ;{ }^{* *}$ indicates that the difference between baseline and endline is significantly different at $p<=0.001$. 
As seen in Figure 6.2, knowledge about services available for women who have experienced violence, namely the helpline and the short stay home, were reported at baseline by just 21-23 percent of men and 5-7 percent of women. Awareness of these services increased significantly between baseline and endline among men (from 23\% to $38 \%$ ) and women (from $7 \%$ to $27 \%$ ) in intervention arm, but remained virtually unchanged among those in the comparison arm.

The results of the DiD model, as presented in Table 6.1, suggest that changes in levels of awareness of the domestic violence law and the fact that a man may be jailed for violations could not be attributed to exposure to the intervention for either men or women (among men, because of the decline in knowledge levels among those in the comparison arm, the significant change observed is not attributable to the intervention).

At the same time, increases in both men's and especially women's knowledge about services for women who have experienced violence may be attributed to their exposure to the intervention. Indeed, exposure to the intervention accounted for most of the increase in awareness of services over the period of the intervention (DiD estimates, 9.2 among men, 17.2 among women).

Table 6.1: Effect of exposure to the intervention programme on awareness of the Domestic Violence Act and/or services for women in distress: Difference in differences estimators

\begin{tabular}{|c|c|c|c|}
\hline & \multirow{2}{*}{$\frac{\text { Comparison arm }}{\text { Change }^{1}}$} & \multicolumn{2}{|c|}{ Intervention arm } \\
\hline & & Change $^{1}$ & $\begin{array}{l}\text { Impact of intervention } \\
\text { (DiD estimate }{ }^{2} \text { ) }\end{array}$ \\
\hline \multicolumn{4}{|c|}{$\begin{array}{l}\text { Percentages reporting knowledge of DV } \\
\text { Act and the fact that a man can be jailed } \\
\text { for perpetrating VAWG }\end{array}$} \\
\hline Married men (ages 18-54) & -8.4 & -0.2 & $8.2^{+} \quad(0.04)$ \\
\hline Married women ages (18-49) & 7.9 & 12.7 & $4.8 \quad(0.05)$ \\
\hline \multicolumn{4}{|c|}{$\begin{array}{l}\text { Percentages reporting knowledge of } \\
\text { services (short stay home or helpline) for } \\
\text { women in distress }\end{array}$} \\
\hline Married men (ages 18-54) & 5.5 & 14.8 & $9.2^{+} \quad(0.05)$ \\
\hline Married women ages (18-49) & 2.5 & 19.7 & $17.2^{* \star *}(0.04)$ \\
\hline
\end{tabular}

Notes: Values in brackets are standard errors; T-test for DiD estimate $>0$ is significant at: ${ }^{+} p \leq 0.10$ and ${ }^{* * *} p \leq 0.001$, respectively; ${ }^{1}$ Endline value minus baseline value; ${ }^{2}$ With adjusted standard errors.

\section{Effect of exposure to the intervention programme on gender role attitudes and attitudes about the acceptability of physical violence within marriage}

In the intervention, several training sessions for PRI representatives as well as sensitisation sessions and street plays for the community at large sought to orient PRI representatives and community members, respectively, about gender power imbalances, and change prevailing inegalitarian gender role attitudes in general, and attitudes about the acceptability of violence against women in particular. As such, we used two indicators - index of gender egalitarian attitudes and index of acceptability of physical violence within marriage. The index of gender-role attitudes summed the number of egalitarian responses expressed by men and women on a total of seven statements posed to them regarding their attitudes towards gender roles. The index of the acceptability of physical violence within marriage summed the number of seven situations in which physical violence is deemed acceptable by respondents.

Findings pertaining to study participants' gender role attitudes at baseline and endline are summarised in Figure 6.3. Findings show that gender role attitudes did not change over the period between the baseline and the endline interview among respondents from both arms: from an average of 3.0-3.1 among men and 2.6-2.7 among women at baseline to almost identical scores-2.8-2.9 and 2.5-2.7, respectively, at endline. 
Figure 6.3: Mean score on the index of gender egalitarian attitudes obtained by men and women in comparison and intervention villages, baseline and endline surveys

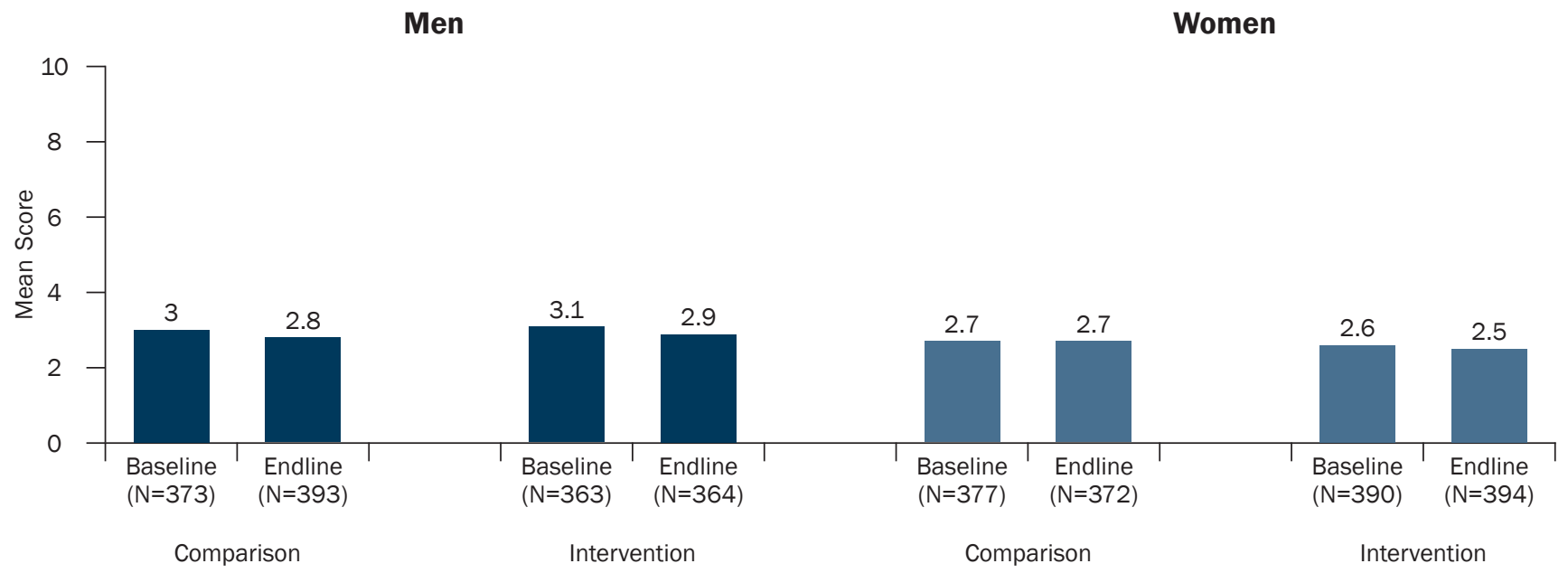

Note: Differences between index values at baseline and endline not significant; Cronbach's alpha BL Men=0.69, Women=0.57; Cronbach's alpha $E L M e n=0.57$, Women $=0.57$.

Figure 6.4: Mean score on the index of acceptability of physical violence within marriage obtained by men and women in comparison and intervention villages, baseline and endline surveys

Men Women

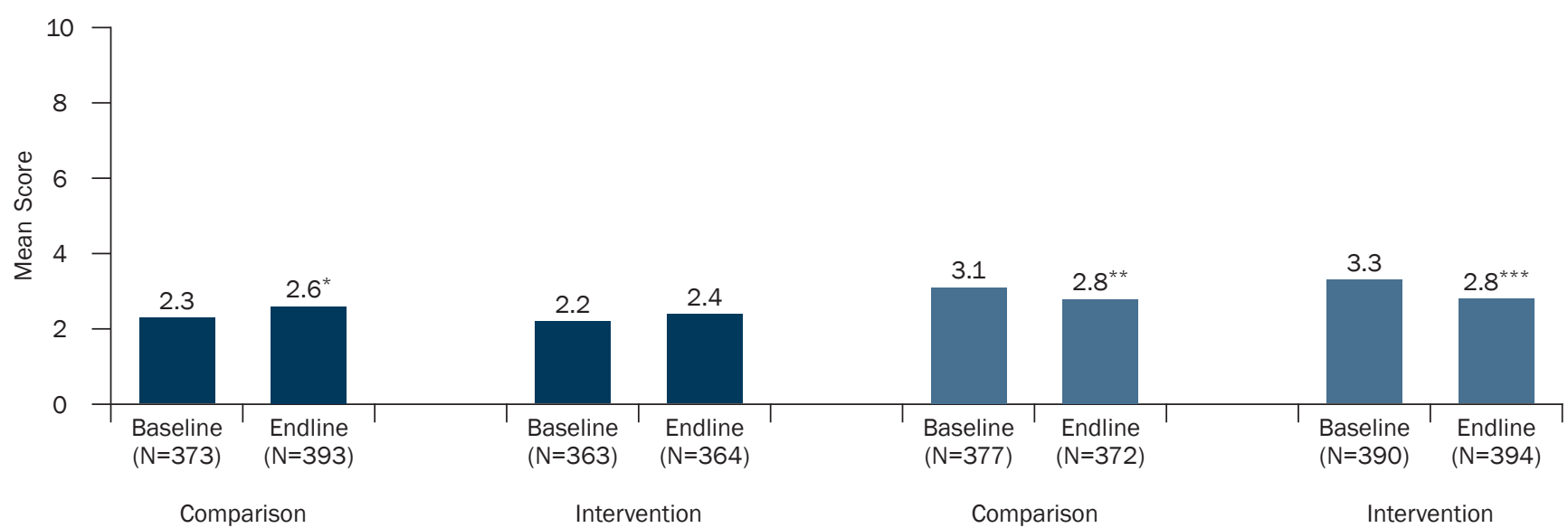

Note: *Indicates that the difference between baseline and endline is significantly different at $p<=0.05 ;{ }^{* *}$ indicates that the difference between baseline and endline is significantly different at $p<=0.01$; ${ }^{* * *}$ indicates that the difference between baseline and endline is significantly different at $p<=0.001$; Cronbach's alpha BL Men=0.72, Women=0.73; Cronbach's alpha EL Men=0.69, Women=0.71.

Findings presented in Figure 6.4 indicate that the number of situations in which respondents justified physical violence within marriage remained largely unchanged between baseline and endline among men from both arms (2.2-2.3 at baseline; $2.4-2.6$ at endline) but declined significantly among women from both arms, from 3.1 to 2.8 among women in the comparison arm, and from 3.3 to 2.8 among those in the intervention arm.

The results of the DiD models, as presented in Table 6.2, confirm that the intervention failed to have any effect on gender role attitudes and attitudes about the acceptability of physical violence in various situations within marriage. 
Table 6.2: Effect of exposure to the intervention programme on gender role attitudes and attitudes about the acceptability of physical violence in marriage: Difference in differences estimators

\begin{tabular}{|c|c|c|c|}
\hline & \multirow{2}{*}{$\begin{array}{c}\text { Comparison arm } \\
\text { Change }^{1}\end{array}$} & \multicolumn{2}{|c|}{ Intervention arm } \\
\hline & & Change $^{1}$ & $\begin{array}{l}\text { Impact of intervention } \\
\left.\quad \text { (DiD estimate }{ }^{2}\right)\end{array}$ \\
\hline \multicolumn{4}{|c|}{ A. Married men (ages 18-54) } \\
\hline Index of gender egalitarian attitudes & -0.2 & -0.2 & $-0.05(0.21)$ \\
\hline $\begin{array}{l}\text { Index of acceptability of physical violence } \\
\text { within marriage }\end{array}$ & 0.3 & 0.2 & $-0.07(0.23)$ \\
\hline \multicolumn{4}{|c|}{ B. Married women ages (18-49) } \\
\hline Index of gender egalitarian attitudes & 0.03 & -0.07 & $-0.09(0.19)$ \\
\hline $\begin{array}{l}\text { Index of acceptability of physical violence } \\
\text { within marriage }\end{array}$ & -0.3 & -0.5 & $-0.1(0.20)$ \\
\hline
\end{tabular}

Notes: Values in brackets are standard errors; ${ }^{1}$ Endline value minus baseline value; ${ }^{2}$ With adjusted standard errors.

A comparison of gender role attitudes displayed by the participants in in-depth interviews suggests a mixed picture. Of the five men who reported unequal gender role attitudes at baseline, the narratives of two suggested no change in gender role attitudes and three suggested a shift towards more egalitarian attitudes. They explained their reasons thus:

Baseline response: In today's time, men and women are not alike. A man is the one who rules at home. A woman has to get permission from him for everything because he is the head of the family and the one who earns money and fulfills the family's needs.

Endline response: Now people are educated. Earlier they would stop women from doing many things, like even going to school... I think there are two types of human beings, one is man and one is woman, so why should we differentiate between them? What is it that a woman cannot do that a man can? Of course they should be equal. [Male, aged 37, completed Class 15, ID30]

Baseline response: No, they are not alike because a woman does only household work. She cannot go out, work and earn money. All this is done by a man only because she does not have that much freedom and she is asked to stay at home only........... A woman could also be allowed to go out and earn money but she should also not take advantage of this freedom, she should not do anything wrong that can bring insult to their family in the society........ Yes, a man has all the rights because he is a man and he can do anything being a man. He is the one who goes out and earns money and fulfills all the needs of the family, that's why people of the family listen to what he says. A woman only stays at home and does household chores only, so she has to follow what her husband says. There is a restriction on woman going out because if a woman goes out much then this can be insulting for her in the society, people start talking bad about her.

Endline response: Men and women should be equal because this is what the government says. The government is giving more value to the woman.... Another reason for a woman to be allowed to go out and earn is because a man has 10 people in his family so faces difficulty in managing the expenses. So we have to do something so that we can eat. That's why there should be participation of both man and woman. [Male, aged 34, completed Class 8, ID34]

Women were more likely than men to acknowledge the injustice of unequal gender roles even at baseline, with six of the ten participants reporting that women should have the same rights as men but did not, and this attitude persisted at both baseline and endline (among the four women who discussed gender role attitudes at endline as well), for example:

Baseline response: Yes, they are equal.... Whatever a man does, a woman can also do. A man goes out to work, a woman can also go out to work.... Yes it is true that a man gets more authority, women cannot go anywhere by themselves whereas men can go out freely. Men come home from work and if they want to 
go anywhere they can so that is why they get more authority in society. ... it is wrong, when a woman can do everything a man does then why should he get all the rights? Why doesn't a woman get equal rights?

Endline response: Yes, they should be equal. A woman can do all the things that a man can do. She can do all the jobs and tasks, she can be educated and learn how to read and write.... A woman can do everything that a man can do, so she should also be getting the same rights as a man does.... A woman does the same amount of work a man does, she also educates her children and more, that is why they should be given equal rights. [Female, aged 32, completed Class 10, ID22]

With regard to the acceptability of marital violence, in both baseline and endline surveys, men and women suggested that while it was preferable to explain to a woman when she errs, violence was justified in some circumstances. For example, of the five men and six women who discussed this issue, all reported attitudes justifying men's entitlement to beat their wife in some circumstances even at endline, for example:

Baseline response: If a woman has illicit relations with some other man then in such a situation it is right to do violence against her because the society also does not give her any authority to do such things. Like this, if a wife uses any kind of intoxicant then it is also right to do violence against her, we see that there are many women who take tobacco or Khaini. If she does not listen to her husband or if she goes out without asking her husband or if she does not do household work in a timely way, then in all these situations, first she should be made to understand, because it is possible that she has some constraint because of which she is unable to do her work. Till then, one should not do any kind of violence on her.

Endline response: Yes, last time I said that if she uses any intoxicants then it is right to beat her, but will she quit it by her husband's scolding? If someone has caught the habit then she will never quit it. If you give her some knowledge about its side effect then she may quit, otherwise she will keep on taking it.... last time I said that first we should make her understand if she makes any mistakes and should give her a chance to improve herself, If she still does not understand, then we are left with only one option that is to beat her.... But will she be persuaded by violation? I don't think so. [Male, aged 38, completed Class 9, ID38]

Baseline response: One shouldn't hit in every situation.... The husband should make her understand, why would she listen to him if he hits her? For example, if she has relations with another person. This is wrong and then everyone will talk about his wife.... In such cases, she should be hit.

Endline response: The man thinks that he has beaten his wife because she has not done some work but it is not right. Beating is not justified, it is really bad and he should not do it. If she has gone for some legitimate work then the husband should never beat her. Even if he thinks that she has gone out without having legitimate work to do, then also violence is not a solution. He should make her understand properly and never beat her. But if a woman continues to do wrong things then her husband has the right to beat her, violence is justified in such a situation. [Female, aged 24, no education, ID25]

As in the case of gender role attitudes, all five men who discussed the topic of men's controlling behaviour at both times upheld men's right to control their wife, indicating no change in attitudes justifying such behaviour following the implementation of the intervention. The majority perception at both times among men was that men are their wife's guardian, as follows:

Baseline response: Men are responsible for earning money and feeding the family. Being the head of the family, he has the right to take all the decisions of the family. The wife should look after the whole house, should not do anything without the permission of her husband, should not go anywhere without asking him, and should serve her parents-in-law. The husband is the one who earns money and fulfils all the needs of the household and feeds his wife too. He takes care of her in every way and fulfils her needs, that's why he is her guardian. This is right and I also completely agree with this that a husband is the guardian of his wife.

Endline response: Yes, after marriage the husband is the only guardian of the wife......I think it is right because if the husband is not the guardian then who will be? If she has a husband then he is her guardian, and if she doesn't have a husband, then who will be her guardian, especially if she doesn't have any children. [Male, aged 37, no education, ID35]

In contrast, women at both times held more egalitarian views about men as guardians of their wife. Of the four women who discussed this issue in both interviews, one believed in mutual 'guardianship' at both times, and three held inegalitarian views at baseline, but more egalitarian ones by endline. As one of this group narrated: 
Baseline response: The woman has less knowledge and the husband has more. As the husband understands things better, he is called the wife's guardian.

Endline response: Both should be each other's guardian. [Female, aged 30, no education, ID23]

\section{Effect of exposure to the intervention programme on men's controlling behaviours over their wife and perpetration of marital violence}

Key objectives of the Do Kadam project were to build more egalitarian marital relationships, and specifically, to reduce men's controlling behaviours over their wife on the one hand, and reduce the perpetration (men)/experience (women) of physical, emotional and sexual violence on the other. To measure the effect of the intervention on these practices, we used four indicators. One was an index of men's controlling behaviour, which summed five possible practices through which men and women reported that they/their husband controlled their wife/them (preventing the wife from seeing friends, restricting her contact with natal family, insisting on knowing her whereabouts at all times, getting angry if she speaks to a man, and expecting her to obtain his permission to seek health care for herself). The remaining three sets of indicators reflect responses about the perpetration (men) and experience (women) of physical, emotional, and sexual violence in the six months preceding the baseline and endline interviews.

Findings pertaining to controlling behaviours of men, as reported by study participants at baseline and endline, are summarised in Figure 6.5. Findings show controlling behaviours as reported by men fell significantly in both the comparison and intervention arms (from 1.5 to 1.3, and from 1.7 to 1.4, respectively). For women in contrast, the score increased significantly among those in the comparison arm (from 1.3 to 1.6) but remained unchanged among those in the intervention arm (1.5-1.6).

Figure 6.5: Mean score on the index of men's controlling behaviours over their wife, as reported by men and women in comparison and intervention villages, baseline and endline surveys

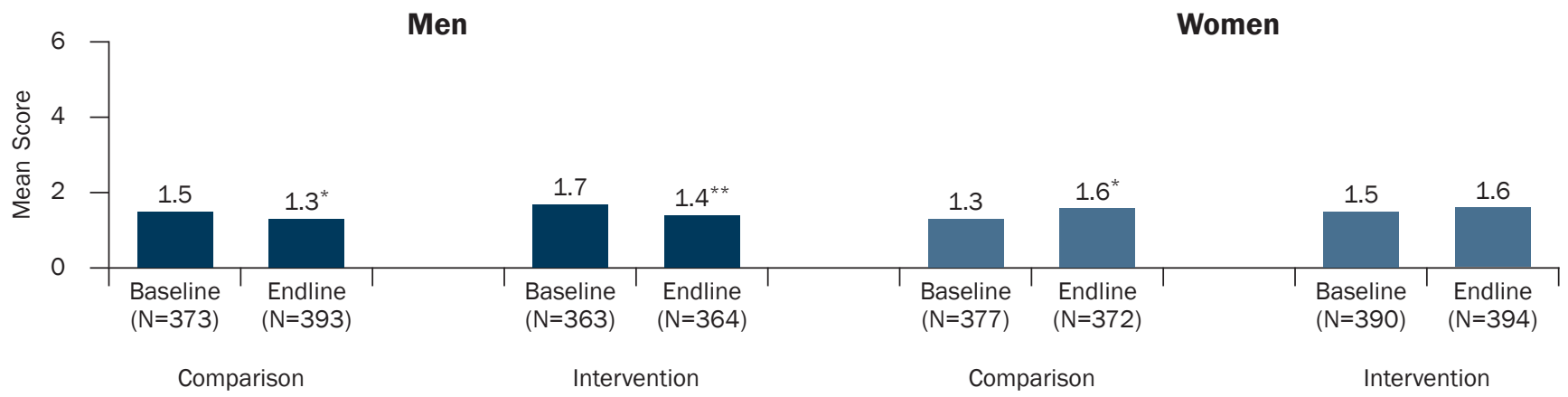

Note: *Indicates that the difference between baseline and endline is significantly different at $p<=0.05 ;{ }^{* *}$ indicates that the difference between baseline and endline is significantly different at $p<=0.01$; Cronbach's alpha BL Men=0.65, Women=0.71; Cronbach's alpha EL Men=0.63, Women $=0.71$.

The situation with regard to men's perpetration and women's experience of physical, emotional, and sexual violence in the six months preceding the baseline and endline interviews, respectively, is reported in Figures 6.6, 6.7, and 6.8. As in the case of attitudes and controlling behaviours, findings suggest that, by and large, the perpetration and experience of violence remained virtually unchanged between baseline and endline. In particular, as evident from Figure 6.6, physical violence remained unchanged. For example, about one-fifth of men from both arms reported the perpetration of physical violence on their wife in the six months preceding the two surveys $(20-22 \%$ at baseline to $17-19 \%$ at endline). Somewhat more women from both arms reported that their husband had perpetrated physical violence against them in the six months (25\%) prior to the baseline interview, and percentages remained largely unchanged (23-25\%) at endline.

In contrast, there was a significant decline in emotional violence in the six months preceding the interview at baseline and endline, among both men and women: among men, from $82 \%$ to $65 \%$ among those in the comparison arm, and from $66 \%$ to $55 \%$ among those in the intervention arm; and among women, from $73 \%$ to $66 \%$ among those in the comparison arm, and from $71 \%$ to $57 \%$ among those in the intervention arm (Figure 6.7). 
Responses regarding the perpetration and experience of sexual violence differed considerably between men and women (Figure 6.8). Among men, at baseline, there was a huge difference in reports of perpetration of sexual violence: 44 percent of those in the comparison arm, and 26 percent of those in the intervention arm; by endline, percentages had fallen significantly in both arms, to 27 percent and 18 percent, respectively. In contrast, among women, while percentages reporting the experience of sexual violence remained unchanged between baseline and endline among those in the intervention arm (43\% at both times), they actually increased among those in the comparison arm (from $42 \%$ to $54 \%$ ).

Findings of the DiD model, presented in Table 6.3, reiterate that the intervention failed to have any effect on the men's controlling behaviours over their wife or on the perpetration and experience of violence-physical, emotional, and sexual-among study participants. Indeed, among men, percentages reporting the perpetration of emotional violence fell more steeply among those in the comparison than the intervention arm; and among women, the

Figure 6.6: Percentages reporting the perpetration (men) and experience (women) of physical violence within marriage in the six months preceding each interview, as reported by men and women in comparison and intervention villages, baseline and endline surveys

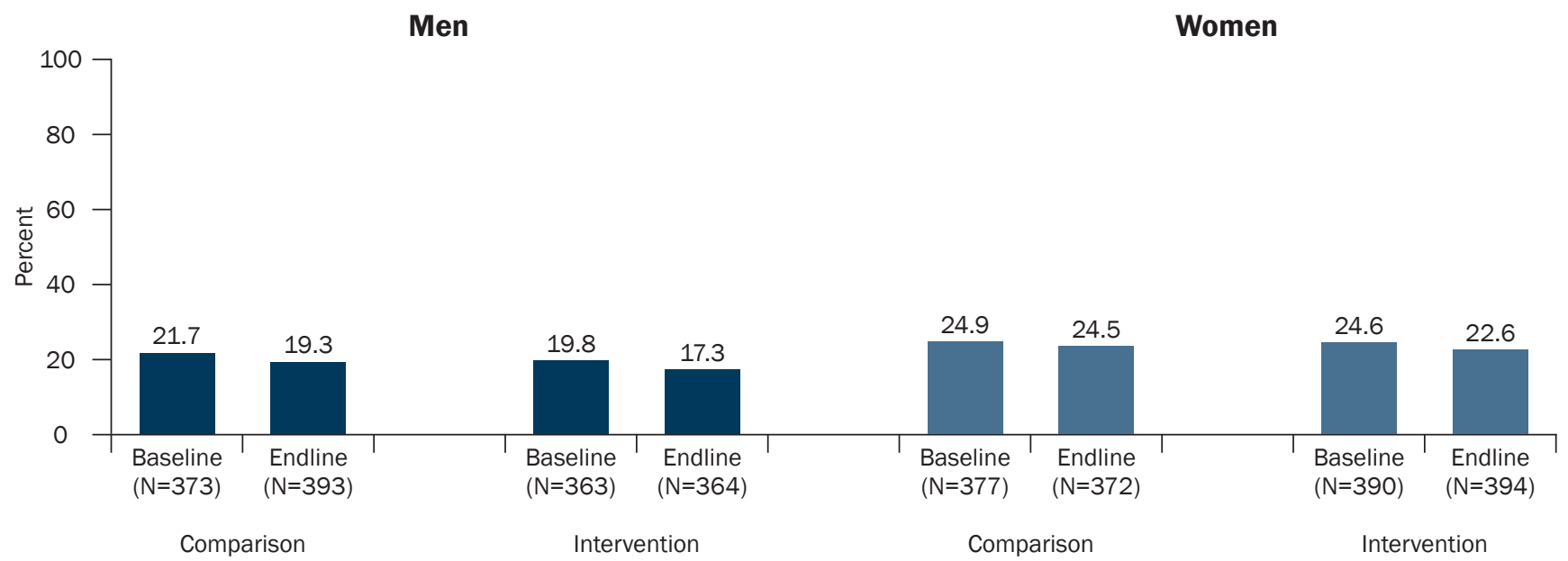

Figure 6.7: Percentages reporting the perpetration (men) and experience (women) of emotional violence within marriage in the six months preceding each interview, as reported by men and women in comparison and intervention villages, baseline and endline surveys

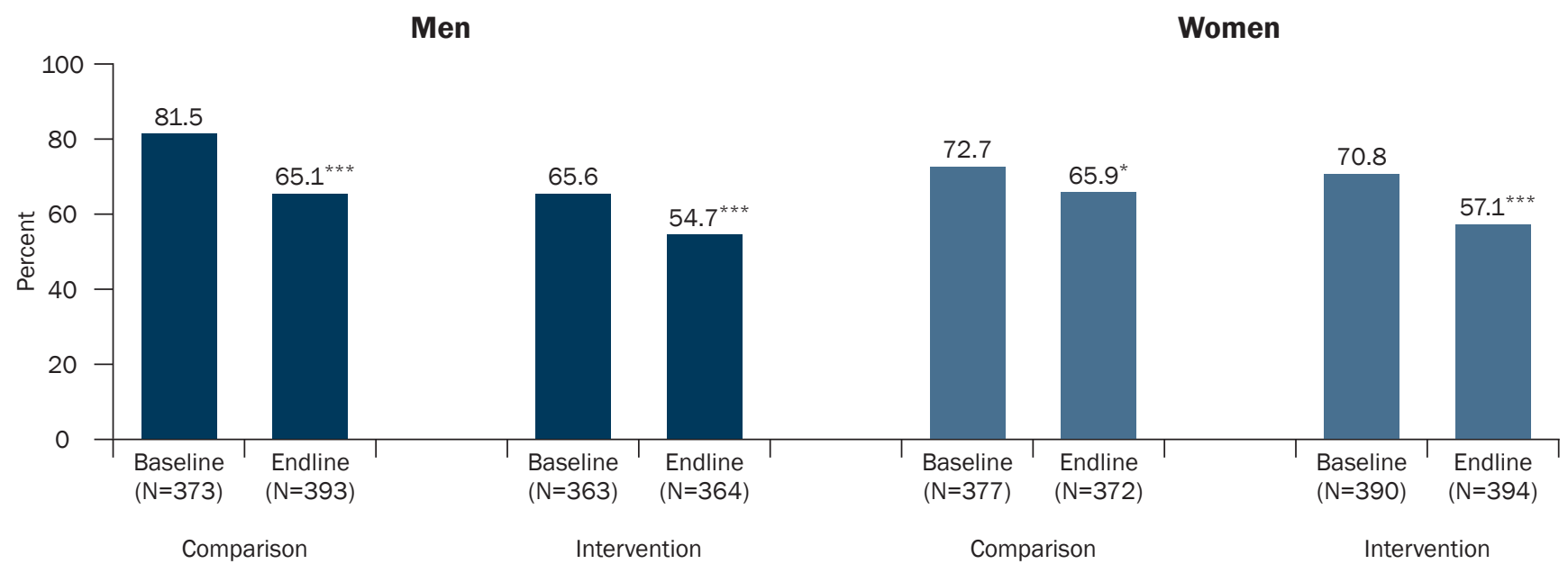

Note: ${ }^{*}$ Indicates that the difference between baseline and endline is significantly different at $p<=0.05 ;{ }^{* *}$ indicates that the difference between baseline and endline is significantly different at $p<=0.001$. 
Figure 6.8: Percentages reporting the perpetration (men) and experience (women) of sexual violence within marriage in the six months preceding each interview, as reported by men and women in comparison and intervention villages, baseline and endline surveys

Men

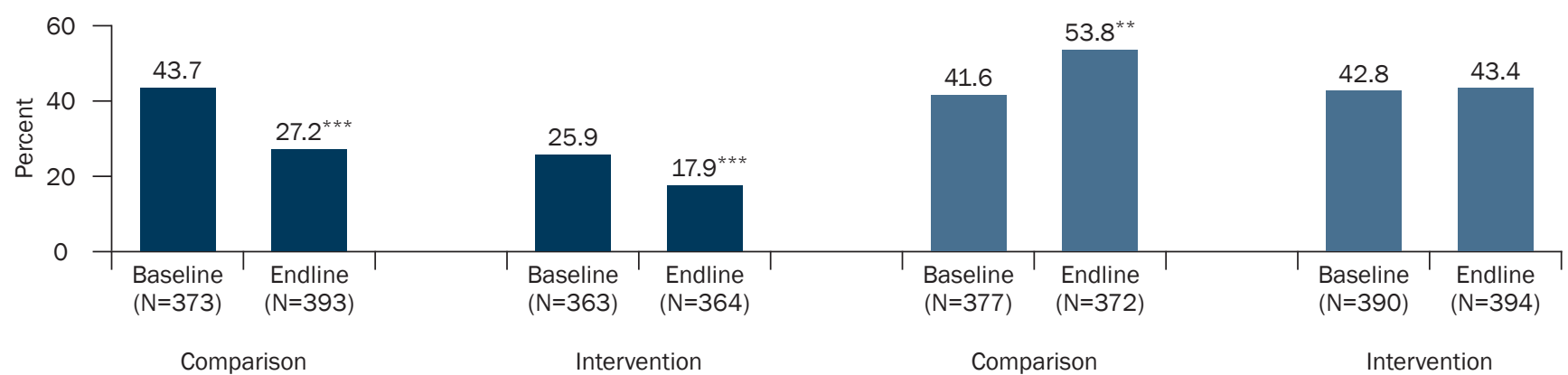

Note: ${ }^{* *}$ Indicates that the difference between baseline and endline is significantly different at $p \leq 0.01 ;{ }^{* *}$ indicates that the difference between baseline and endline is significantly different at $p \leq 0.001$.

Table 6.3: Effect of exposure to the intervention programme on men's controlling behaviours and marital violence, as reported by men and women: Difference in differences estimators

\begin{tabular}{|c|c|c|c|}
\hline & \multirow{2}{*}{$\begin{array}{c}\text { Comparison arm } \\
\text { Change }^{1}\end{array}$} & \multicolumn{2}{|c|}{ Intervention arm } \\
\hline & & Change $^{1}$ & $\begin{array}{l}\text { Impact of intervention } \\
\text { (DiD estimate }{ }^{2} \text { ) }\end{array}$ \\
\hline \multicolumn{4}{|c|}{ A. Married men (ages 18-54) } \\
\hline Men's controlling behaviour & -0.2 & -0.3 & $-0.05(0.16)$ \\
\hline \multicolumn{4}{|l|}{ Physical violence } \\
\hline Physical violence, six months & -2.4 & -2.5 & $-0.1(0.05)$ \\
\hline \multicolumn{4}{|l|}{ Emotional violence } \\
\hline Emotional violence, six months & -16.4 & -10.9 & $5.5(0.07)$ \\
\hline \multicolumn{4}{|l|}{ Sexual violence } \\
\hline Sexual violence, six months & -16.5 & -8.0 & $8.4^{+}(0.05)$ \\
\hline \multicolumn{4}{|c|}{ B. Married women ages (18-49) } \\
\hline Husband's controlling behaviour & 0.3 & 0.1 & $-0.19(0.16)$ \\
\hline \multicolumn{4}{|l|}{ Physical violence } \\
\hline Physical violence, six months & 0.4 & -2.0 & $-1.6(0.04)$ \\
\hline \multicolumn{4}{|l|}{ Emotional violence } \\
\hline Emotional violence, six months & -6.8 & -13.7 & $-6.8(0.07)$ \\
\hline \multicolumn{4}{|l|}{ Sexual violence } \\
\hline Sexual violence, six months & 12.2 & 0.6 & $-11.5^{*}(0.05)$ \\
\hline
\end{tabular}

Notes: Values in brackets are standard errors; T-test for DiD estimate $>0$ is significant at: ${ }^{+} p \leq 0.10$ and ${ }^{*} p \leq 0.05$, respectively; ${ }^{1}$ Endline value minus baseline value; ${ }^{2}$ With adjusted standard errors.

experience of sexual violence increased significantly among those in the comparison arm and remained unchanged among those in the intervention arm. This suggests, in both instances, that participation in the intervention did not succeed in reducing violence among those in the intervention arm.

As mentioned in Chapter 1, ten women and ten men were purposively selected for in-depth interview on the basis of their responses to the baseline survey. Of these, two each had reported experiencing (women) or perpetrating (men) severe, moderate, or no violence; and two each reported that their husband/they consumed or did not consume alcohol. We note that some of those who reported alcohol consumption may also have reported the perpetration/ 
experience of marital violence. In all, at the baseline in-depth interview, five men acknowledged perpetrating violence against their wife and eight women reported experiencing such violence. At endline, most men and women who discussed this issue reported that violence persisted, for example:

Baseline response: Sometimes violence happens when she does not listen to what I say or when she does not look after the children properly. I get angry and I beat her but this does not happen regularly, this happens only rarely. Recently, only 4-5 days ago, she did not feed our cattle and in the evening when I came back home the animals were still hungry then I got angry and beat her... But sometimes it happens that I force her to have sex. Sometimes when she is not willing but I want sex, I make forceful relations with her. This also does not happen regularly, it happens rarely. Mostly we make physical relations with both our consent but sometimes a situation arises when I have to make forceful relations with her. Around 5-6 month back I made forceful sexual relations with her, even then she didn't say anything, just remained quiet.

Endline response: It's been more than a year now since I last slapped her, I have stopped because she does everything properly.... Sometimes I forced her to have sex, she did not want to do that but I forcefully made her do this. Ten times approximately in the last year. [Male, aged 34, completed Class 8, ID34]

Men who reported that they had not beaten their wife suggested moreover that they had not done so as their wife was obedient and gave no cause for violence, for example:

Baseline response: No, I haven't done anything like this ever because there hasn't been any situation because of which I had to do violence against her.

Endline response: No, I haven't done anything like this. She does everything on time and does not give me any reason to complain so why should I do violence against her? [Male, aged 45, completed Class 9, ID38]

Women, likewise, reported no change in their experience of violence. As at baseline, some women reported the experience of physical violence. For example:

Baseline response: Yes, I am afraid of him, when he comes from outside I fear he might hit me, or fear that he has drunk.....If I need to ask his permission to go to my parent's house, first I see how his mood is. If I ask when he is angry then I will be hit so I see and then ask. Regarding money also I ask him only when he is in a good mood....Sometimes, if he is in a bad mood, he slaps me. It happens once or twice a month. About four months ago, he wanted me to sleep with him and I said no so he gave me one slap.... Once, I didn't give him food when he asked for it, so he beat me. It happens every 10-15 days but sometime even once in two days.... He forces me to have sex, and this is the case in all homes.

Endline response: Men beat in anger, that is why I am afraid of my husband. When he is angry I stay away from him. When his anger recedes, I ask if he wants food, etc. Yes, it does happen sometimes even now that he beats me. If I beat the children, he beats me in anger and says, 'why have you beaten the kids?'... Yes he does force me to have sex, I give in, what else can I do? [Female, aged 24, no education, ID25]

\section{Alcohol abuse}

The Do Kadam project also sought to address alcohol abuse, namely to change men's alcohol abuse practice, a practice linked with exacerbating violence. We note that very few women (less than $2 \%$ ) reported alcohol use, thus we focus here on men's practices. To measure the effect of the intervention on these practices, we used the following indicators: men's reports of alcohol consumption at least once a week or more frequently, women's reports of their husband's alcohol consumption at least once a week or more frequently, and women's reports of observing their husband drunk at least once a week.

The findings presented in Figure 6.9 highlight huge gender differences in percentages reporting men's alcohol consumption at both baseline and endline, with women far more likely to acknowledge their husband's alcohol consumption practices than men were to admit to alcohol consumption. There was little change in the practice over the course of the intervention as reported by men (from $27 \%$ to $29-32 \%$ ) and women (from $49 \%$ to $51 \%$ among those in the comparison arm and from $44 \%$ to $41 \%$ among those in the intervention arm). 
Figure 6.9: Percentages reporting men's (men)/husbands' (women) alcohol consumption at least once a week or more frequently, as reported by men and women in comparison and intervention villages, baseline and endline surveys

Men

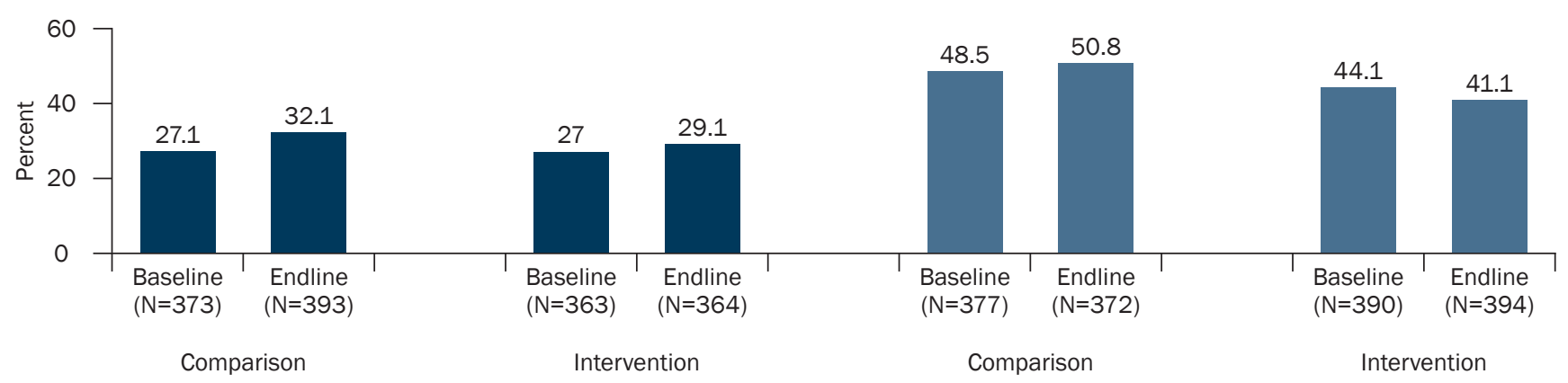

Figure 6.10 presents the percentages of women reporting that they had witnessed their husband drunk at least once in the week preceding the interview. Findings suggest percentages so reporting declined significantly between baseline and endline for women in both groups, nevertheless the decline was steeper among those in the intervention arm (from $38 \%$ to $18 \%$ ) than in the comparison arm (42\% to $30 \%$ ).

Findings of the DiD model, presented in Table 6.4, suggest that the intervention had little or no effect on men's reports of alcohol consumption, but did indeed have an effect on women's reports about their husband's alcohol consumption. Findings from women reveal that the intervention had a significant effect on the frequency of their husband's alcohol consumption, and provide some suggestion of a reduction in their husband's displays of drunkenness.

Reports in in-depth interviews of men's/husband's alcohol consumption also remained fairly unchanged between the two in-depth interviews, although several men suggested that they had reduced their alcohol consumption in the period between the baseline and endline interviews:

Baseline response: Yes, I sometimes consume alcohol. Telling you truly, I drink alcohol 1-2 times I a week. Whenever I drink, I drink a quarter of a bottle only. There is no change in my behaviour after consuming alcohol. I do not drink so much that I get intoxicated and behave differently. I drink only to get relief from physical stress.

Endline response: Yes now I drink just 4-5 times in a month. [Male, aged 27, no education, ID37]

Figure 6.10: Percentages of women reporting that they had witnessed their husband drunk at least once a week in comparison and intervention villages, baseline and endline surveys

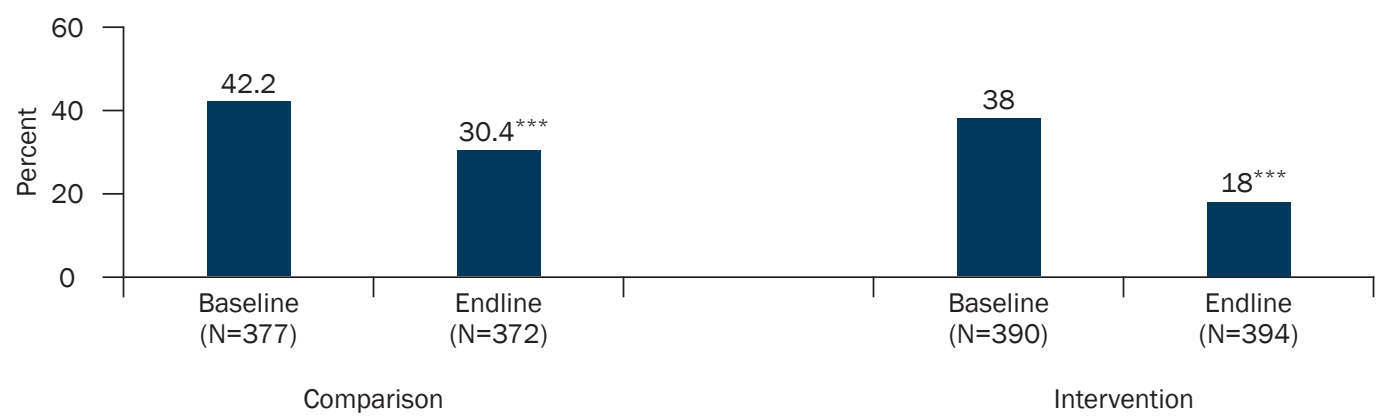

Note: ${ }^{* *}$ Indicates that the difference between baseline and endline is significantly different at $p<=0.001$. 
Table 6.4: Effect of exposure to the intervention programme on men's/husbands' alcohol consumption, as reported by men and women: Difference in differences estimators

\begin{tabular}{|c|c|c|c|}
\hline & \multirow{2}{*}{$\frac{\text { Comparison arm }}{\text { Change }^{1}}$} & \multicolumn{2}{|c|}{ Intervention arm } \\
\hline & & Change $^{1}$ & $\begin{array}{l}\text { Impact of intervention } \\
\text { (DiD estimate }{ }^{2} \text { ) }\end{array}$ \\
\hline \multicolumn{4}{|c|}{ Men's reports } \\
\hline Consumes alcohol at least once a week & 5.0 & 2.1 & $-2.9(0.04)$ \\
\hline \multicolumn{4}{|c|}{ Women's reports } \\
\hline Husband consumes alcohol at least one a week & 2.3 & -3.0 & $-5.3^{*}(0.03)$ \\
\hline $\begin{array}{l}\text { Witnessed husband drunk at least once/week in } \\
\text { past } 12 \text { months }\end{array}$ & -11.8 & -19.9 & $-8.10(0.05)$ \\
\hline
\end{tabular}

Notes: Values in brackets are standard errors; T-test for DiD estimate >0 is significant at: ${ }^{*} p \leq 0.05$; ${ }^{1}$ Endline value minus baseline value; ${ }^{2}$ With adjusted standard errors

Women's reports also suggest that some husbands reduced their alcohol consumption, and others continued to consume alcohol. Of the five women who reported on their husband's alcohol consumption at baseline and endline, one reported that it had reduced, while others suggested that there had been no change. For example:

Baseline response: Once a month.

Endline response: He may drink after an interval of many days. Only if someone forces him to drink. [Female, aged 25, no education, ID24]

Baseline response: He drinks every day. He fights, hits me, and all that when he drinks. When he is not drinking then he doesn't say anything. Then he is completely okay.

Endline response: Never misses a day. Doesn't let me do anything unless he gets his drink.... After drinking he barks, fights, uses abusive words. [Female, aged 30, no education, ID26]

\section{Summary}

The intervention was conducted in a poorly developed and hugely traditional setting, in which educational attainment levels were typically modest, gender norms hierarchical and violence against women widely accepted. Our evaluation confirms the huge challenges faced in such a context in changing norms and behaviours relating to marital power differences and the pervasiveness of marital violence. It shows that the seven-month intervention intended to engage locally elected representatives in changing norms and behaviours did not succeed in doing so. Although changes between baseline and endline responses were significant on several outcome indicators, there was little evidence, after accounting for secular changes and changes due to other external factors in comparison and intervention arms, that key outcome indicators had been positively affected.

Effect were however observed in a couple of indicators. For one, although the intervention had no effect on raising community members' knowledge about the law and penalties for violating it, it had a significant effect on raising awareness about support services for women who experienced violence among both men and women.

Second, while exposure to the intervention had little or no effect on men's reports of alcohol consumption, it did indeed have an effect on women's reports about their husband's alcohol consumption. Findings from women suggest that the intervention had a significant effect on reducing the frequency of their husband's alcohol consumption.

Other key outcome indicators were not affected by exposure to the intervention, as evident from survey findings and corroborated by findings from in-depth interviews with men and women. Traditional gender norms, as measured by attitudes towards gender roles and violence against women, remained strong and virtually unchanged in both arms. 
Husband's controlling behaviours were also unaffected by exposure to the intervention. As observed in Chapter 2 , at baseline, large proportions of men and women reported that they/their husband controlled the wife's movements and actions, and at endline, there was no evidence of a decline in these practices in either arms.

Finally, marital violence remained widespread in intervention and comparison arms. About one-fifth of men and onesixth of women reported physical violence at both times. Men's perpetration of sexual violence fell significantly in both arms, while women's experience of sexual violence actually increased among those in the comparison arm and remained unchanged in the intervention arm. Emotional violence also declined significantly among both men and women in both arms. There was no evidence however that it was exposure to the intervention that was responsible for these changes. 


\section{Chapter 7 \\ Summary and recommendations}

This chapter summarises the major findings of the project with regard to the acceptability and effectiveness of the Do Kadam Barabari Ki Ore model. The model was implemented at the community-level to sensitise and build the skills of locally elected representatives to act as change agents and orient community members about issues related to gender roles, alcohol abuse, and violence against women, and to change attitudes and practices surrounding violence against women. This chapter also highlights lessons learned for programme implementation, sustainability, and up-scaling.

\section{Summary}

We implemented a model that oriented PRI members about such social issues as gender imbalances, alcohol abuse, and marital violence. We also built their commitment, communications skills and organisational skills to act as change agents to transform community attitudes and practices on these issues. Our evaluation sought to assess the extent to which this model succeeded in changing community-level attitudes and practices as well as among PRI representatives.

The intervention was delivered over a period of seven months in two Panchayat areas of Patna district, Bihar. The intervention included several components-orientation and capacity-building of PRI representatives on a regular basis starting, with a three-day training programme followed by fortnightly training and planning sessions; and support for PRI representatives to hold sensitisation sessions with their communities and street plays intended to encourage a dialogue about gender roles, alcohol abuse, and marital violence; and to intervene in cases of alcohol abuse and violence against women. Events such as community-level sensitisation sessions and street plays were held fortnightly in each Panchayat area. Programme implementation was accompanied by a strong monitoring component.

A quasi-experimental research design, using a mixed method approach, was used to evaluate the effectiveness of the intervention. Baseline surveys were conducted among a randomly selected sample of married women aged 18-49, and married men aged 18-54 residing in intervention sites, and a matched control site comprising two Panchayat areas of Patna district prior to the implementation of the intervention. We also conducted in-depth interviews with selected men and women from the community and selected PRI representatives to better understand their perspectives and experiences. After the intervention was completed, in addition, that is, about nine months following the baseline assessment, we repeated the survey among a freshly selected cross-section of men and women from households enumerated during the baseline survey, and repeated in-depth interviews with the men, women and PRI representatives whom we had interviewed at baseline. We obtained a response rate of over $90 \%$ among men and women at both baseline and endline; a total of 736 men and 767 women were interviewed in the baseline survey, and 757 and 766, respectively, in the endline survey. Repeated in-depth interviews were held moreover with 10 men and 10 women from the community and 16 of the 18 PRI representatives ( 9 men and 7 of 9 women).

\section{Programme exposure}

The programme did indeed reach a large number of community members. More than two in three men and three in five women had heard about the Do Kadam programme. Awareness of activities varied considerably both by gender and by type of activity. Men were more likely than women to report awareness, and more study participants reported awareness of community-level sensitisation sessions and especially street plays than other activities. Relatively few study participants reported interventions by PRI representatives in cases of violence against women or alcohol abuse.

Participation in community-level sensitisation sessions and street plays was also reported by more men than women, both in the survey and in in-depth interviews. In the survey, for example, more than one-third of men had attended a street play and one-quarter a sensitisation session organised by the programme, compared to about one-fifth of 
women. Reasons for not attending project meetings and events differed for men and women. The most prominent reasons expressed by men related to time conflicts, namely that the timing of events was unsuitable and that their work responsibilities conflicted with the timing of events. Among women, while similar reasons were expressed, many women reported that the location of the event was unsuitable for them, that is, either too far away or in too public a place. Many also reported that their husband or other family members had not permitted them to attend. At the same time, large proportions of men and women who attended meetings and street plays could recall their messages, notably those relating to violence against women and alcohol abuse. In in-depth interviews, too, those who had any exposure to the programme indicated that violence was a key theme of meetings and nukkad nataks (street plays), along with other social issues such as child marriage and gender biased sex selection.

With regard to such process indicators as interaction with PRI representatives, and PRI representatives' discourses on or interventions on issues related to gender equality, violence against women and alcohol abuse, findings confirmed that discourses delivered by PRIs on such social issues as violence against women, gender roles, and alcohol abuse increased very significantly during the intervention period. The intervention succeeded in increasing the participation of community members in meetings and other events organised by PRI representatives as part of their regular duties, and far more significantly increased participation in community-level sensitisation sessions and events held by PRI representatives as part of the Do Kadam programme.

Acceptability was noted by PRI representatives as well. All had attended the Do Kadam training programmes, most had participated in organising community-level sensitisation sessions and street plays, and several reported personal experience intervening in cases of alcohol abuse or marital violence, or holding protests to ban the sale of alcohol in their constituencies. Most narratives were hugely positive, and described in detail the content and messages of the training programmes, meetings, and street plays.

\section{Programme effectiveness}

Four key programme objectives were to engage locally elected representatives in raising community members' awareness about the DV Act and services available for women in distress, reversing discriminatory gender role attitudes and attitudes about the acceptability of violence against women, and reducing men's controlling behaviours towards their wife as well as the perpetration (men) and experience of marital violence, and reducing men's alcohol abuse. Findings indicate that participation in the seven-month intervention did not succeed in achieving all of these objectives. Although changes between baseline and endline responses were significant on several outcome indicators, there was little evidence, after accounting for secular changes and changes due to other external factors in comparison and intervention arms that key outcome indicators had been positively affected.

\section{- Awareness of the DV Act and services for women in distress}

Although the intervention had no effect on raising community members' knowledge about DV Act, including penalties for violating it, it had contributed significantly to enhancing women's and men's awareness about services available for women in distress.

\section{- Men's alcohol abuse}

The intervention clearly resulted in a reduction in alcohol abuse among men in the intervention arm. While exposure to the intervention had no effect on men's reports about frequency of alcohol consumption, it did have an effect on women's reports of the frequency of their husband's alcohol use.

\section{- Gender role attitudes and attitudes about the acceptability of marital violence}

Other key outcome indicators were not affected by exposure to the intervention, as evident from survey findings and corroborated by findings from in-depth interviews with men and women. Traditional gender norms, as measured by attitudes towards gender roles and violence against women, remained strong and virtually unchanged in both arms.

\section{- Men's controlling behaviour and perpetration of marital violence}

Neither men's controlling behaviours nor men's perpetration and women's experience of violence within marriage were affected by exposure to the intervention. As at baseline, large proportions of men and women reported that 
they/their husband controlled the wife's movements and actions, and at endline, there was no evidence of a decline in these practices in either arm. Likewise, marital violence remained widespread in intervention and comparison arms. About one-fifth of men and one-sixth of women reported physical violence in the six months preceding the baseline and endline interviews, respectively. Men's perpetration of sexual violence fell significantly in both arms, while women's experience of sexual violence actually increased among those in the comparison arm and remained unchanged in the intervention arm. Emotional violence also declined significantly among both men and women in both arms. There was no evidence however that it was exposure to the intervention that was responsible for these changes.

\section{Self-perceived changes in the six months preceding the endline interview}

Evidence of the effectiveness of the programme also comes from community members' own assessments in the endline survey of changes in their life in the six months preceding the endline survey, roughly the period covered by the intervention. A larger proportion of study participants in the intervention than comparison arm perceived positive changes in this period. Specifically, study participants in the intervention arm were more likely than their counterparts in the comparison arm to report they were better informed about violence-related matters and more conscious about alcohol misuse than before. Women from the study arm, moreover, were more likely than their counterparts from the comparison arm to report confidence about seeking help in case of violence and improvements in marital relations. Moreover, while somewhat larger proportions of men and women in the intervention rather than comparison arm perceived that violence against women had declined at the communitylevel, few men and women from both intervention and comparison arms perceived any change in the ease with which alcohol could be procured in their community.

\section{Self-perceived changes observed by PRI representatives}

PRI representatives noted considerable changes in their own gender role attitudes, attitudes about marital violence, and attitudes about alcohol abuse. Several male representatives also reported that they had reduced their alcohol misuse, had stopped committing violence against their wife, and generally experienced more egalitarian marital relations: helping their wife with housework, spending more time with family; acknowledging their wife's right to make decisions, move around freely, and control money. While a few female PRI representatives acknowledged the link between exposure to the Do Kadam programme and a reduction in the experience of marital violence, somewhat more suggested that the change had occurred for reasons unrelated to the programme.

Fewer PRI representatives commented on changes in gender role attitudes, marital violence, and alcohol abuse at the community-level. Although some did note these changes, several implied that the programme should have been implemented for a longer period in order to have resulted in sustained changes in attitudes and behaviours and expressed fear that if the programme were not continued, the community would regress into pre-programme violence- and alcohol-related practices, and the young, notably young men and boys would not benefit from its messages about behaviour change.

\section{Factors compromising programme effectiveness}

The intervention was conducted in a poorly developed and hugely traditional setting, in which educational attainment levels were typically modest, gender norms hierarchical, and violence against women pervasive and widely accepted. Our evaluation confirms the huge challenges faced in such a context in changing norms and behaviours relating to marital power differences and the pervasiveness of marital violence, and may have compromised the effectiveness of the programme.

First, we acknowledge the uneven reach of the programme. In this context in which women's mobility is hugely curtailed, it is no surprise that the intervention reached more men than women. And given wide power differentials, many women reported that the location of the event was inappropriate for them or that their husband or other family members had refused to permit them to attend the event.

Second, as seen in Chapter 5, PRI representatives themselves came from the same community as others, and were influenced by the same sociocultural context. As such, many were poorly educated and uncomfortable speaking in public forums, communications skills were limited, gender disparities persisted, and female PRI members had far 
less authority than their male counterparts. Moreover, many PRI representatives adhered to unequal gender norms, perceived that men were entitled to perpetrate marital violence and exercise control over their wife. Moreover, while PRI representatives are mandated to pay as much attention to infrastructure development and so on as for social issues, these latter were not prioritised and PRI representatives did not typically perceive that changing attitudes and behaviours comprised part of their responsibilities. As such, their ability to impart new messages relating to gender roles and violence against women was limited, requiring considerable support from $\mathrm{C} 3$, the implementing agency and partner.

Third, we acknowledge additional concerns that may have detracted from the overall impact of participation in the intervention. For one, the intervention lasted just seven months, and held events approximately twice a month in each village. While this may have been sufficient to encourage a questioning of traditional norms and practices if exposure were regular and engaged a large proportion of community members, the irregular exposure of most community members to the events may have limited the effect that the intervention had on the community.

Finally, we also concede that the community-level activities we designed have not attracted community members fully, and prior efforts may have been needed to identify the kinds of activities that may have appealed to communities. Perhaps single-sex events and/or events directed at different groups, for example, farmers or parents of school-going children, or addressing specific themes of interest, such as, for example, livelihoods opportunities and social sector programmes for which community members may be eligible, or venues where subgroups typically assemble, for example, meetings called by members of various mandals or meetings held by frontline health workers for women with young children, would have been a better entry point through which to approach the topic of inegalitarian gender roles and violence against women.

\section{Recommendations}

The Do Kadam Barabari Ki Ore was designed to work within the existing community leadership structure, that is, locally elected representatives, to foster social change. Such a programme was envisaged to ensure community ownership and sustainability. Several lessons can be drawn from the experience of implementing the Do Kadam Barabari Ki Ore model that are relevant for programmes intended to reverse inegalitarian gender norms and reduce violence against women.

\section{Recognise that breaking down gender inegalitarian norms and practices requires multi-pronged and sustained efforts}

Our findings have reinforced the vast gender disparities prevailing in the project setting, as well as the limited role that PRI representatives typically play in affecting social change in their communities. It has also highlighted that PRI representatives themselves hold traditional attitudes, are not necessarily sensitive to the need to change such practices as alcohol abuse and violence against women, and lack the leadership skills necessary to mobilise communities. Yet they remain a powerful and untapped community-level resource for promoting social change. However, it clearly requires far more than the seven months of activities conducted under the Do Kadam programme. Indeed, it requires a strong PRI capacity building phase, a strong demonstration phase in which NGOs conduct events and meetings, and show locally elected representatives both how to organise a meeting, as well as how to convey messages, intervene confidently in case of violations, and promote social change. Finally, a transitional mentorship phase is needed, in which the organisation and conduct of events is taken over by PRI representatives themselves, with minimal or no external involvement. While this was the model the Do Kadam programme implemented, through C3 and Abhiyan, we recognise that this three-phased approach is likely more time-consuming than our project.

\section{Take steps to ensure more regular exposure}

Findings that exposure to the intervention events-community-level sensitisation sessions and street plays-was irregular, calls for measures that ensure that community members attend the programme regularly. Female study participants who did not attend the programme argued that the location of the event was unsuitable for them or that their husband or family member had denied permission to attend. Male and female study participants cited competing demands on their time. And finally, not all community members were aware of the programme and the events it organised. Efforts need to be made to better understand and accommodate reasons for poor attendance. 
PRI representatives may need to reach all community members in their homes, inform them about the intervention, share with them a schedule of events and services that PRI representatives can provide, and convey to them the legitimacy of the programme. If women's hesitation to attend the programme is linked to the fact that men also attend, separate events may need to be organised for women. And given that household chores and other time commitments inhibited many from attending the programme regularly, it would need to be more flexible in setting session timings to accommodate these constraints.

\section{Ensure more intensive capacity-building of PRI representatives}

While the PRI department is entrusted with providing leadership capacity-building of PRI representatives, many have not had an opportunity to build leadership skills, are unaccustomed to communicating in public events, and have not been oriented about their responsibilities with regard to upholding social justice, empowering women, and addressing the needs of the most vulnerable. In this background, it would be useful to provide PRI representatives leadership training, apprise them of the importance of their roles as agents of social change in their communities, and build their skills in community mobilisation, communication and negotiation, along with efforts, as conducted by the Do Kadam programme, to change attitudes, facilitate exposure to available services, and organise events intended to transmit specific messages relating to social change.

\section{Integrate a module on gender and violence against women in the larger PRI curriculum}

Given that deep-rooted gender stereotypical norms underpin several social issues that PRI representatives are entrusted to address, and given the findings from this study that exposing PRI representatives to a gender transformative curriculum can help them to adopt gender egalitarian norms, it is important and timely to integrate a module on gender and violence against women in the larger PRI curriculum.

\section{Consider a sub-group focus}

In the current programme, events, meetings, and street plays were conducted for the community at large, and messages conveyed were general. It is possible that general messages are more difficult to internalise and adapt to one's own situation; organisers may thus prefer to hold meetings addressing specific groups of community members: men, women, and the young, those assembled at places where liquor is available, those in school, and so on.

The PRI structure is ideal for fostering social change; locally elected representatives have the authority and responsibility to mobilise communities, empower the most vulnerable, and work through existing structures to combat social problems. Our model has demonstrated some promise-PRI representatives did indeed succeed in convening community members in forums that raised issues related to violence and alcohol abuse, men's and women's awareness about services for women in distress did indeed expand, and women's assessments of their husband's alcohol consumption suggested some reduction in men's alcohol abuse. Our findings suggest however that PRI representatives require ongoing sensitisation about their responsibilities in the social arena, communication and negotiation skill building, and a better understanding of their own rights as well as their responsibilities for the well-being of their electorate. Empowering PRI representatives to take on this role is necessary, and models such as Do Kadam hold promise for mentoring PRI representatives to take on this responsibility. 


\section{Appendix 1 Construction of the wealth index}

Type of house: 2 for pucca; 1 for semi-pucca; 0 for kachcha

Agricultural land owned: 2 if the household owns some land; 0 for no land

Main source of light: 3 for electricity; 2 for kerosene

Access to toilet facility: 4 for own flush toilet; 2 for shared flush toilet or own pit toilet; 1 for shared pit toilet or other types of toilet; 0 for no toilet facility

Cooking fuel used: 2 for liquid petroleum gas, electricity or bio-gas; 1 for kerosene, wood, crop residue, dung cakes, coal or charcoal; 0 for other types of cooking fuel, for example, straw, shrubs or grass

Access to drinking water facility: 4 for own piped water, hand-pump or covered well; 3 for own open well; 2 for public or shared piped water, hand-pump or covered well; 1 for public

or shared open well; 0 for other sources of drinking water, for example, surface water, tanker/truck or rainwater

Access to electricity: 3 for electricity; 0 for no electricity

Ownership of household assets: 4 for car or truck; 3 each for motorcycle or scooter, refrigerator, computer/laptop, telephone (landline or mobile), colour television; tractor or thresher; 2 each for bicycle, electric fan, radio or transistor, black and white television, sewing machine, water pump, animal-drawn cart; 1 for watch or clock;

0 for each of the above items that the household does not possess. 


\section{References}

Abramsky, T., K. Devries, L. Kiss et al. 2014. 'Findings from the SASA! Study: A cluster randomized controlled trial to assess the impact of a community mobilization intervention to prevent violence against women and reduce HIV risk in Kampala, Uganda,' BMC Medicine, 12:122, DOI: 10.1186/s12916-014-0122-5

Ashenfelter 0. 1978. 'Estimating the effect of training programs on earnings,' Review of Economics and Statistics 60(1): 47-57.

Ashenfelter, O. and D. Card. 1985. 'Using the longitudinal structure of earnings to estimate the effect of training programs,' Reviews of Economics and Statistics 67(4): 648-660.

Diop, N., M. M. Faye, A. M. J. Cabral et al. 2004. The TOSTAN program: Evaluation of a Community-Based Education Program in Senegal. Washington, DC: Population Council.

Directorate of Census Operations, Bihar. 2014. District Census Handbook, Patna: Village and town-wise primary census abstract (PCA). Series-11, Part XII-B. Patna: Directorate of Census Operations, Bihar. Accessed on 1 March 2016 at http://www. censusindia.gov.in/2011census/dchb/1028_PART_B_DCHB_PATNA.pdf

Ellsberg, M., D. J. Arango, M. Mortonn et al. 2014. 'Prevention of violence against women and girls: What does the evidence say?,' The Lancet, 385 (9977): 1555-1566.

Government of Bihar. (n.d.). The Bihar Panchayat Raj Act, 2006 an Act to replace the Bihar Panchayat Raj Act, 1993 as amended up to date. Accessed on 9 April, 2016 at http://www.panchayat.gov.in/documents/10198/350801/BiharPRAct_2006_ English.pdf.

International Institute for Population Sciences. 2016. National Family Health Survey-4, 2015-2016, State Factsheet, Bihar. Mumbai: International Institute for Population Sciences.

International Institute for Population Sciences and Macro International. 2007. National Family Health Survey (NFHS-3), India, 2005-06. Mumbai: International Institute for Population Sciences.

International Institute for Population Sciences and Population Council. 2009. Youth in India, Situation and Needs 2006-07: Bihar. Mumbai: International Institute for Population Sciences

Jejeebhoy, S. J., K. G. Santhya and R. Acharya. 2014. 'Violence against women in South Asia: The need for the active engagement of the health sector,' Global Public Health, 9(6): 678-690.

Jejeebhoy, S. J., K. G. Santhya and S. Sabarwal. 2013. Gender-based Violence: A Qualitative Exploration of Norms, Experiences and Positive Deviance. New Delhi: Population Council.

Krug, Etienne G., L. L. Dahlberg, J. A. Mercy et al. 2002. World Report on Violence and Health. Geneva: World Health Organisation.

Office of the Registrar General and Census Commissioner. (n.d). Annual Health Survey 2012-13, Fact Sheet: Bihar. New Delhi: Office of the Registrar General and Census Commissioner. Accessed on 29 February 2016 at http://www.censusindia.gov.in/ vital_statistics/AHSBulletins/AHS_Factsheets_2012-13/FACTSHEET-Bihar.pdf .

Office of the Registrar General and Census Commissioner, India. 2013. Primary Census Abstract, Data Highlights, India, Series 1. New Delhi: Office of the Registrar General and Census Commissioner, India. Accessed on 1 March 2016 at http://www. censusindia.gov.in/2011census/PCA/PCA_Highlights/pca_highlights_file/India/Chapter-3.pdf.

Office of the Registrar General and Census Commissioner, India. 2015a. C-1 Population by Religious Community-2011. New Delhi: Office of the Registrar General and Census Commissioner, India. Accessed on 1 March 2016 at http://www. censusindia.gov.in/2011census/C-01/DDW10C-01\%20MDDS.XLS.

Office of the Registrar General and Census Commissioner, India. 2015b. C-2 Marital Status by Age and Sex. New Delhi: Office of the Registrar General and Census Commissioner, India. Accessed on 1 March 2016 at http://www.censusindia.gov. in/2011census/C-series/c-2/DDW-1000C-02-fer3-MDDS.xls.

Office of the Registrar General and Census Commissioner, India. 2015c. F-1 Number of Women and Ever Married Women by Present Age, Parity and Total Children Ever Born by Sex. New Delhi: Office of the Registrar General and Census Commissioner, India. Accessed on 3 March, 2016 at http://www.censusindia.gov.in/2011census/F-series/f1/2011-F01-1000-Rev4-MDDS. XLSX. 
Planning Commission. 2013. Press Note on Poverty Estimates, 2011-12. Accessed on 14 October 2015 at http:// planningcommission.nic.in/news/pre_pov2307.pdf.

Rural Development and Panchayat Raj Department, Government of Tamil Nadu. (n.d). The Tamil Nadu Panchayats Act, 1994 (Tamil Nadu Act 21 of 1994), Chapter III Formation and Constitution of Village Panchayats, Panchayat Union Councils and District Panchayats. Accessed on 9 April, 2016 at http://www.tnrd.gov.in/pract/chapter_III.htm.

Wagman, J. A., R. H. Gray, J. C. Campbell et al. 2014. 'Effectiveness of an integrated intimate partner violence and HIV prevention intervention in Rakai, Uganda: Analysis of an intervention in an existing cluster randomised cohort,' The Lancet Global Health, 3(1): e223-33, Doi: 10.1016/S2214-109X(14)70344-4. 


\section{Authors}

Shireen J Jejeebhoy, formerly Senior Associate, Population Council, New Delhi

A J Francis Zavier, Senior Programme Officer, Population Council, New Delhi

K G Santhya, Senior Associate, Population Council, New Delhi

Rajib Acharya, Associate II, Population Council, New Delhi

Neelanjana Pandey, Programme Officer I, Population Council, New Delhi

Santosh Kumar Singh, Assistant Programme Officer II, Population Council, New Delhi

Komal Saxena, Senior Programme Administrator, Population Council, New Delhi

Aparajita Gogoi, Executive Director, Centre for Catalyzing Change, New Delhi

Madhu Joshi, Senior Advisor, Centre for Catalyzing Change, New Delhi

Sandeep Ojha, State Programme Coordinator, Centre for Catalyzing Change, Patna 


\title{
List of Investigators
}

\author{
House Listers \\ Devendra Kumar \\ Kundan Kumar \\ Deepak Kumar Pandey \\ Hrishikesh Pandey \\ Brhamanand Saraswati \\ Avadhesh Singh \\ Anil Kumar Sinha \\ Jaishankar Tiwari
}

\section{Field Supervisors/Editors}

\section{Nazma}

Sulekha Gautam

Binit Jha

Ruchi Kumari

Anju Sharma

Dipu Kumar Sharma

Sarita Sharma

\section{Field Investigators}

Rajnikant
Vanshika Bharti
Kamini Devi
Kiran Devi
Ranju Devi
Kamlesh Kumar
Kamlesh Kumar
Krishna Kumari
Rekha Kumari
Renu Kumari
Sushmita Kumari
Diwakar Maji
Bhaskar Mishra
Alok Panday
Renu Kumari Prabha
Ram Shankar
Rajnikant Shukla
Laxman Singh


Printed at :

Systems Vision

Email:systemsvision96@gmail.com

Mobile:+91-98102 12565 
